\title{
HEPPA-II model-measurement intercomparison project: EPP indirect effects during the dynamically perturbed NH winter 2008-2009
}

\author{
Bernd Funke $^{1}$, William Ball ${ }^{2}$, Stefan Bender ${ }^{4}$, Angela Gardini ${ }^{1}$, V. Lynn Harvey ${ }^{5}$, Alyn Lambert ${ }^{6}$, \\ Manuel López-Puertas ${ }^{1}$, Daniel R. Marsh ${ }^{7}$, Katharina Meraner ${ }^{8}$, Holger Nieder $^{4}$, Sanna-Mari Päivärinta ${ }^{3,9}$, \\ Kristell Pérot $^{10}$, Cora E. Randall ${ }^{5}$, Thomas Reddmann ${ }^{4}$, Eugene Rozanov ${ }^{2,11}$, Hauke Schmidt ${ }^{8}$, Annika Seppälä ${ }^{3}$, \\ Miriam Sinnhuber ${ }^{4}$, Timofei Sukhodolov ${ }^{2}$, Gabriele P. Stiller ${ }^{4}$, Natalia D. Tsvetkova ${ }^{12}$, Pekka T. Verronen ${ }^{3}$, \\ Stefan Versick ${ }^{4,14}$, Thomas von Clarmann ${ }^{4}$, Kaley A. Walker ${ }^{13}$, and Vladimir Yushkov ${ }^{12}$ \\ ${ }^{1}$ Instituto de Astrofísica de Andalucía, CSIC, Apdo. 3004, 18008 Granada, Spain \\ ${ }^{2}$ Physikalisch-Meteorologisches Observatorium, World Radiation Center, Davos, Switzerland \\ ${ }^{3}$ Earth Observation Unit, Finnish Meteorological Institute, Helsinki, Finland \\ ${ }^{4}$ Karlsruhe Institute of Technology (KIT), Institute of Meteorology and Climate Research (IMK-ASF), P.O. Box 3640, \\ 76021 Karlsruhe, Germany \\ ${ }^{5}$ Laboratory for Atmospheric and Space Physics, University of Colorado, Boulder, USA \\ ${ }^{6}$ Jet Propulsion Laboratory, California Institute of Technology, Pasadena, California, USA \\ ${ }^{7}$ National Center for Atmospheric Research, Boulder, Colorado, USA \\ ${ }^{8}$ Max Planck Institute for Meteorology, Hamburg, Germany \\ ${ }^{9}$ Department of Physics, University of Helsinki, Helsinki, Finland \\ ${ }^{10}$ Chalmers University of Technology, Göteborg, Sweden \\ ${ }^{11}$ Institute for Atmospheric and Climate Science ETH, Zurich, Switzerland \\ ${ }^{12}$ Central Aerological Observatory, Moscow, Russia \\ ${ }^{13}$ Department of Physics, University of Toronto, Toronto, Ontario, Canada \\ ${ }^{14}$ Karlsruhe Institute of Technology (KIT), Steinbuch Centre for Computing (SCC), Karlsruhe, Germany
}

Correspondence to: Bernd Funke (bernd@iaa.es)

Received: 2 November 2016 - Discussion started: 9 December 2016

Revised: 14 February 2017 - Accepted: 22 February 2017 - Published: 14 March 2017

\begin{abstract}
We compare simulations from three high-top (with upper lid above $120 \mathrm{~km}$ ) and five medium-top (with upper lid around $80 \mathrm{~km}$ ) atmospheric models with observations of odd nitrogen $\left(\mathrm{NO}_{x}=\mathrm{NO}+\mathrm{NO}_{2}\right)$, temperature, and carbon monoxide from seven satellite instruments (ACE-FTS on SciSat, GOMOS, MIPAS, and SCIAMACHY on Envisat, MLS on Aura, SABER on TIMED, and SMR on Odin) during the Northern Hemisphere (NH) polar winter 2008/2009. The models included in the comparison are the 3-D chemistry transport model 3dCTM, the ECHAM5/MESSy Atmospheric Chemistry (EMAC) model, FinROSE, the Hamburg Model of the Neutral and Ionized Atmosphere (HAMMONIA), the Karlsruhe Simulation Model of the Middle At-
\end{abstract}

mosphere (KASIMA), the modelling tools for SOlar Climate Ozone Links studies (SOCOL and CAO-SOCOL), and the Whole Atmosphere Community Climate Model (WACCM4). The comparison focuses on the energetic particle precipitation (EPP) indirect effect, that is, the polar winter descent of $\mathrm{NO}_{x}$ largely produced by EPP in the mesosphere and lower thermosphere. A particular emphasis is given to the impact of the sudden stratospheric warming (SSW) in January 2009 and the subsequent elevated stratopause (ES) event associated with enhanced descent of mesospheric air. The chemistry climate model simulations have been nudged toward reanalysis data in the troposphere and stratosphere while being unconstrained above. An odd nitrogen upper 
boundary condition obtained from MIPAS observations has further been applied to medium-top models. Most models provide a good representation of the mesospheric tracer descent in general, and the EPP indirect effect in particular, during the unperturbed (pre-SSW) period of the $\mathrm{NH}$ winter 2008/2009. The observed $\mathrm{NO}_{x}$ descent into the lower mesosphere and stratosphere is generally reproduced within $20 \%$. Larger discrepancies of a few model simulations could be traced back either to the impact of the models' gravity wave drag scheme on the polar wintertime meridional circulation or to a combination of prescribed $\mathrm{NO}_{x}$ mixing ratio at the uppermost model layer and low vertical resolution. In March-April, after the ES event, however, modelled mesospheric and stratospheric $\mathrm{NO}_{x}$ distributions deviate significantly from the observations. The too-fast and early downward propagation of the $\mathrm{NO}_{x}$ tongue, encountered in most simulations, coincides with a temperature high bias in the lower mesosphere $(0.2-0.05 \mathrm{hPa})$, likely caused by an overestimation of descent velocities. In contrast, uppermesospheric temperatures (at $0.05-0.001 \mathrm{hPa}$ ) are generally underestimated by the high-top models after the onset of the ES event, being indicative for too-slow descent and hence too-low $\mathrm{NO}_{x}$ fluxes. As a consequence, the magnitude of the simulated $\mathrm{NO}_{x}$ tongue is generally underestimated by these models. Descending $\mathrm{NO}_{x}$ amounts simulated with mediumtop models are on average closer to the observations but show a large spread of up to several hundred percent. This is primarily attributed to the different vertical model domains in which the $\mathrm{NO}_{x}$ upper boundary condition is applied. In general, the intercomparison demonstrates the ability of stateof-the-art atmospheric models to reproduce the EPP indirect effect in dynamically and geomagnetically quiescent $\mathrm{NH}$ winter conditions. The encountered differences between observed and simulated $\mathrm{NO}_{x}, \mathrm{CO}$, and temperature distributions during the perturbed phase of the $2009 \mathrm{NH}$ winter, however, emphasize the need for model improvements in the dynamical representation of elevated stratopause events in order to allow for a better description of the EPP indirect effect under these particular conditions.

\section{Introduction}

The potential impact of energetic particle precipitation (EPP) on regional climate is nowadays becoming recognized. Solar forcing recommendations for the recently launched Climate Model Intercomparison Project Phase 6 (Eyring et al., 2016) include, for the first time, the consideration of energetic particle effects (Matthes et al., 2016). EPP is strongly linked to solar activity and hence to the solar cycle, either directly by coronal mass ejections producing sporadically large fluxes of solar energetic particles or indirectly by the quasi-continuous impact of the solar wind on the Earth's magnetosphere. In the mesosphere and lower thermosphere (MLT), EPP-induced ionization initiates the production of odd nitrogen and odd hydrogen (the latter below $\sim 85 \mathrm{~km}$ ), both of them destroying ozone via catalytic cycles. Odd nitrogen $\left(\mathrm{NO}_{x}=\mathrm{NO}+\mathrm{NO}_{2}\right)$ is long-lived during polar winter and is then regularly transported down from its source region into the stratosphere to altitudes well below $30 \mathrm{~km}$ (e.g. Randall et al., 2007; Funke et al., 2014a). This so-called EPP indirect effect contributes significant amounts of $\mathrm{NO}_{x}$ to the polar middle atmosphere during each winter. EPP-induced ozone changes are thought to modify the thermal structure and winds in the stratosphere which, in turn, modulate the strength of the Arctic polar vortex. The introduced signal could then propagate down to the surface, introducing significant variations of regional climate, particularly in the Northern Hemisphere (NH) (Seppälä et al., 2009; Baumgaertner et al., 2011; Rozanov et al., 2012; Seppälä and Clilverd, 2014; Maliniemi et al., 2014).

At present, many chemistry climate models account for EPP-induced ionization and its chemical impact on the neutral atmosphere, which is required for the simulation of atmospheric EPP effects and ultimately for the investigation of potential EPP-climate links. A comprehensive evaluation of these models' capacity to reproduce observed EPP effects by means of coordinated intercomparison studies is a necessary step towards this goal. The High Energy Particle Precipitation in the Atmosphere (HEPPA) model vs. data intercomparison initiative (Funke et al., 2011) evaluated the chemical response of nitrogen and chlorine species in nine atmospheric models to the "Halloween" solar proton event in late October 2003 with observations taken by the Michelson Interferometer for Passive Atmospheric Sounding (MIPAS) on Envisat. Reasonable agreement of observed and modelled reactive nitrogen and ozone changes was found, demonstrating the models' overall ability to reproduce the direct EPP effect by solar protons. However, most models failed to adequately describe the repartitioning of nitrogen compounds in the aftermath of the event which could be attributed to deficiencies in the representation of the D-region ion chemistry and motivated recent model developments (Egorova et al., 2011; Verronen et al., 2016; Andersson et al., 2016).

The observation-based evaluation of the simulated atmospheric effects of magnetospheric particles, which are thought to be of higher relevance for climate, is more challenging because of the quasi-continuous flux of electrons compared to protons and the difficulty in separating between local production and downward transport of $\mathrm{NO}_{x}$ during polar winter. Although a pronounced dependence of reactive nitrogen enhancements in the polar winter stratosphere and mesosphere on the geomagnetic activity levels has been demonstrated (Funke et al., 2014b), dynamical variability, particularly in the $\mathrm{NH}$, can mask out this effect. In particular, the occurrence of elevated stratopause (ES) events following sudden stratospheric warmings (SSWs) during Arctic winters often causes much larger mesospheric $\mathrm{NO}_{x}$ enhancements than expected from the actual geomagnetic activity level, after a brief $\mathrm{NO}_{x}$ depletion related to the weakened 
vortex during the SSW. The ability of climate models to adequately simulate tracer transport in Arctic winters, including perturbed winters characterized by SSW and ES events, is therefore crucial to accurately model EPP effects and their possible $\mathrm{NH}$ regional climate impacts.

Simulations of mesospheric tracer descent during dynamically perturbed $\mathrm{NH}$ winters have been compared with observations in several studies. Using the KArlsruhe SImulation Model of the middle Atmosphere (KASIMA) with specified dynamics below $48 \mathrm{~km}$ and prescribed $\mathrm{NO}_{x}$ concentrations from MIPAS night-time $\mathrm{NO}_{2}$ observations above $55 \mathrm{~km}$, Reddmann et al. (2010) calculated the amount of EPP-NO ${ }_{x}$ entering the stratosphere from July 2002 to March 2004. KASIMA reproduced the MIPAS observations of $\mathrm{NO}_{x}$ entering the stratosphere reasonably well, even during the SSW winter 2003/2004. However, the ability of the model to adequately simulate mesospheric tracer transport could not be tested because of the constrained $\mathrm{NO}_{x}$ in the mesosphere. Salmi et al. (2011) and Päivärinta et al. (2016), in turn, used FinROSE with constrained $\mathrm{NO}_{x}$ at the upper boundary $(\sim 80 \mathrm{~km})$ for both early 2009 and 2012 . Their results show that FinROSE is able to qualitatively reproduce the downward descent of $\mathrm{NO}_{x}$ from the MLT region into the stratosphere, but the actual $\mathrm{NO}_{x}$ amounts can differ significantly from the observations. In the case of chemical transport models (CTMs), the results are strongly affected by the meteorological data, i.e. a source of uncertainty, used to drive the model. McLandress et al. (2013) used a version of the Canadian Middle Atmosphere Model (CMAM) that was nudged toward reanalysis data up to $1 \mathrm{hPa}$ to examine the impacts of parameterized orographic and non-orographic gravity wave drag (GWD) on the zonal mean circulation of the mesosphere during the perturbed NH winters 2006 and 2009 in comparison with temperature and carbon monoxide (CO) observations from the Microwave Limb Sounder (MLS) on Aura. They found that non-orographic GWD is primarily responsible for driving the circulation that results in the descent of $\mathrm{CO}$ from the thermosphere following the warmings. Randall et al. (2015) investigated the $\mathrm{NO}_{x}$ descent during the Arctic winter/spring of 2004 with Whole Atmosphere Community Climate Model (WACCM) simulations that were nudged to Modern-Era Retrospective Analysis for Research and Applications (MERRA) data. They found that their simulated $\mathrm{NO}_{x}$, although qualitatively reproducing the enhanced descent after the ES event, was up to a factor of 5 too low compared with satellite observations. This underestimation was attributed to missing NO production by high-energy electrons in the mesosphere in combination with an underestimation of mesospheric descent during the recovery phase after the SSW. Siskind et al. (2015) compared simulations of mesospheric tracer descent in the winter and spring of 2009 with two versions of WACCM, one constrained with data from MERRA, which extends up to $50 \mathrm{~km}$, and the other constrained to the Navy Operational Global Atmospheric Prediction System-Advanced Level Physics High Altitude
(NOGAPS-ALPHA), which extends up to $92 \mathrm{~km}$. By comparison with Solar Occultation for Ice Experiment (SOFIE) data they showed that constraining WACCM to NOGAPSALPHA yields a dramatic improvement in the simulated descent of enhanced $\mathrm{NO}_{x}$ and very low methane.

Most of these studies suggest that the model representation of the perturbed dynamics during $\mathrm{NH}$ winters with SSWs and ES events has a crucial impact on the simulated amount of $\mathrm{NO}_{x}$ transported into the stratosphere and that a proper parameterization of unresolved GWD is key to achieving agreement with observations. However, previous studies focused on individual models, making it difficult to assess the overall ability of state-of-the-art atmospheric models to reproduce the EPP indirect effect in NH winters. Comprehensive multi-model intercomparisons addressing dynamically perturbed NH winters, however, have so far been restricted to the assessment of the temperature zonal mean, planetary wave, and tidal variability during the 2009 SSW event in the middle and upper atmosphere (Pedatella et al., 2014), as well as to the impacts on the ionosphere variability (Pedatella et al., 2016). Further, although our knowledge of temperature and tracer distributions in polar winters has dramatically increased with the advent of atmospheric satellite observations, specific intercomparisons and validation efforts focussing on such conditions are sparse. A systematic assessment of this knowledge is therefore essential to quantitatively diagnose the model performance with respect to mesospheric tracer transport under perturbed (and unperturbed) polar winter conditions.

A coordinated intercomparison project focussing on tracer descent and the EPP indirect effect during such a winter was therefore initiated in the frame of the SPARC/WCRP's SOLARIS-HEPPA activity. In this so-called HEPPA-II project, simulations of the $\mathrm{NH}$ polar winter 2008/2009 from eight atmospheric models have been compared with observations of temperature and concentrations of $\mathrm{NO}_{x}$ and $\mathrm{CO}$ from seven satellite instruments including the Atmospheric Chemistry Experiment Fourier Transform Spectrometer (ACE-FTS) on SciSat, the Envisat instruments Global Ozone Monitoring by Occultation of Stars (GOMOS), MIPAS, and the SCanning Imaging Absorption spectroMeter for Atmospheric CHartographY (SCIAMACHY), as well as MLS on Aura, the Sounding of the Atmosphere using Broadband Emission Radiometry (SABER) instrument on the Thermosphere, Ionosphere, Mesosphere, Energetics and Dynamics (TIMED) satellite, and the Sub-Millimetre Radiometer (SMR) on Odin. The 2008/2009 winter was chosen for this intercomparison exercise not only because of its peculiar dynamical conditions, characterized by the pronounced SSW in January and the unusually strong descent of odd nitrogen despite the low geomagnetic activity level around solar minimum, but also because of the availability of a large number of observations from different satellite instruments that allowed for a detailed evaluation of the model simulations. The models included in the compari- 
son are the 3-D chemistry transport model (3dCTM), the ECHAM5/MESSy Atmospheric Chemistry (EMAC) model, FinROSE, the Hamburg Model of the Neutral and Ionized Atmosphere (HAMMONIA), KASIMA, the modelling tools for SOlar Climate Ozone Links studies (SOCOL and CAOSOCOL), and WACCM (Version 4). Only three of these models (3dCTM, HAMMONIA, and WACCM) extend up into the lower thermosphere where a large fraction of EPPinduced odd nitrogen production occurs. All other models have their upper lid in the mesosphere and require an odd nitrogen upper boundary condition (UBC), accounting for EPP production higher up, for simulating the introduced EPP indirect effect in the model domain. This UBC has been constructed from $\mathrm{NO}_{x}$ observations of the MIPAS instrument taken during the Arctic winter 2008-2009. The chemistry climate model simulations have been nudged toward reanalysis data below $1 \mathrm{hPa}$ while being unconstrained above. The restriction of specified dynamics to the stratosphere is a compromise that is hoped to provide a realistic evolution of mesospheric meteorology by upward control, while still allowing for the assessment of self-generated tracer descent in the models.

In this study we report results from the HEPPA-II intercomparison project. A major aim is the identification and characterization of model biases and their uncertainties in the simulations of the perturbed 2008/2009 NH winter by systematically comparing to the suite of satellite observations. For this purpose, common diagnostics are applied in all comparisons, and the sampling characteristics of the instruments are taken into account. Since the study focusses on the evaluation of the ability of the models to simulate the source and transport of MLT tracers by means of observed quantities (i.e. temperature and trace gas abundances), any more sophisticated analysis, e.g. qualifying the different GW drag parameterizations, is outside the scope of this comparison. However, our analysis should motivate such studies to identify the deficits in key processes of this vertical coupling.

The paper is organized as follows: Sect. 2 gives an overview on the satellite observations and data products used in this study. Section 3 describes the participating chemistry climate and transport models. The $\mathrm{NO}_{x}$ UBC employed in the medium-top models is described in Sect. 4, and Sect. 5 introduces the intercomparison method. Results of the intercomparisons are discussed in Sect. 6 with focus on the representation of the EPP indirect effect by the high-top models in the upper mesosphere and lower thermosphere and, in Sect. 7, with focus on the upper-stratospheric and mesospheric representation in all models.

\section{Satellite observations}

\subsection{ACE-FTS/SciSat}

The ACE-FTS has performed infrared solar occultation measurements from the SciSat satellite since February 2004 (Bernath et al., 2005). The SciSat satellite is in a highly inclined circular orbit $\left(74^{\circ}\right)$ and thus provides measurements from $85^{\circ} \mathrm{N}$ to $85^{\circ} \mathrm{S}$ over each year with a significant focus on polar measurements. Up to 30 measurements are made each day by ACE-FTS, extending from the cloud tops to $\sim 150 \mathrm{~km}$. ACE-FTS observations of temperature, CO, and $\mathrm{NO}_{x}$ during Arctic ES winters have been analysed in several previous studies (e.g. Randall et al., 2009, 2015). Here, version 3.0 of the ACE-FTS dataset was used, which covers 21 February 2004 to 30 September 2010. The ACE-FTS retrieval algorithm is described in Boone et al. (2005) and the specific details of version 3.0/3.5 are provided in Boone et al. (2013). $\mathrm{NO}_{x}$ is provided from ACE-FTS using the retrieved $\mathrm{NO}(6-107 \mathrm{~km})$ and $\mathrm{NO}_{2}(7-52 \mathrm{~km})$ profiles. Above $52 \mathrm{~km}$, where both sunset and sunrise $\mathrm{NO}_{2}$ concentrations are very small and hence not detectable, the scaled a priori $\mathrm{NO}_{2}$ profile has been used to extend the $\mathrm{NO}_{x}$ profiles to the higher altitudes. The $\mathrm{CO}$ profiles extend from 5 to $110 \mathrm{~km}$ and temperature is retrieved from 15 to $125 \mathrm{~km}$. The vertical resolution of the ACE-FTS measurements is $\sim 3 \mathrm{~km}$, based on the instrument field of view (Boone et al., 2005).

The version $3.5 \mathrm{NO}$ profiles differ from HALOE by -15 to $+6 \%$ between 27 and $53 \mathrm{~km}$ and from summertime MIPAS measurements by -9 to $+2 \%$ between 36 and $52 \mathrm{~km}$ (Sheese et al., 2016a). For $\mathrm{NO}_{2}$, the bias found between ACE-FTS and a suite of other limb and occultation sounders is better than $18 \%$ from 17 to $27 \mathrm{~km}$ and $-15 \%$ from 28 to $41 \mathrm{~km}$ (Sheese et al., 2016a). For both of these species, a box model was used to apply a diurnal scaling to the ACE-FTS profiles before the comparisons. ACE-FTS CO has been compared with MIPAS and MLS by Sheese et al. (2016b). On average, there is a $-11 \%$ bias between 28 and $50 \mathrm{~km}$ with respect to MIPAS and a bias of $\pm 10 \%$. Based on comparisons with coincident satellite observations (within $350 \mathrm{~km}$ and $3 \mathrm{~h}$ ), it has been found that ACE-FTS v3.5 temperatures agree to within $\pm 2 \mathrm{~K}$ between 15 and $40 \mathrm{~km}$, within $\pm 7 \mathrm{~K}$ between 40 and $80 \mathrm{~km}$, and within $\pm 12 \mathrm{~K}$ between 80 and $100 \mathrm{~km}$ (P. Sheese, personal communication, 2016).

\subsection{GOMOS/Envisat}

GOMOS was a stellar occultation instrument on the polar orbiting Envisat satellite, operating between 2002 and 2012 (Bertaux et al., 2010). This satellite has been flying in a sunsynchronous orbit at approximately $800 \mathrm{~km}$ altitude. GOMOS consisted of a UV-visible (VIS) spectrometer, two IR channels, and two photometers, measuring the stellar flux through the atmosphere at high sampling frequency. GOMOS measured vertical profiles of $\mathrm{O}_{3}, \mathrm{NO}_{2}, \mathrm{NO}_{3}, \mathrm{H}_{2}, \mathrm{O}$, 
$\mathrm{O}_{2}$, and aerosols in the middle atmosphere. Here, we have used GOMOS $\mathrm{NO}_{2}$ profiles (version GOPR_6.0c_6.0f) measured in night-time conditions (solar zenith angle at tangent point location $>107^{\circ}$; solar zenith angle at spacecraft location $>90^{\circ}$ to avoid stray light). The altitude range for $\mathrm{NO}_{2}$ in non-polar conditions is $20-50 \mathrm{~km}$ and extends up to $70 \mathrm{~km}$ in polar winter when enhanced amounts of $\mathrm{NO}_{2}$ are present in the atmosphere (Seppälä et al., 2007; Hauchecorne et al., 2007). The typical precision of the $\mathrm{NO}_{2}$ measurements is 5$20 \%$ while the systematic error of the $\mathrm{NO}_{2}$ observations is estimated to be of the order of few percent (1-5\%) (Tamminen et al., 2010; Verronen et al., 2009). Vertical resolution is $4 \mathrm{~km}$ (Kyrölä et al., 2010). As NO is quickly converted into $\mathrm{NO}_{2}$ by reaction with $\mathrm{O}_{3}$ after sunset, the night-time GOMOS $\mathrm{NO}_{2}$ measurements used here are a reasonable representation of stratospheric and lower mesospheric $\mathrm{NO}_{x}$.

Because stars are used as the light source, the locations of the observations change with time. A representative distribution of the latitudes sampled during the course of a year can be seen in Figs. 7-9 of Bertaux et al. (2010). Due to this sampling, for the $\mathrm{NH}$ polar region in winter 2008-2009, GOMOS night-time $\mathrm{NO}_{2}$ observations were available for the period of December 2008-January 2009. GOMOS measurements provide the constituent profiles as number densities. For the purpose of this study these were converted to volume mixing ratios (VMRs) using temperature and pressure profiles from the WACCM model (see below).

\subsection{MIPAS/Envisat}

The MIPAS instrument (Fischer et al., 2008) on Envisat provided global stratospheric and mesospheric measurements of temperature (García-Comas et al., 2014), $\mathrm{NO}$ and $\mathrm{NO}_{2}$ (Funke et al., 2014a), CO (Funke et al., 2009), as well as numerous other trace species (e.g. von Clarmann et al., 2009, 2013) during 2002-2012. Here, we use observations taken in the nearly continuous nominal observation mode (scanning range $6-70 \mathrm{~km}$, hereinafter referred to as MIPAS-NOM), as well as occasional special mode observations (middle and upper-atmospheric observation modes covering 20-100 and $40-170 \mathrm{~km}$, respectively, hereinafter referred to as MIPASUA), the latter taken with a frequency of about 1 out of 5 days. We also use special mode UA observations which include three orbits per day passing the $20^{\circ} \mathrm{W}-70^{\circ} \mathrm{E}$ and $160^{\circ} \mathrm{E}-110^{\circ} \mathrm{W}$ sectors during $14-18$ and $21-27$ January 2009 and which were taken as support for the Dynamics and Energetics of the Lower Thermosphere in Aurora 2 (DELTA2) campaign (Abe et al., 2006).

MIPAS-NOM $\mathrm{NO}_{x}$ data have been built from $\mathrm{NO}$ and $\mathrm{NO}_{2}$ data versions V5r_NO_220 and V5r_NO2_220, respectively. MIPAS-UA $\mathrm{NO}_{x}$ data are based on data versions V4o_NO_501/611 and V4o_NO2_501/600. In the middleto high-latitude polar winters, typical vertical resolutions are 4-6 $\mathrm{km}$ below $50 \mathrm{~km}$ and $6-9 \mathrm{~km}$ above, while the single measurement precision is on the order of $5-15 \%$. System- atic errors, dominated by non-local thermodynamic equilibrium (non-LTE) uncertainties of $\mathrm{NO}$ and $\mathrm{NO}_{2}$, have been estimated to be less than $10 \%$. CO data (version V5r_CO_220) used here have a single measurement precision ranging from $20-30 \%$ above $45 \mathrm{~km}$ to $70-80 \%$ in the lower stratosphere. The vertical resolution is $6-12 \mathrm{~km}$. The single measurement precision of temperature data (versions v5r_T_220 and v5r_T_521/621 for MIPAS-NOM and MIPAS-UA, respectively) is $0.5-2 \mathrm{~K}$ below $70 \mathrm{~km}$ and $2-7 \mathrm{~K}$ above. The systematic error is typically $1-3 \mathrm{~K}$ below $85 \mathrm{~km}$ and $3-11 \mathrm{~K}$ above. The average vertical resolution is $3-6 \mathrm{~km}$ below $90 \mathrm{~km}$ and 6-10 km above.

\subsection{MLS/Aura}

The MLS instrument (Waters et al., 2006) was launched on 15 July 2004 and measures thermal microwave emission from Earth's limb. On each day MLS provides 3500 vertical profiles of temperature and trace gases between $82^{\circ} \mathrm{S}$ and $82^{\circ} \mathrm{N}$ spaced $\sim 1.5^{\circ}$ apart along great circles following the orbit track. Manney et al. (2009) employed MLS data version 3.2 to analyse tracer transport during the Arctic ES winter 2006. Here, we use version 4.2 temperature and CO. Temperature is deemed useful for scientific studies between 316 and $0.001 \mathrm{hPa}$. The vertical resolution is $5 \mathrm{~km}$ near $40 \mathrm{~km}$ and increases to $\sim 10 \mathrm{~km}$ near $90 \mathrm{~km}$ (Livesey, 2016). In the mesosphere, systematic and random errors are $2.5 \mathrm{~K}$ and comparisons with correlative measurements show a $0-7 \mathrm{~K}$ cold bias (Schwartz et al., 2008). CO is recommended for scientific use from 215 to $0.0046 \mathrm{hPa}$ (Pumphrey et al., 2007). The vertical resolution is $4-5 \mathrm{~km}$ in the stratosphere and $6-7 \mathrm{~km}$ in the mesosphere. Froidevaux et al. (2006) indicate that the CO data have a $25-50 \%$ positive bias in the mesosphere. Estimates of absolute accuracy are $10 \%$ (Filipiak et al., 2005). For this work, temperature and $\mathrm{CO}$ data have been filtered using the precision, status, quality, and convergence values provided by the MLS science team (Livesey, 2016).

\subsection{SABER/TIMED}

The SABER instrument is a 10 channel limb scanning radiometer (Russell III et al., 1999), launched in December 2001 on board the NASA TIMED mission. SABER was measuring in the "northward" viewing mode $\left(83^{\circ} \mathrm{N}\right.$ to $\left.52^{\circ} \mathrm{S}\right)$ during the subperiods: 1 October-17 November in 2008; 11 January-15 March and 18-31 May in 2009. The rest of the days, i.e. 17 November 2008-15 January 2009 and 15 March-19 May in 2009, it was observing in the "southward" viewing mode $\left(52^{\circ} \mathrm{N}\right.$ to $\left.83^{\circ} \mathrm{S}\right)$. There is a rich literature dealing with the analysis of SABER temperature version 1.07 (Remsberg et al., 2008) in the context of NH polar winter dynamics (e.g. Siskind et al., 2007; Yamashita et al., 2013). Our study uses data from the Level $2 \mathrm{~A}$ files of version 2.0. Typical single measurement random errors are $<0.5 \mathrm{~K}$ below $55 \mathrm{~km}$, $1-2 \mathrm{~K}$ in the mesosphere, and $\sim 7 \mathrm{~K}$ above. The systematic 
errors are $<1.5 \mathrm{~K}$ below $75 \mathrm{~km}, 4 \mathrm{~K}$ at $85 \mathrm{~km}$, and $5 \mathrm{~K}$ at $100 \mathrm{~km}$ (Remsberg et al., 2008; García-Comas et al., 2008). The vertical resolution is about $2 \mathrm{~km}$. A thorough comparison of these temperatures with those measured by other satellites, MIPAS, ACE-FTS, MLS, OSIRIS, SOFIE, and by lidar measurements has been recently carried out by GarcíaComas et al. (2014) in a study about the validation of MIPAS vM21 temperatures. The comparison of SABER v2.0 with MIPAS vM21 is remarkably good, with differences smaller than $2 \mathrm{~K}$ at all altitudes and seasons, except for high-latitude summers above $65 \mathrm{~km}$ where they are $3-4 \mathrm{~K}$ at $65-80 \mathrm{~km}$ (MIPAS colder) and 5-7 $\mathrm{K}$ around the mesopause (MIPAS warmer).

\subsection{SMR/Odin}

The SMR instrument is a limb emission sounder aboard Odin, a Swedish-led satellite launched in 2001 in cooperation with the Canadian, French, and Finnish space agencies (Murtagh et al., 2002). Odin is orbiting the Earth in a sun-synchronous orbit at an initial altitude of $580 \mathrm{~km}$ and at Equator-crossing times varying between 06:00 and 07:00 local time for the morning overpass (18:00 and 19:00 local time fore the evening overpass). These parameters are slightly changing with time due to the drifting orbit. SMR is measuring globally a variety of trace gases and the temperature from the upper troposphere to the lower thermosphere (Merino et al., 2002).

Nitric oxide is retrieved from the observation of thermal emission lines in a band centred around $551.7 \mathrm{GHz}$. The version 2.1 of NO data is used in this study. The overall vertical coverage is from 7 to $115 \mathrm{~km}$, and in the altitude range considered here the vertical resolution is about $7 \mathrm{~km}$ (Pérot et al., 2014). NO data are available approximately 4 days per month after 2007, on an irregular basis of 2 observation days in a 14-day cycle. Systematic errors amount to $3 \%$ from spectroscopic parameters, $2 \%$ from calibration, and 3-6\% from sideband suppression (Sheese et al., 2013). The single measurement retrieval error amounts to $44-48 \%$, in the case of Antarctic night-time mesosphere-lower thermosphere, as studied by Sheese et al. (2013). A comparison study performed by Bender et al. (2015) showed that SMR NO measurements were consistent with NO measurements by SCIAMACHY, MIPAS, and ACE-FTS despite the different measurement methods and retrieval strategies used for these four instruments.

\subsection{SCIAMACHY/Envisat}

The SCIAMACHY (see Burrows et al., 1995; Bovensmann et al., 1999) is a limb-sounding UV-VIS-NIR spectrometer on Envisat. Among the main measurement modes, the nominal limb mode carried out limb measurements from ground to $105 \mathrm{~km}$ until mid-October 2003, and after 15 October 2003 up to 91 km. From July 2008 until April 2012, SCIAMACHY carried out a special mesosphere-lower thermosphere mode (MLT), scanning from 50 to $150 \mathrm{~km}$ for 1 day every 2 weeks.

Nitric oxide is retrieved from the NO gamma bands (UV channel 1, 230-314 nm) (Bender et al., 2013, 2017) in the $60-160 \mathrm{~km}$ range using a tomographic approach. The retrieval from the MLT mode yields the NO number densities with a vertical resolution of 5-10 km between 70 and $150 \mathrm{~km}$. With the nominal mode, the same resolution is achieved between 65 and $80 \mathrm{~km}$. The average single orbit measurement error amounts to about $30 \%$. Systematic errors amount to $7 \%$ from uncertain spectroscopic data, $3 \%$ from uncertainties in the solar spectrum (Chance and Kurucz, 2010), and about $10 \%$ from temperature uncertainties. Because the NO gamma bands are fluorescent emissions, the retrieval of NO is restricted to daylight observations. Polar winter data are therefore restricted to latitudes equatorward of the polar night terminator (around $70^{\circ}$ in the mesosphere-lower thermosphere at winter solstice).

The retrieved NO number densities from the MLT mode have been compared to ACE-FTS, MIPAS, and SMR (Bender et al., 2015). The measurements were found to be consistent among all instruments with SCIAMACHY retrieving slightly lower densities compared to the other instruments during polar winter but higher values in mesospheric polar summer and mid-to-low latitudes.

\section{Chemistry climate models}

In the following, the participating atmospheric models are described and details on the set-up of the simulations are provided. Since the dynamical evolution in the mesosphere is strongly constrained by the behaviour of the lower atmosphere, particularly during a perturbed $\mathrm{NH}$ winter, model simulations have been either nudged to or rely entirely on meteorological reanalysis data in order to allow for comparisons to observations. High-top models, having their upper lid above $120 \mathrm{~km}$ and including explicit schemes for consideration of $\mathrm{NO}_{x}$ production by particle-induced ionization, are described in Sect. 3.1. Medium-top models, having their upper lid around $80 \mathrm{~km}$, are described in Sect. 3.2. These models applied a common odd nitrogen UBC in order to account for EPP production above the model domain (see Sect. 4). A summary of the different model settings and characteristics is given in Table 1.

\subsection{High-top models}

\subsubsection{3dCTM}

3dCTM is a global 3-D chemistry transport model developed based on the chemistry scheme of the SLIMCAT model (Chipperfield, 1999) and the transport scheme of the CTMB Sinnhuber et al. (2003) for use in the middle atmosphere up to the lower thermosphere. Temperature as well as horizontal and vertical wind fields are prescribed by data from 
the LIMA general circulation model (Berger, 2008), and the model upper boundary is defined by the availability of these data. For the version used here, LIMA is nudged to $\left(1^{\circ} \times 1^{\circ}\right)$ ECMWF operational data with a constant nudging of temperature, zonal and meridional winds between the surface and $35 \mathrm{~km}$, and a linear decrease in nudging strength to $45 \mathrm{~km}$, the upper limit of the nudging area. No parameterization of the GWD is implemented either in LIMA or in 3dCTM. Only waves with horizontal scales of $\geq 500 \mathrm{~km}$ and a temporal resolution of 2-12 h are represented Berger (2008). A comparison of momentum flux climatologies provided in Fig. 7 of Berger (2008) with common GWD schemes as shown, e.g. in Fig. 5 of Holton and Zhu (1984), shows that the gravity wave momentum flux in the mesosphere is underestimated by LIMA by about a factor of 2-3 in both the summer and winter hemisphere. In the winter hemisphere, the vertical structure of the GW momentum flux is also somehow different; while Holton and Zhu (1984) essentially show one broad peak at $\sim 65-95 \mathrm{~km}$ altitude, varying in strength from -80 to $120 \mathrm{~ms}^{-1} \mathrm{~d}^{-1}$, the LIMA profile shows a double peak structure with a broad peak of $-40-60 \mathrm{~ms}^{-1} \mathrm{~d}^{-1}$ at $\sim 70$ $90 \mathrm{~km}$ altitude, a minimum in $90-100 \mathrm{~km}$, and a secondary peak above $100 \mathrm{~km}$. This means that the vertical downward motion throughout the mesosphere will be underestimated during winter.

The model chemistry scheme has been adapted from the original SLIMCAT code for use in the mesosphere and lower thermosphere as described in Sinnhuber et al. (2012): the model considers the photolysis of $\mathrm{O}_{2}, \mathrm{CO}_{2}, \mathrm{CH}_{4}$, and $\mathrm{H}_{2} \mathrm{O}$ in the far-UV wavelength range down to the Lyman $\alpha$ line. Also, in the mesosphere and lower thermosphere, chemical families are not considered for $\mathrm{NO}_{x}$ and $\mathrm{O}_{x}$ species, and $\mathrm{H}_{2} \mathrm{O}, \mathrm{O}_{2}$, and $\mathrm{H}_{2}$ are now integrated as active chemical species in the model. Additionally, parameterizations for the impact of atmospheric ionization from particle impact and photoionization are considered based on ion-chemistry model studies (Nieder et al., 2014). The photoionization rate is based on the parameterization of Solomon and Qian (2005); particle impact ionization rates are prescribed using the four-dimensional field provided by the AIMOS model (Wissing and Kallenrode, 2009) version 1.2. Model data are output every $15 \mathrm{~min}$ and interpolated onto the satellite geolocations from this.

\subsubsection{HAMMONIA}

HAMMONIA is an upward extension of the ECHAM5 atmospheric general circulation model (Roeckner et al., 2006). The model's dynamics and radiation are fully coupled to the chemical Model of Ozone and Related Tracers (MOZART, Kinnison et al., 2007). A detailed description of the model is given by Schmidt et al. (2006). To simulate the effects of EPP, HAMMONIA is modified to incorporate the ion chemistry of the $\mathrm{E}$ and $\mathrm{F}$ region as described in Kieser (2011) and Meraner and Schmidt (2016). The ion chemistry treats 5 ion-electron recombinations and 12 ion-neutral reactions including 50 neutral and 6 charged $\left(\mathrm{O}^{+}, \mathrm{O}_{2}^{+}, \mathrm{N}^{+}, \mathrm{N}_{2}^{+}\right.$, $\mathrm{NO}^{+}, \mathrm{e}^{-}$) components. Additionally, five reactions directly involving energetic particles are considered. The corresponding reaction rates are calculated using the particle-induced ionization rates provided by Atmospheric Ionization Module Osnabrück (AIMOS version 1.6) (Wissing and Kallenrode, 2009). The explicit simulation of energetic particle effects on chemistry is limited to above $10^{-3} \mathrm{hPa}$, whereas below this altitude the production of $\mathrm{N}\left({ }^{2} \mathrm{D}\right), \mathrm{N}\left({ }^{4} \mathrm{~S}\right)$, and $\mathrm{HO}_{x}$ is parameterized following Jackman et al. (2005a). Photochemistry includes six reactions involving radiation at wavelengths shorter than Lyman- $\alpha$. Therefore the parameterization of Solomon and Qian (2005) and the observed $10.7 \mathrm{~cm}$ solar radio flux is used. Orographic gravity waves are parameterized according to Lott and Miller (1997), while nonorographic gravity waves are parameterized according to the Doppler-spread theory from Hines (1997). A geographically uniform isotropic gravity wave source spectrum with a constant root-mean-square (RMS) wave wind speed of $0.8 \mathrm{~m} \mathrm{~s}^{-1}$ launched at $830 \mathrm{hPa}$ is used. Additional to the homogeneous source of gravity waves, HAMMONIA considers the generation of gravity waves from tropospheric fronts following Charron and Manzini (2002). At locations where frontogenesis occurs the gravity wave spectrum is launched with an RMS wave wind speed of $2 \mathrm{~m} \mathrm{~s}^{-1}$ instead of $0.8 \mathrm{~m} \mathrm{~s}^{-1}$. A more detailed description of the gravity wave scheme used in HAMMONIA is given in Meraner et al. (2016). Note also that this setting of the gravity wave parameters differs from the simulation of the same winter analysed in Pedatella et al. (2014) where the waves were launched at about $650 \mathrm{hPa}$ and no frontal sources were used. Sea surface temperature and sea ice cover are taken from the Atmospheric Model Intercomparison Project 2 (AMIP2) climatology. Output is provided every $2 \mathrm{~h}$ and afterwards interpolated to the satellite geolocations. The model is nudged from 850 to $1 \mathrm{hPa}$ with an upper and lower transition zone to the 6-hourly values of the ERA-Interim reanalysis data (Dee et al., 2011). The "spin-up" time is 1 year starting on 1 January 2008.

\subsubsection{WACCM}

For the simulations presented here, the NCAR Community Earth System Model (http://www.cesm.ucar.edu/, Hurrell et al., 2013) is used with the Whole Atmosphere Community Climate Model as its atmospheric component (Marsh et al., 2013) (hereinafter referred to as WACCM4). The model is forced with meteorological fields from the Modern Era Retrospective Analysis for Research and Applications (MERRA), a NASA reanalysis using the Goddard Earth Observing System Data Assimilation System Version 5 (Rienecker et al., 2011). The forcing is achieved by relaxing temperature, zonal and meridional winds, and surface pressure with a time constant of $50 \mathrm{~h}$ from the surface to $40 \mathrm{~km}$. Above that level the forcing is reduced linearly, so that the model is 
Table 1. Summarized description of the atmospheric models involved in this study.

\begin{tabular}{|c|c|c|c|c|c|c|c|}
\hline $\begin{array}{l}\text { High-top } \\
\text { model }\end{array}$ & $\begin{array}{r}\text { Vertical } \\
\text { domain }(\mathrm{km})\end{array}$ & $\begin{array}{r}\text { Horizontal } \\
\text { resolution }\end{array}$ & $\begin{array}{l}\text { Vert. res. } \\
(\mathrm{km})\end{array}$ & $\begin{array}{l}\text { Meteorological data } \\
\text { nudging }\end{array}$ & $\begin{array}{l}\text { Family } \\
\text { approach }^{\text {a }}\end{array}$ & $\begin{array}{l}\text { Kinetic } \\
\text { data }^{b}\end{array}$ & $\begin{array}{l}\mathrm{EPP}^{-\mathrm{NO}_{x}} \\
\text { production }\end{array}$ \\
\hline 3dCTM & $\sim 10-150$ & $2.5^{\circ} \times 3.75^{\circ}$ & $\sim 1-3$ & LIMA (ECMWF < $1 \mathrm{hPa}$ ) & no & S06 & AIMOS 1.2 \\
\hline HAMMONIA & $\sim 0-250$ & $1.9^{\circ} \times 1.9^{\circ}$ & $\sim 3$ & ERA-I $(<1 \mathrm{hPa})$ & no & S06 & AIMOS 1.6 \\
\hline WACCM & $\sim 0-140$ & $1.9^{\circ} \times 2.5^{\circ}$ & $\sim 1.5$ & MERRA $(<50 \mathrm{~km})$ & no & S11 & auroral prod. \\
\hline $\begin{array}{l}\text { Medium-top } \\
\text { model }\end{array}$ & & & & & & & $\begin{array}{l}\mathrm{NO}_{x} \mathrm{UBC} \\
\text { range }(\mathrm{hPa})\end{array}$ \\
\hline CAO-SOCOL & $\sim 0-80$ & $3.75^{\circ} \times 3.75^{\circ}$ & $\sim 2$ & ERA-I $(<1 \mathrm{hPa})$ & no & S06 & 0.01 \\
\hline FinROSE & $\sim 0-80$ & $6^{\circ} \times 3^{\circ}$ & $\sim 2-7$ & ECMWF (whole model domain) & no & S06 & $0.03-0.01$ \\
\hline KASIMA & $\sim 7-120$ & $2.8^{\circ} \times 2.8^{\circ}$ & $0.75-3.8$ & ERA-I $(<1 \mathrm{hPa})$ & no & S03 & 0.03 \\
\hline EMAC & $\sim 0-80$ & $2.8^{\circ} \times 2.8^{\circ}$ & $\sim 1-4$ & ERA-I $(<0.2 \mathrm{hPa})$ & reduced & S11 & $0.09-0.01$ \\
\hline SOCOL & $\sim 0-80$ & $2.8^{\circ} \times 2.8^{\circ}$ & $\sim 2$ & ERA-I $(<1 \mathrm{hPa})$ & no & S11 & 0.01 \\
\hline
\end{tabular}

a See model descriptions in Sect. 3 for details.

b S11: Sander, S. P. et al. (2011); S03: Sander et al. (2003); S06: Sander et al. (2006)

free-running between $50 \mathrm{~km}$ and the model top at approximately $140 \mathrm{~km}\left(4.5 \times 10^{-6} \mathrm{hPa}\right)$. Heating rates and photolysis are calculated using observed daily solar spectral irradiance based on the empirical model of Lean et al. (2005) and geomagnetic activity effects in the auroral region are parameterized in terms of the Kp index (Marsh et al., 2007). The standard WACCM chemistry is described and evaluated extensively in WMO (2010). Reaction rates are from Sander, S. P. et al. (2011). For these simulations we have modified the $\mathrm{N}+\mathrm{N}_{2}$ reaction to include two additional pathways as described in Funke et al. (2008). It should be noted that both WACCM and HAMMONIA use the same chemical solver based on the MOZART3 chemistry (Kinnison et al., 2007), include the same set of ionized species, and use the parameterized EUV ionization rates from Solomon and Qian (2005). For these simulations the latter parameterization has been extended to include the photoionization of $\mathrm{CO}_{2}$ in the EUV. Above $5 \times 10^{-4} \mathrm{hPa}(\sim 100 \mathrm{~km})$ ionization from electrons is calculated by the WACCM parameterized aurora. It is assumed that $1.25 \mathrm{~N}$ atoms are produced per ion pair and divide the $\mathrm{N}$ atom production between ground state, $\mathrm{N}\left({ }^{4} \mathrm{~S}\right)$, at 0.55 per ion pair and excited state, $\mathrm{N}\left({ }^{2} \mathrm{D}\right)$, at 0.7 per ion pair (Jackman et al., 2005b; Porter et al., 1976). This simulation followed the "REFC1D" protocol of the Chemistry Climate Model Initiative (Eyring et al., 2013) for the specification of time-dependent greenhouse gases and ozone-depleting substances. WACCM constituent and temperature profiles were saved at the model grid point and time step (model time step is $30 \mathrm{~min}$ ) closest to each of the MIPAS observation locations. Eddy diffusion created by the dissipation of parameterized gravity waves in WACCM depends on the value assumed for the Prandtl number, $\mathrm{Pr}$, which describes the ratio of the eddy momentum flux to the eddy flux of potential temperature or chemical species. In these simulations $\operatorname{Pr}=4$, as in the study of Garcia et al. (2014).

\subsection{Medium-top models}

\subsubsection{CAO-SOCOL}

Since HEPPA-I (Funke et al., 2011) the CCM SOCOL (modelling tool for studies SOlar Climate Ozone Links) has been upgraded to version 3 with substantial changes related to the advection of the species. These changes and the detailed evaluation of the new version performance were documented by Stenke et al. (2013). The CCM SOCOL v.3 consists of the MEZON chemistry transport model (Egorova et al., 2003) and MA-ECHAM5, the middle atmosphere version of the ECHAM general circulation model (Roeckner et al., 2006). Dynamical and physical processes in SOCOL are calculated every $15 \mathrm{~min}$ within the model, while full radiative and chemical calculations are performed every $2 \mathrm{~h}$. Chemical constituents are transported using a flux-form semi-Lagrangian scheme (Lin and Rood, 1996), and the chemical solver is based on a Newton-Raphson iterative method taking into account 41 chemical species, 140 gas-phase reactions, 46 photolysis reactions, and 16 heterogeneous reactions. The CCM SOCOL v. 3 was installed in CAO (Central Aerological Observatory, Moscow, Russian Federation) and modified to use assimilation of the meteorological fields from the ERA-I reanalysis, which is necessary to reproduce the considered SSW and ES events in January 2009. The model is nudged from 850 to $1 \mathrm{hPa}$ using the Jeuken et al. (1996) approach. Orographic gravity waves are parameterized according to Lott and Miller (1997). Non-orographic gravity waves are parameterized using Hines (1997) scheme implemented to ECHAM5 with a constant RMS wave wind speed of $1.0 \mathrm{~m} \mathrm{~s}^{-1}$ introduced at $830 \mathrm{hPa}$ for all geographical locations. The daily mean $\mathrm{NO}_{x}$ mixing ratio at $0.01 \mathrm{hPa}$ from MIPAS measurements (see Sect. 4) was used as the UBC at the uppermost model layer. The $\mathrm{NO}_{x}$ mixing ratio was divided between $\mathrm{NO}$ and $\mathrm{NO}_{2}$ according to their ratio in the 
model for any particular time step at the second layer from the model top. Model output was interpolated in time and space to the provided satellite geolocations.

\subsubsection{EMAC}

The EMAC model is a numerical chemistry and climate simulation system that includes submodels describing tropospheric and middle atmosphere processes and their interaction with oceans, land, and human influences (Jöckel et al., 2010). It uses the second version of the Modular Earth Submodel System (MESSy2) to link multi-institutional computer codes. The core atmospheric model is the fifthgeneration European Centre Hamburg general circulation model (ECHAM5, Roeckner et al., 2006). For the present study we applied EMAC (ECHAM5 version 5.3.02, MESSy version 2.50) in the T42L90MA resolution. The model is nudged to ERA-Interim reanalysis data from the surface to $0.2 \mathrm{hPa}$ (with decreasing nudging strength in the transition region in the five levels above) using the nudging coefficients suggested in Jeuken et al. (1996). The UBC for $\mathrm{NO}_{x}$ is prescribed in the top four layers $(0.01$ to $0.09 \mathrm{hPa})$ of the model. For gravity waves we used the submodel GWAVE which contains the original Hines non-orographic gravity wave routines (Hines, 1997) from ECHAM5 in a modularized structure. We tuned the parameter rmscon (RMS wind speed at bottom launch level of $642.9 \mathrm{hPa}$ ), which controls the dissipation of gravity waves, to $0.8 \mathrm{~m} \mathrm{~s}^{-1}$. For gas-phase reactions we used the submodel MECCA (Sander, R. et al., 2011) and for photolysis the submodel JVAL (Sander et al., 2014). Included were 110 gas-phase reactions and 44 photolysis reactions. The $\mathrm{NO}_{x}$ family was reduced to $\mathrm{NO}$ and $\mathrm{NO}_{2}$. The chemical tracers were initialized from a multi-annual EMAC model run. Model output was done for each time step $(10 \mathrm{~min})$ which afterwards was interpolated to the satellite geolocations.

\subsubsection{FinROSE}

FinROSE is a global 3-D CTM (further developed model version of the one described by Damski et al., 2007). The model dynamics for the whole model domain is forced with external meteorological data, whereas the vertical wind is calculated inside the model by using the continuity equation. In this study FinROSE is nudged with ECMWF operational analysis data. This means that changes in the atmospheric composition do not affect the model dynamics, and gravity wave parameterization is included already in the meteorological forcing data. FinROSE reproduces the distributions of 41 species from the stratosphere up to the mesosphere and lower thermosphere and also includes about 120 homogeneous reactions and 30 photodissociation processes. Photodissociation frequencies are calculated using a radiative transfer model (Kylling et al., 1997). In addition to homogeneous chemistry, the model also includes heterogeneous chemistry, i.e. forma- tion and sedimentation of polar stratospheric clouds (PSCs) and reactions on PSCs. The model is designed for middle atmospheric studies and thus the chemistry is not defined in the troposphere, but the tropospheric abundances are given as boundary conditions. For this study, the UBC for $\mathrm{NO}_{x}$ (i.e. $\mathrm{NO}+\mathrm{NO}_{2}$ ) was implemented in the MLT region at about $0.03-0.01 \mathrm{hPa}$ (the top two model layers). Output in the satellite geolocations was composed already during the model run by finding the closest model grid point and time step to every geolocation.

\subsubsection{KASIMA}

The KASIMA model is a 3-D mechanistic model of the middle atmosphere including full middle atmosphere chemistry (Kouker et al., 1999). The model can be coupled to specific meteorological situations by using analysed lower boundary conditions and nudging terms for vorticity, divergence, and temperature. Here the version used for the HEPPA-I experiment has been applied (Funke et al., 2011) but with a horizontal resolution of about $2.8^{\circ} \times 2.8^{\circ}$ (T42). The frequency of output is every $6 \mathrm{~h}$. The model is nudged to ERA-Interim analyses below $1 \mathrm{hPa}$. A numerical time step of $6 \mathrm{~min}$ was used in the experiments. The model uses a Lindzen-type parameterization (Holton, 1982) to include the effect of breaking gravity waves, but no specific parameterization of orographic gravity waves. Further details of the model are found in Funke et al. (2011). The UBC for $\mathrm{NO}_{x}$ was set at the $0.3 \mathrm{hPa}$ level, and not above. This occasionally causes deviations between the observations and the model above this level.

\subsubsection{SOCOL}

The applied version of the CCM SOCOL improves upon CAO-SOCOL and was prepared for participation in the IGBP/SPARC CCMI project. The tropospheric chemistry component was extended by adding the Mainz Isoprene Mechanism (MIM-1), which comprises 16 organic species and a further 44 chemical reactions (Pöschl et al., 2000). The cloud influence on photolysis rates was introduced using a cloud modification factor (Chang et al., 1987). Interactive lightning source of $\mathrm{NO}_{x}$ was introduced following the Price and Rind (1992) approach and adopting local scaling factors based on satellite measurements. The kinetic constants and absorption cross sections were updated following Sander, S. P. et al. (2011). The new parameterization of the UV heating rates (Sukhodolov et al., 2014) as well as $\mathrm{NO}_{x}$ and $\mathrm{HO}_{x}$ production by energetic particles (Rozanov et al., 2012) was adopted. For HEPPA-II the model was run with T42 horizontal resolution, which corresponds approximately to $2.8^{\circ} \times 2.8^{\circ}$, and 39 vertical levels between the ground and $0.01 \mathrm{hPa}$. The nudging set-up and $\mathrm{UBC}$ for $\mathrm{NO}_{x}$ are the same as in CAO-SOCOL. 

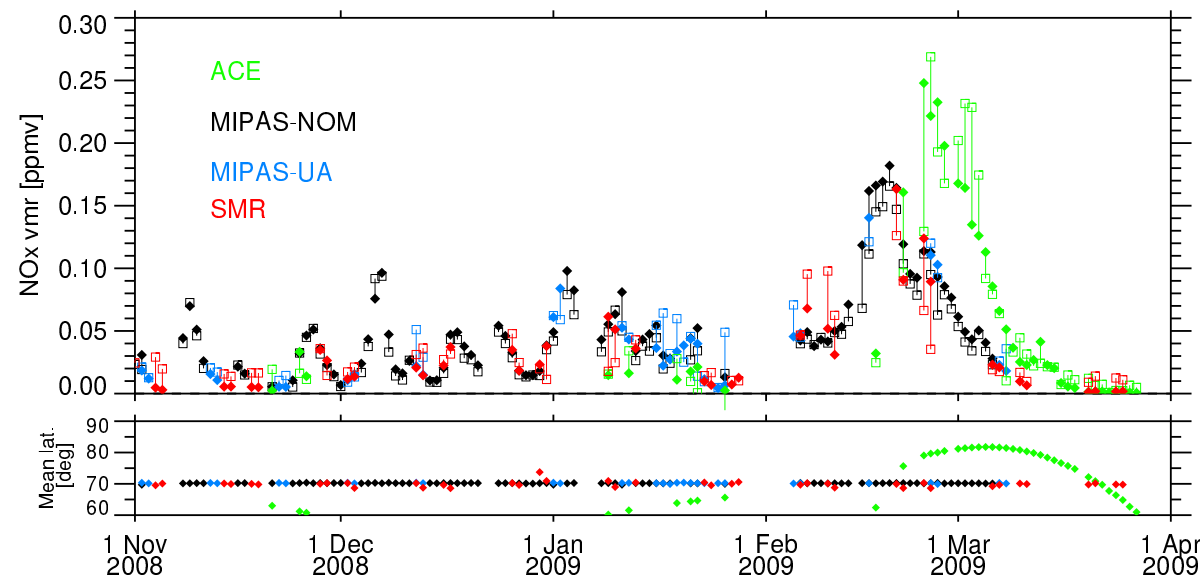

Figure 1. Upper panel: daily averaged $\mathrm{NO}_{x}$ mixing ratios from satellite observations (open squares) at $0.022 \mathrm{hPa}$ within $60-90^{\circ} \mathrm{N}$ (black is MIPAS-NOM, blue is MIPAS-UA, red is SMR/Odin, green is ACE-FTS) and those of the upper boundary condition (filled diamonds) sampled at the respective observations' time and location. Lower panel: mean latitude averaged over all observations of the individual instruments within $60-90^{\circ} \mathrm{N}$. All averages are area-weighted.

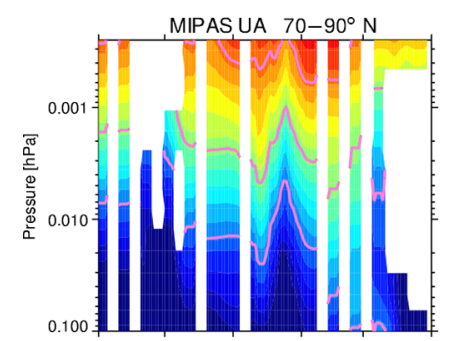

$\begin{array}{llllll}1 \text { Nov } & \text { Dec } & 1 \text { Jan } & 1 \text { Fed } & \text { Mar } & 1 \text { Apr } \\ 2008 & 2008 & 2009 & 2009 & 2009 & 2009\end{array}$
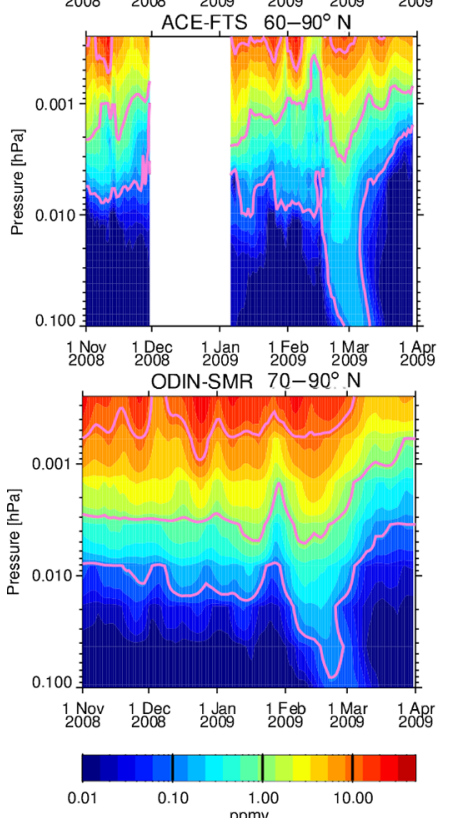

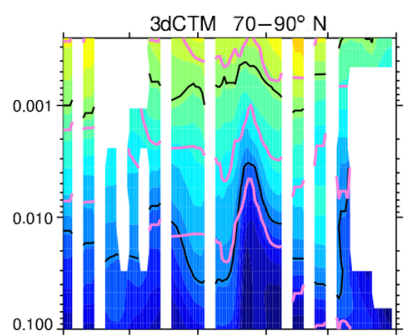

$\begin{array}{llllll}1 \text { Nov } & 1 \text { Dec } & 1 \mathrm{Jan} & 1 \mathrm{feb} & 1 \mathrm{Mar} & 1 \mathrm{AAg} \\ 2008 & 2008 & 2009 & 2009 & 2009 & 2009\end{array}$
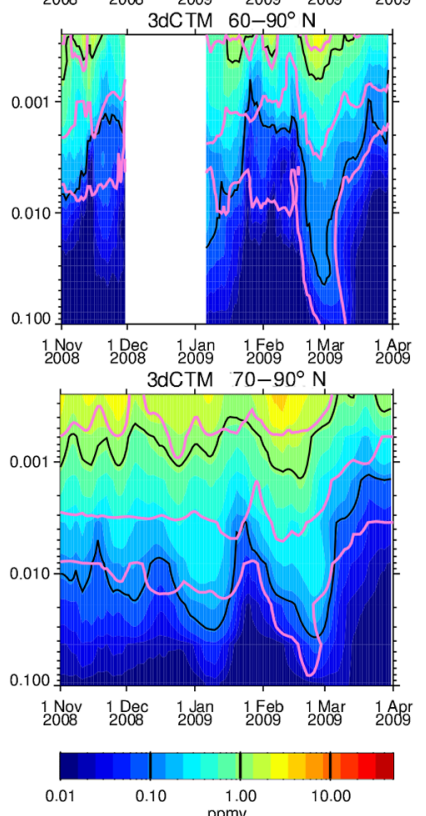

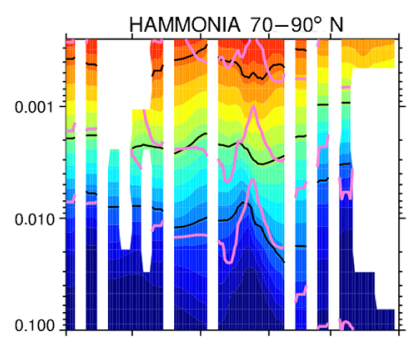

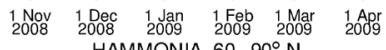
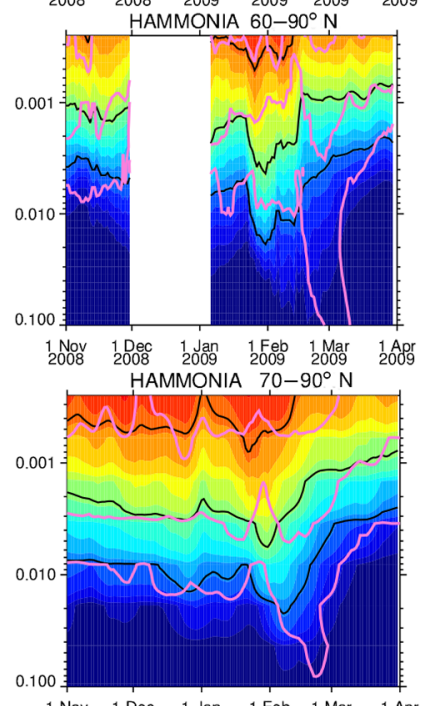

$\begin{array}{llllll}1 \text { Nov } & 1 \mathrm{Dec} & 1 \mathrm{Jan} & 1 \mathrm{Feb} & 1 \mathrm{Mar} & 1 \mathrm{Apr} \\ 2008 & 2008 & 2009 & 2009 & 2009 & 2009\end{array}$

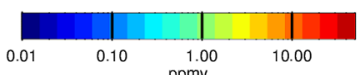

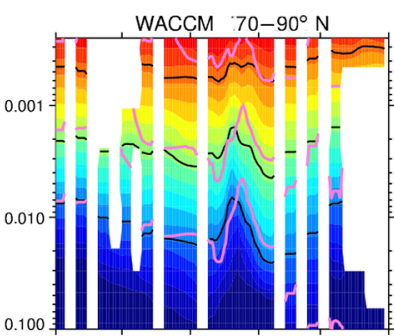

$\begin{array}{llllll}1 \text { Noy } & 1 \text { Dec } & 1 \mathrm{Jan} & 1 \mathrm{Feb} & 1 \mathrm{Mar} & 1 \mathrm{Apr} \\ 2008 & 2008 & 2009 & 2009 & 2009 & 2009\end{array}$

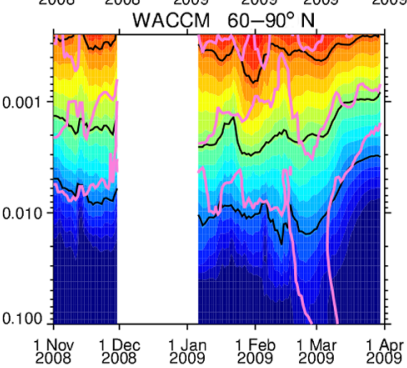

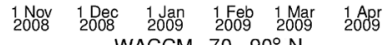
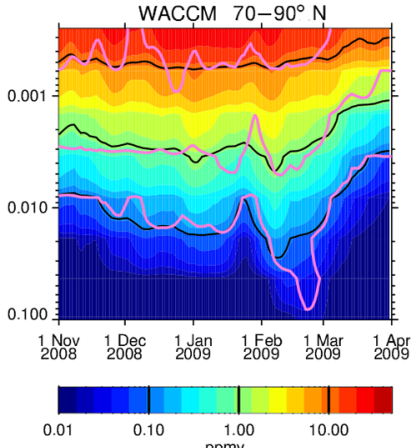

Figure 2. Observed and modelled $\mathrm{NO}_{x}$ VMRs of MIPAS and ACE (upper two rows) and NO of SMR (lower row) in NH polar MLT region during November 2008-March 2009. Model output of the "high-top" models 3dCTM, HAMMONIA, and WACCM has been sampled at the locations and times of the observations (MPAS-UA, ACE-FTS, and SMR) for comparison. Pink lines indicate the observed VMR levels of $0.1,1$, and 10 ppmv. White regions reflect missing or not meaningful data. 


\section{$4 \mathrm{NO}_{x}$ UBC for medium-top models}

The UBC for $\mathrm{NO}_{x}$ mixing ratio has been constructed from MIPAS-NOM observation data versions v4o_NO_200 and v4o_NO2_200 by projecting individual observations onto a regular grid in longitude, latitude, pressure level, and time with daily cadence using a distance-weighting algorithm. All observations taken within $\pm 12 \mathrm{~h}$ time difference, $\pm 10^{\circ}$ latitude, and $\pm 25^{\circ}$ longitude have been considered at each grid point (weighted by the inverse distance squared) and have been vertically interpolated to a fixed pressure grid. Data gaps in space and time have been filled by linear interpolation. Note that in the model-measurement intercomparisons a newer version of MIPAS $\mathrm{NO}_{x}$ is used, which was not available when the UBC was generated prior to the model runs. The horizontal resolution of the $\mathrm{NO}_{x} \mathrm{UBC}$ is $1.25^{\circ} \times 2.5^{\circ}$ (latitude $\times$ longitude). Thirteen vertical pressure levels within $1-0.01 \mathrm{hPa}$ are covered to allow for interpolation to the respective upper lid of the models. The $\mathrm{NO}_{x}$ UBC has been evaluated by comparing with available satellite observations (see Fig. 1). To avoid sampling errors in the comparisons, the UBC field has been sampled at the measurements' locations of each day before averaging over the polar cap region. In general, there is very good agreement (within 10-20\%) with independent $\mathrm{NO}_{x}$ observations. However, larger differences up to $20-50 \%$ occur sporadically for observations close to the vortex edge (e.g. when comparing to ACT-FTS at the end of February) where horizontal gradients are very pronounced.

\section{Intercomparison strategy}

The discrete horizontal sampling of satellite observations can cause large uncertainties in intercomparisons of observed and modelled averaged quantities, particularly if the sampling is sparse, irregular, or variable in time (Toohey et al., 2013). To reduce the impact of sampling errors, we follow the same approach that was successfully applied in the first HEPPA intercomparison study (Funke et al., 2011): the model output has been sampled at the locations and times of the individual observations and has been vertically interpolated to the observed pressure levels. If available (i.e. in the case of MIPAS and MLS), averaging kernels have been applied to the model results as described in Funke et al. (2011). Profiles have only been considered in the vertical range where the instruments' sensitivity is high enough to provide meaningful data; the remaining profile regions have been excluded in both observations and model results.

Model-measurement comparisons were performed on basis of daily and/or quasi-monthly averaged zonal mean data, which have been calculated in the same way for both observations and simulations. For most comparisons, data have been further binned within $70-90^{\circ} \mathrm{N}$, applying areaconserving $(\cos (\theta))$ weights. Note, however, that the sam- pled portion of this latitude bin varies from instrument to instrument, making a direct comparison of the observational results difficult. However, the comparison of model biases with respect to different observational datasets is mostly unaffected. The binning has been extended to $60-90^{\circ} \mathrm{N}$ in the comparisons to ACE-FTS data in order to allow for evaluations prior to February 2009. We recall that ACE-FTS has a discrete but time-varying latitude coverage (see Fig. 1) such that the resulting averages represent only a small fraction of the entire bin.

\section{Upper mesosphere and lower thermosphere}

In this section $\mathrm{NO}_{x}, \mathrm{CO}$, and temperature fields of the hightop models 3dCTM, HAMMONIA, and WACCM are compared to the observations in the MLT, the source region of odd nitrogen produced by EPP. Although, strictly speaking, temperature is not a tracer of vertical motion, the adiabatic warming during periods of strong descent introduces observable changes of the thermal structure of this region which can be used as diagnostics of vertical transport in the models. The simultaneous evaluation of modelled $\mathrm{NO}_{x}, \mathrm{CO}$, and temperature distributions allows then to attribute model biases to deficiencies in the simulation of either particle-induced $\mathrm{NO}_{x}$ production or of dynamics.

Figure 2 shows the vertical distribution of $\mathrm{NH}$ polar $\mathrm{NO}_{x}$ over time in the simulations and MIPAS-UA, ACE-FTS, and ODIN-SMR observations at 0.1 to $2 \times 10^{-4} \mathrm{hPa}$. SCIAMACHY observations of NO densities have not been included in this figure because $\mathrm{NH}$ polar observations are only available after the beginning of February. Note that MIPASUA and ACE-FTS provided $\mathrm{NO}_{x}$ VMRs, while SMR observed NO VMR only. This, however, introduces differences only below approximately $0.01 \mathrm{hPa}$ since $\mathrm{NO}_{x}$ is entirely in the form of NO above. The comparisons with the three instruments provide a consistent picture of model biases. While WACCM and HAMMONIA reproduce the observations fairly well during the whole time period in the upper mesosphere and lower thermosphere (above the $0.01 \mathrm{hPa}$ level), 3dCTM exhibits too small $\mathrm{NO}_{x}$ abundances in this vertical region. Below the $0.01 \mathrm{hPa}$ level and during the preSSW phase of the winter (November-January), WACCM and HAMMONIA agree well with the observations while $3 \mathrm{dCTM}$ overestimates $\mathrm{NO}_{x}$ in this vertical region during most of the pre-SSW phase.

The SSW event starts with the breakdown of the polar vortex, and the dilution of the mesospheric $\mathrm{NO}_{x}$ by upwelling and increased horizontal mixing. This is clearly observed by MIPAS and SMR as a decrease of $\mathrm{NO}_{x}$ between roughly 0.01 and $0.001 \mathrm{hPa}$. This initial $\mathrm{NO}_{x}$ decrease is captured well by WACCM and 3dCTM, though it is too weak in the HAMMONIA simulation. The initial decrease of $\mathrm{NO}_{x}$ during the SSW is followed by strong downwelling of $\mathrm{NO}_{x}$ leading to a pronounced increase of mesospheric $\mathrm{NO}_{x}$ and the development 

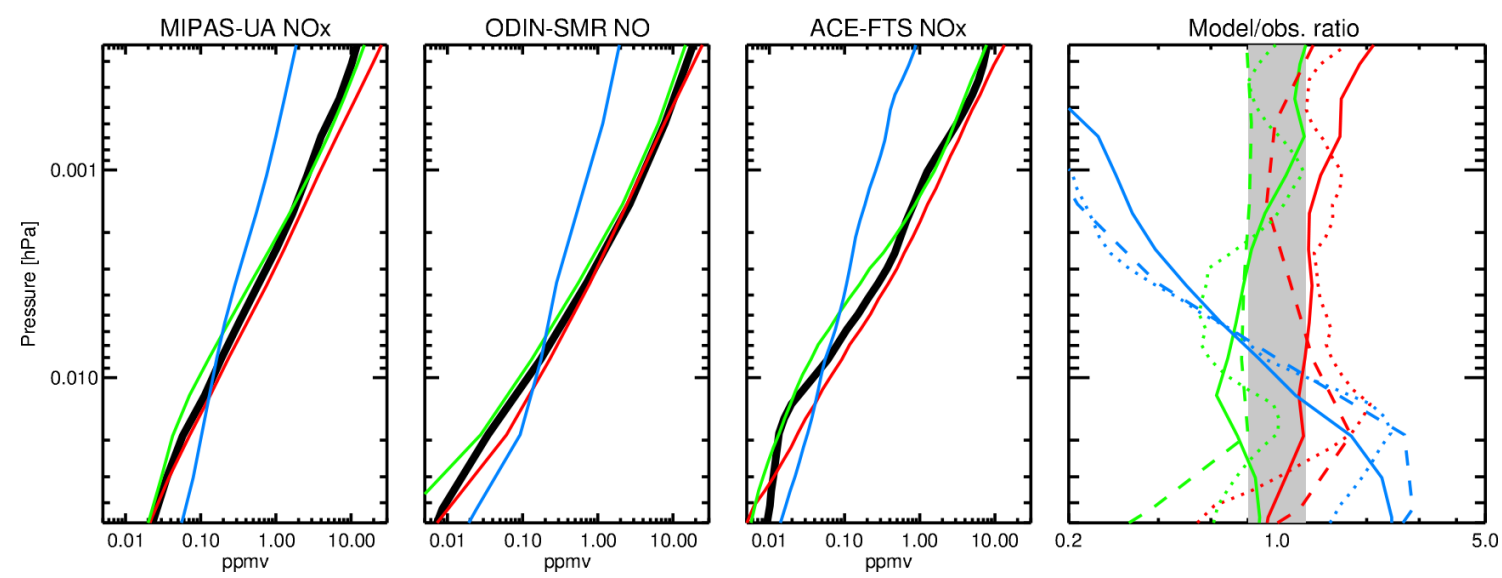

Figure 3. Comparison of observed polar mid-winter $\mathrm{NO}_{x}$ mean profiles (thick black lines) a to 3dCTM (blue), HAMMONIA (green), and WACCM (red). Right panel: ratio of model results and MIPAS-UA (solid), SMR/Odin (dashed), and ACE-FTS (dotted) observations. The grey shaded area indicates the $\pm 25 \%$ range. Data have been averaged over $70-90^{\circ} \mathrm{N}$ and 5 December $2008-12 \mathrm{January} 2009\left(60-90^{\circ} \mathrm{N}\right.$ and 5 November 2008-12 January 2009 in the case of ACE-FTS).

of the characteristic $\mathrm{NO}_{x}$ "tongue". This is qualitatively captured by all models, however, the amount of $\mathrm{NO}_{x}$ transported into the lower mesosphere (below $0.01 \mathrm{hPa}$ ) is significantly underestimated. The timing of the onset of the enhanced descent varies considerably among the models and, compared to the observations, occurs slightly too early in HAMMONIA and too late in 3dCTM. The onset of ES-related $\mathrm{NO}_{x}$ increases in WACCM coincides with the observed onset, however, the modelled increases appear to last for a shorter time.

\subsection{Unperturbed early (pre-SSW) phase}

In the following, the observed and modelled vertical structure of $\mathrm{NO}_{x}, \mathrm{CO}$, and temperature during mid-winter (pre-SSW phase) is analysed in more detail to evaluate the models' ability to reproduce the EPP indirect effect for unperturbed conditions. Figure 3 compares the observed and modelled $\mathrm{NO}_{x}$ mid-winter mean profiles averaged over $70-90^{\circ} \mathrm{N}$ and 5 December 2008-15 January $2009\left(60-90^{\circ} \mathrm{N}\right.$ and 5 November 2008-15 January 2009 in the case of ACE-FTS) above the altitude of $0.05 \mathrm{hPa}$. The observed vertical structure of $\mathrm{NO}_{x}$ is reasonably well reproduced by HAMMONIA and WACCM during this period. Differences with respect to the observations are mostly within 20-50\%, with WACCM being overall more on the high side and HAMMONIA more on the low side (particularly at altitudes below $0.002 \mathrm{hPa}$ ). As discussed earlier, the $3 \mathrm{dCTM}$ simulations show a much less pronounced vertical gradient resulting in a significant (in terms of the observational spread) $\mathrm{NO}_{x}$ underestimation (up to a factor of 8 ) at altitudes above $10^{-2} \mathrm{hPa}$ and overestimation (up to a factor of 3 ) below. Figure 4 compares the corresponding mean profiles of CO, observed by MIPAS-UA, MLS, and ACE-FTS above the altitude of $0.5 \mathrm{hPa}$. Again, WACCM and HAMMONIA show a vertical gradient that is roughly in agreement with the observations. In contrast, the abso- lute CO values of WACCM are slightly (up to $40 \%$ ) higher while HAMMONIA underestimates the $\mathrm{CO}$ abundances by a factor of 2-3. The latter can be explained by missing thermospheric production mechanisms in the model, specifically the $\mathrm{CO}_{2}$ photolysis in the extreme ultraviolet (at wavelengths $<121 \mathrm{~nm}$ ) and the reaction of $\mathrm{CO}_{2}$ with the atomic oxygen ion (Garcia et al., 2014), that act in addition to the photolysis of $\mathrm{CO}_{2}$ in Lyman-alpha and the Schumann-Runge continuum. The $3 \mathrm{dCTM}$ simulations, similarly as for $\mathrm{NO}_{x}$, show a gradient in the mesosphere that is too weak compared to the observations, resulting in an underestimation above $0.03 \mathrm{hPa}$ and an overestimation below. The corresponding temperature profiles (see Fig. 5), observed by MIPAS-UA, MLS, and ACE-FTS (note that SABER is not included because the observations in December cover only up to $52^{\circ} \mathrm{N}$ ) indicate good agreement with the observations for HAMMONIA and a slight warm bias of 5-10 K for WACCM. Mesospheric $3 \mathrm{dCTM}$ temperatures are systematically too cold by $10-30 \mathrm{~K}$ in the middle and lower mesosphere.

The good overall agreement of $\mathrm{NO}_{x}, \mathrm{CO}$, and temperature from HAMMONIA and WACCM with the observations in December suggests that both $\mathrm{NO}_{x}$ sources and dynamical conditions are well represented by these models, allowing for an adequate description of the EPP indirect effect in the MLT during unperturbed conditions early in $\mathrm{NH}$ winters. Interestingly, the consideration of ionization induced by mid-energy electron in HAMMONIA (via AIMOS) does not introduce noticeable differences in the NO distribution with respect to WACCM, the latter only accounting for auroral electrons. This suggests that the impact of mid-energy electron during the solar minimum 2008/2009 NH winter was rather small. $3 \mathrm{dCTM}$ simulations, in contrast, show significant discrepancies with the observations. The similarity of the model bias in the vertical gradients of $\mathrm{NO}_{x}$ and $\mathrm{CO}$ suggests that these differences with respect to the observations are due to the 

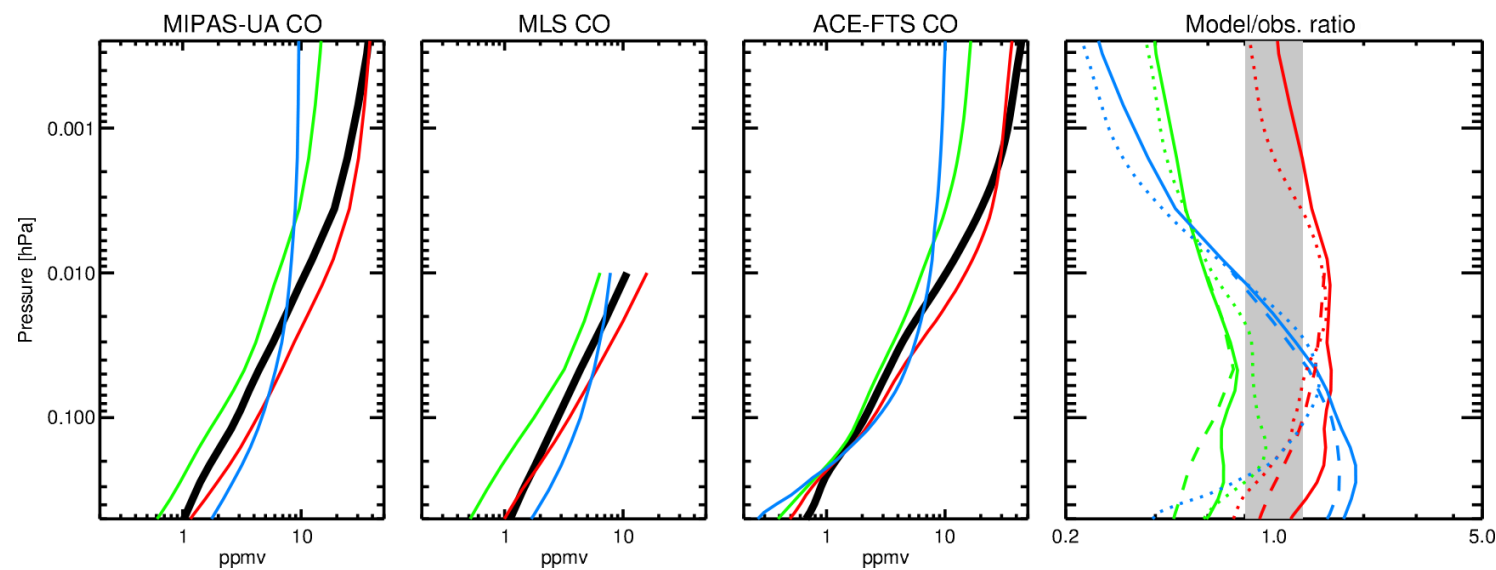

Figure 4. Comparison of observed polar mid-winter CO mean profiles (thick black lines) to 3dCTM (blue), HAMMONIA (green), and WACCM (red). Right panel: ratio of model results and MIPAS-UA (solid), MLS (dashed), and ACE-FTS (dotted) observations. The grey shaded area indicates the $\pm 25 \%$ range. Data have been averaged over $70-90^{\circ} \mathrm{N}$ and 5 December 2008-12 January 2009 (60-90 $\mathrm{N}$ and 5 November 2008-12 January 2009 in the case of ACE-FTS).
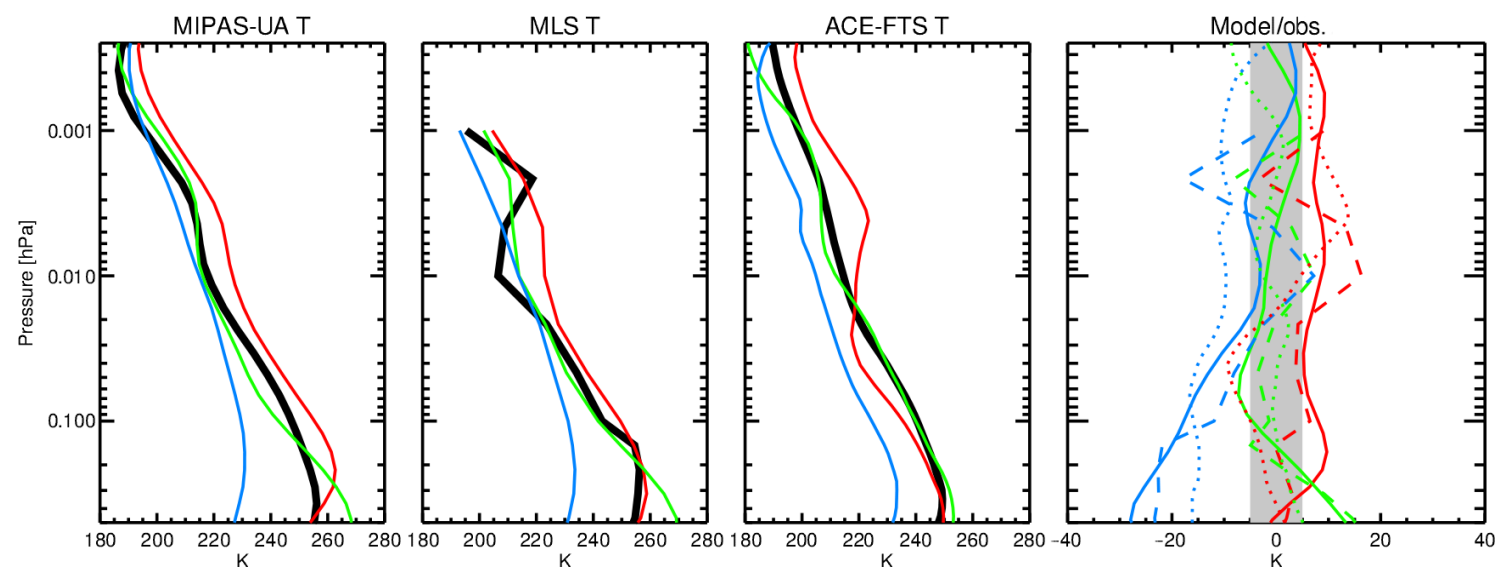

Figure 5. Comparison of observed polar mid-winter temperature mean profiles (thick black lines) to 3dCTM (blue), HAMMONIA (green), and WACCM (red). Right panel: temperature difference of the simulations and MIPAS-UA (solid), MLS (dashed), and ACE-FTS (dotted) observations. The grey shaded area indicates the $\pm 5 \mathrm{~K}$ range. Data have been averaged over $70-90^{\circ} \mathrm{N}$ and 5 December $2008-12$ January 2009 (60-90 $\mathrm{N}$ and 5 November 2008-12 January 2009 in the case of ACE-FTS).

representation of dynamics in 3dCTM rather than to the EPP source. The vertical gradient of the $3 \mathrm{dCTM} \mathrm{CO}$ and $\mathrm{NO}_{x}$ profiles both show values in the lower thermosphere that are too low and values in the upper to mid-mesosphere that are too high. The underestimation of lower thermospheric $\mathrm{CO}$ is likely due to the model chemistry as, like in HAMMONIA, neither the EUV photolysis of $\mathrm{CO}_{2}$ nor the production of $\mathrm{CO}$ by positive ion chemistry in the lower thermosphere are considered in 3dCTM. The underestimation of thermospheric $\mathrm{NO}_{x}$ could be caused by a too-weak NO production or too-fast transport out of the (polar) source region, either by horizontal mixing or across the mesopause. The high values of both $\mathrm{CO}$ and $\mathrm{NO}_{x}$ in the mesosphere, however, are likely due to the representation of mesospheric dynamics in 3dCTM, which is driven by temperatures and wind fields from the LIMA model. A likely reason seems the neglect of subscale $(\leq 500 \mathrm{~km})$ gravity waves in the LIMA model, leading to an underestimation of the GW drag throughout the mesosphere but to an overestimation in the lowermost thermosphere (see Sect. 2.7). This leads to a suppression of vertical motion in the mesosphere, which is also reflected in a negative bias in temperatures, and, consequently, to an accumulation of $\mathrm{CO}$ and $\mathrm{NO}_{x}$.

\subsection{Perturbed late (post-SSW) phase}

Figure 6 compares the observed and modelled $\mathrm{NO}_{x}$ February mean profiles corresponding to the perturbed post-SSW phase of this winter, characterized by enhanced descent of $\mathrm{NO}_{x}$. This comparison includes also SCIAMACHY NO density averages. Above $0.005 \mathrm{hPa}$, a larger spread of modelmeasurement differences compared to December is found, 

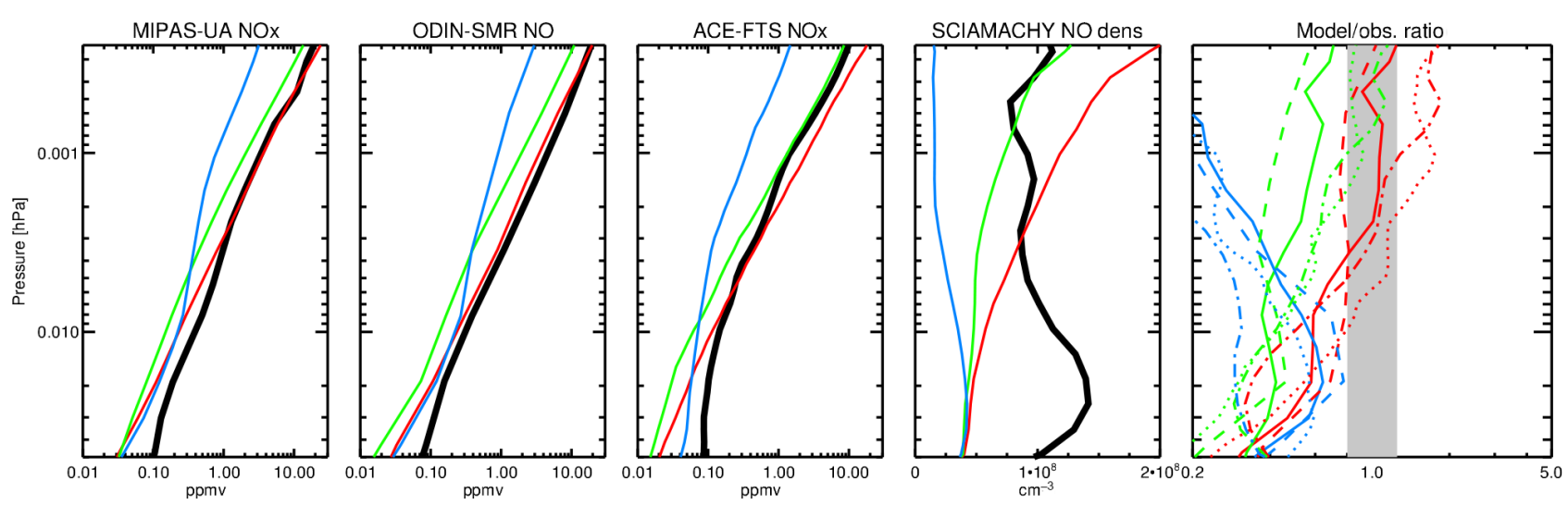

Figure 6. Comparison of observed $\mathrm{NO}_{x}$ mean profiles (thick black lines) for February 2009 (during the ES event) and $70-90^{\circ} \mathrm{N}$ to $3 \mathrm{dCTM}$ (blue), HAMMONIA (green), and WACCM (red). Right panel: ratio of model results and MIPAS-UA (solid), SMR/Odin (dashed), ACEFTS (dotted), and SCIAMACHY (dash-dotted) observations. The grey shaded area indicates the $\pm 25 \%$ range. Data have been averaged over $70-90^{\circ} \mathrm{N}$ and 1 February-1 March 2009 (60-90 $\mathrm{N}$ and 1 February 2008-15 March 2009 in the case of ACE-FTS).

likely related to the enhanced spatial and temporal variability. On average, however, these differences are very similar to those encountered during mid-winter. Below $0.005 \mathrm{hPa}$, all models systematically underestimate the observed $\mathrm{NO}_{x}$ increases associated with the ES event by a factor of 2-3.

Adiabatic heating associated with the enhanced mesospheric descent is responsible for the reformation of the stratopause at a pressure level as high as $0.005 \mathrm{hPa}$. Figure 7 shows the temporal evolution of the vertical temperature structure at $70-90^{\circ} \mathrm{N}$ in January-March as observed by SABER and simulated by 3dCTM (LIMA), HAMMONIA, and WACCM. We have chosen this observational dataset for the comparison to the models because of its full temporal coverage in this period and the high vertical resolution in the entire vertical range. The observed elevated stratopause started to develop at the beginning of February and remained at around $0.01 \mathrm{hPa}$ for a month before it descended to its climatological height in the course of March. The highest stratopause temperatures during the elevated phase were reached around 20 February. Although all models simulate an elevated stratopause, its temporal evolution differs significantly from the observations. HAMMONIA and WACCM show an ES onset and formation level similar to the observed ones, but highest temperatures at this level are reached immediately after the onset, about 20 days earlier than in the observations. In both models, the ES level starts to descend immediately after its formation, more quickly than observed and faster in HAMMONIA than in WACCM. During the descent, the modelled stratopauses become increasingly warmer. $3 \mathrm{dCTM}$, in contrast, simulates a much later onset (about 2 weeks after the observed one) and the ES temperatures are much colder than in the observations. However, the modelled ES remains at an elevated level for a longer time (although slightly lower than the observed ES) and the time delay until reaching the maximum ES temperatures is comparable to the observed temperature evolution. These dif- ferences between 3dCTM on the one hand and WACCM, HAMMONIA, and mostly also the observations on the other hand highlight the role of subscale gravity waves for the temporal evolution of the ES event. The onset of the SSW event is driven mainly by large-scale planetary waves breaking down the horizontal circulation and is captured comparatively well by all three models. However, the reformation of the stratopause at upper-mesospheric altitudes is driven by small-scale gravity waves reaching up to the upper mesosphere after the event. As these smaller gravity waves are essentially missing in the LIMA data, the build-up of the elevated stratopause is delayed in $3 \mathrm{dCTM}$, and its strength is weaker.

To investigate whether the encountered differences between the models and SABER data are robust with respect to instrumental uncertainties, we extend the analysis to MIPASUA, ACE, and MLS temperature observations and compare the model differences to all observations (see Fig. 8). Despite minor changes related to the different latitude range covered by the instruments, the encountered model biases are consistent for all instruments, indicating a too-cold mesosphere of $3 \mathrm{dCTM}$ and a dipole-type pattern in HAMMONIA and, less pronounced, in WACCM with colder temperatures after the ES onset in the upper mesosphere and warmer temperatures below.

A similar analysis of $\mathrm{NH}$ polar temperature evolution in early 2009 in several whole atmosphere models (including HAMMONIA) and MLS observations has been performed by Pedatella et al. (2014). Their Fig. 1 can be directly compared to our Fig. 7. In agreement with our results, most of the investigated models in the study of Pedatella et al. (2014) did not maintain the stratopause height near $0.01 \mathrm{hPa}$ until the end of February as in the observations, except WACCM$\mathrm{X}$, which was nudged to NOGAPS-ALPHA reanalysis data (assimilating observed temperatures) up to $92 \mathrm{~km}$. Siskind et al. (2015) further showed with WACCM simulations of the 

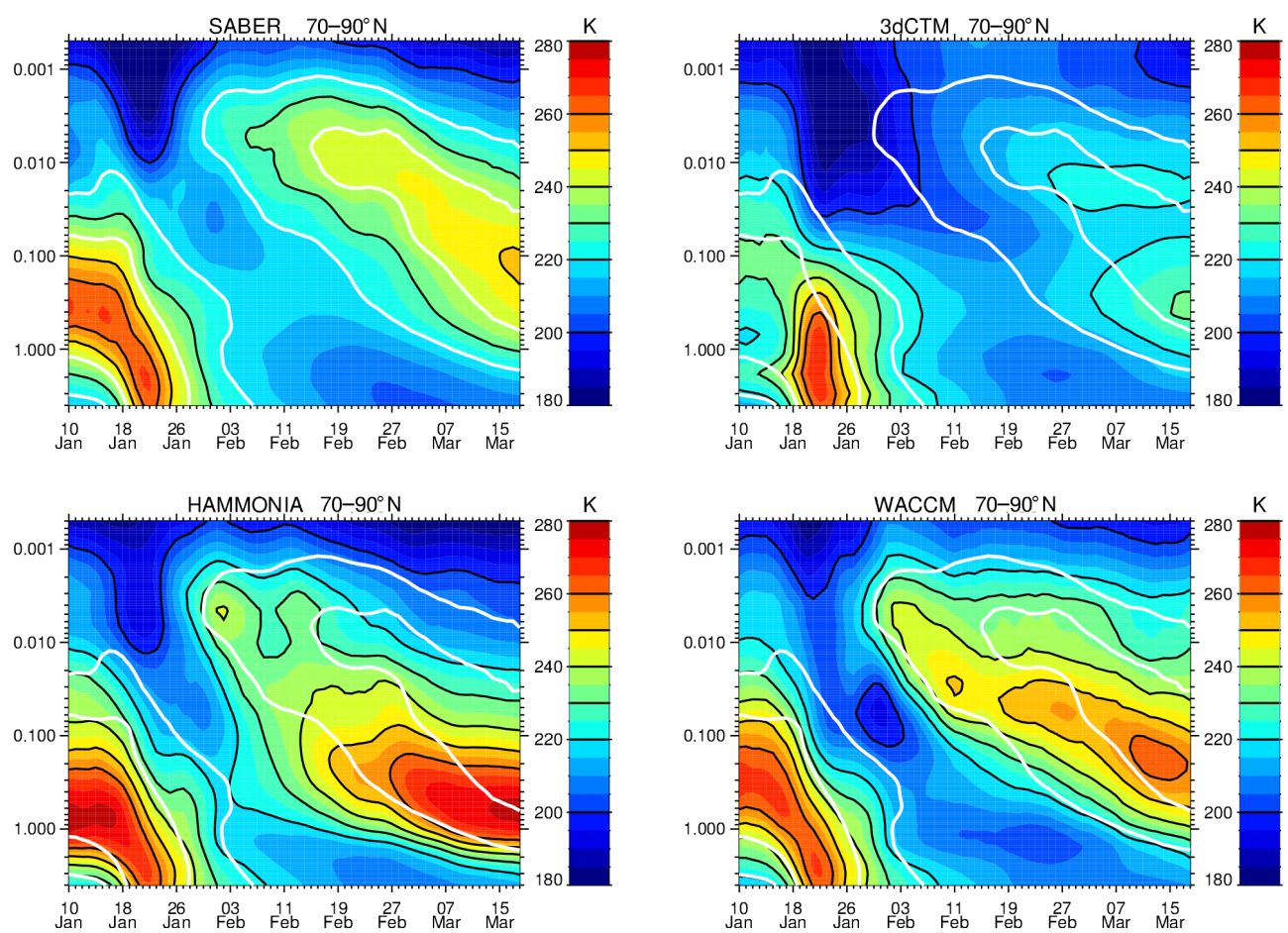

Figure 7. Temporal evolution of daily averaged polar cap temperatures at $4-0.0005 \mathrm{hPa}$ from SABER observations and simulations of 3dCTM, HAMMONIA, and WACCM (from top left to bottom right). The white contours correspond to the observed temperatures of 220 and $240 \mathrm{~K}$.

same $\mathrm{NH}$ winter that nudging to a more realistic meteorology (with an ES evolution closer to the observations) up to $92 \mathrm{~km}$ dramatically improves the simulated NO descent during this event compared to SOFIE observations.

Unresolved non-orographic GWD is thought to play a crucial role in the strengthening of mesospheric descent in the vicinity of the NO source region during ES events by providing enhanced westward momentum, which forces a poleward and downward residual circulation (Siskind et al., 2010; Chandran et al., 2011; McLandress et al., 2013). Motivated by the results of our analysis, Meraner et al. (2016) investigated the sensitivity of the HAMMONIA model to changes in the parameterization of non-orographic gravity waves. By weakening the amplitude of the gravity waves at the source level, they could substantially improve the modelled temperature and $\mathrm{NO}_{x}$ increases (both in terms of timing and amount) compared to the MIPAS observations. They found that the amount of transported $\mathrm{NO}_{x}$ depends strongly on the altitude at which momentum is deposited in the mesosphere. Smaller gravity wave amplitudes favour the wave breaking and momentum deposition at higher altitudes, closer to the NO source region. The structural similarities of HAMMONIA and WACCM temperature biases suggest that changes in the non-orographic GWD parameterization might also improve the representation of $\mathrm{NO}_{x}$ descent during ES events in WACCM.

\section{Upper stratosphere and mesosphere (USM)}

In this section $\mathrm{CO}, \mathrm{NO}_{x}$, and temperature fields of all involved models are compared to the observations in the USM. The aim is to evaluate the models' ability to reproduce $\mathrm{NO}_{x}$ transport into the stratosphere during both the unperturbed pre-SSW phase and the ES event and to identify whether discrepancies with respect to the observations are related to dynamics or chemistry. The latter is of particular concern for the medium-top models applying the $\mathrm{NO}_{x} \mathrm{UBC}$.

\subsection{CO}

$\mathrm{CO}$ is an excellent tracer of vertical motion in the USM during polar winter because of its pronounced vertical gradient in this region and the long chemical lifetime under dark conditions. Further, the relatively less pronounced gradient at higher altitudes (compared to $\mathrm{NO}_{x}$ ) results in a weaker sensitivity to dynamical variability in the MLT, hence allowing us to study the descent in the USM separately. In addition, the very low stratospheric $\mathrm{CO}$ background concentrations allow us to trace mesospheric descent down to altitudes below $30 \mathrm{~km}$ without the need to invoke tracer correlations as in the case of odd nitrogen (Funke et al., 2014a).

CO observations are available from MLS, ACE, and MIPAS. As an example, Fig. 9 compares the MIPAS-NOM CO temporal evolution with the models. At a first glance, the ob- 

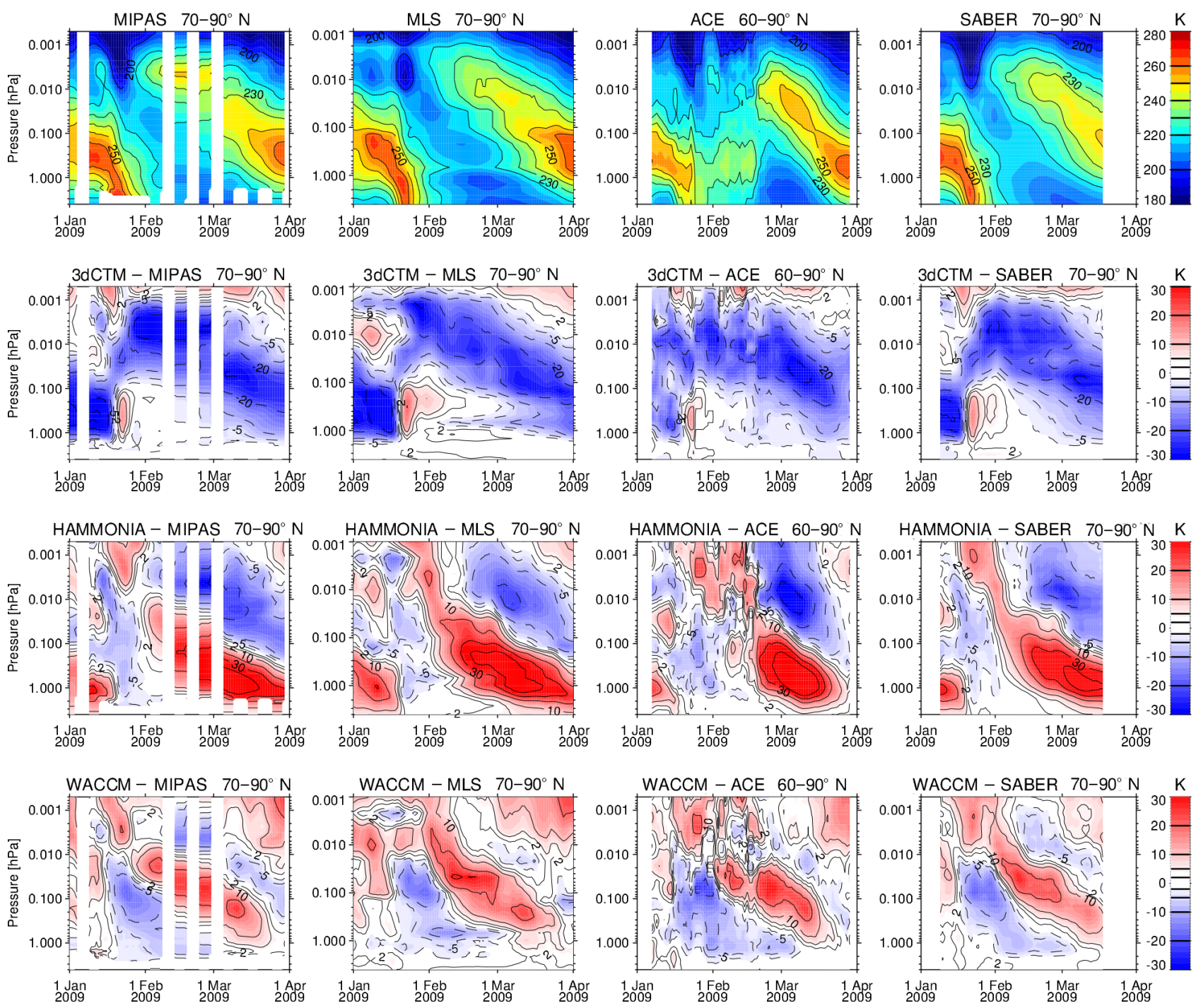

Figure 8. Top: temporal evolution of daily averaged polar cap temperatures at 4-0.0005 hPa observed by MIPAS-UA, MLS/Aura, ACE-FTS, and SABER (from left to right). Bottom: corresponding differences between temperatures simulated with the "high-top" models (3dCTM, HAMMONIA, and WACCM) and the observations.

served evolution of the $\mathrm{CO}$ vertical distribution is qualitatively well reproduced by most models except for FinROSE, which exhibits a very weak vertical gradient all over the winter. This behaviour is caused by a simplified $\mathrm{CO}_{2}$ representation leading to overestimation of $\mathrm{CO}$ production and a largely enhanced $\mathrm{CO}$ background in the middle and upper atmosphere. All other models capture the observed polar winter descent down to pressure levels around $3 \mathrm{hPa}$ in the first part of the winter, the sudden reduction of CO during the SSW caused by meridional mixing and upwelling, as well as the enhanced descent during the ES event.

A more quantitative analysis is provided by Figs. 10 and 11, comparing the modelled $\mathrm{CO}$ evolutions at 0.02 and $0.5 \mathrm{hPa}$, respectively, to MIPAS-NOM and MLS observations (note that FinROSE is not included here because of the unrealistically high mixing ratios). The comparisons to both instruments provide a very similar picture, hence confirming the robustness of the encountered model biases. Observed $\mathrm{CO}$ abundances at $0.02 \mathrm{hPa}$ are around 6-8 ppmv during the pre-SSW phase, decrease to 4 ppmv during the SSW, and show a pronounced peak of 12-14 ppmv in February related to the ES event. Medium-top models exhibit slightly lower $\mathrm{CO}$ abundances (around $5 \mathrm{ppmv}$ ) that do not vary significantly over the winter. This behaviour is expected since transport of lower thermospheric $\mathrm{CO}$ into the model domain is typically not considered and, as consequence, dynamically induced variations are mostly absent at this pressure level close to the models' upper lid. As an exception, tracers are transported in KASIMA above the chemical domain at $90 \mathrm{~km}$ which causes accumulation effects, resulting 


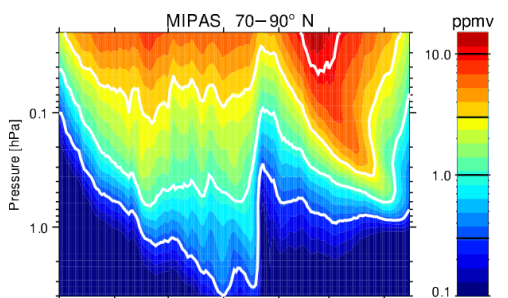

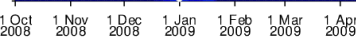

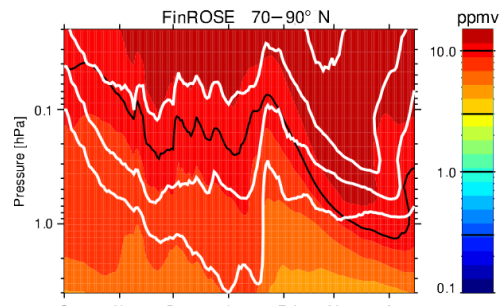

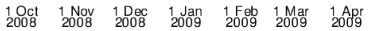

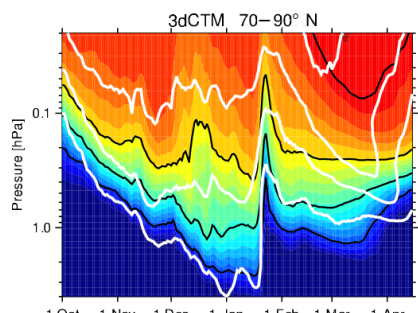

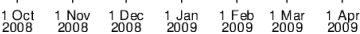

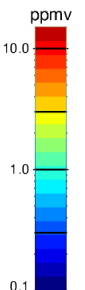

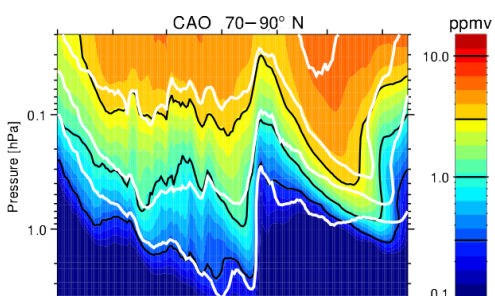

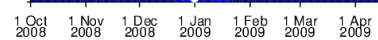

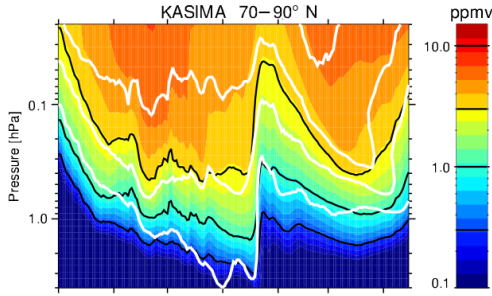

$\begin{array}{ccccccc}1 \text { Oct } & 1 \text { Nov } & 1 \text { Doc } & \text { Jan } & 1 \text { Feb } & \text { Mar } & \text { A Apr } \\ 2008 & 2008 & 2008 & 2009 & 2009 & 2009 & 2009\end{array}$

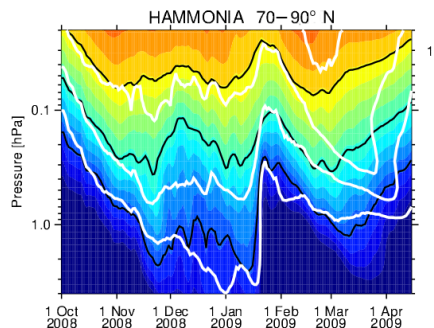

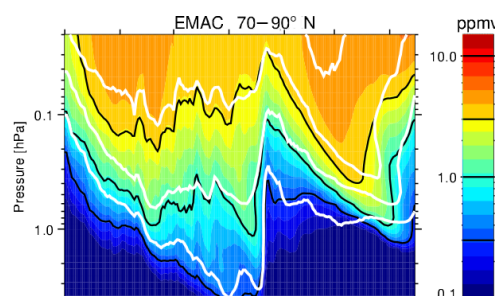

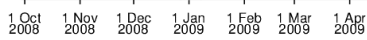

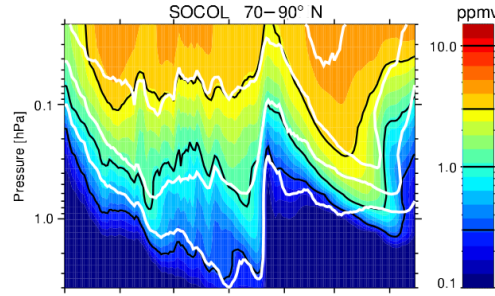

$\begin{array}{lllllll}1 \mathrm{Oct} & 1 \mathrm{Nov} & 1 \mathrm{Dec} & 1 \mathrm{Jan} & 1 \mathrm{Feb} & 1 \mathrm{Mar} & \text { A Apt } \\ 2008 & 2008 & 2008 & 2009 & 2009 & 2009 & 2009\end{array}$
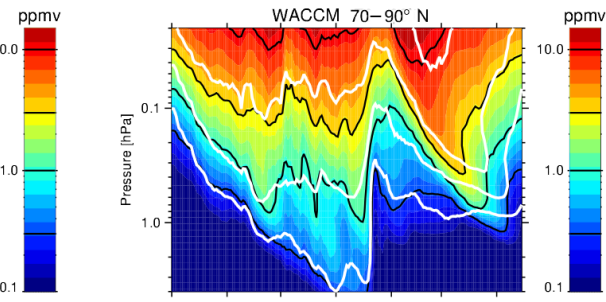

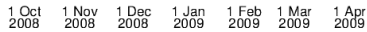

Figure 9. MIPAS-NOM and modeled temporal evolutions of $\mathrm{CO}$ at $4-0.02 \mathrm{hPa}$ within $70-90^{\circ} \mathrm{N}$. White lines indicate the observed VMR levels of $0.3,1,3$, and 10 ppmv.

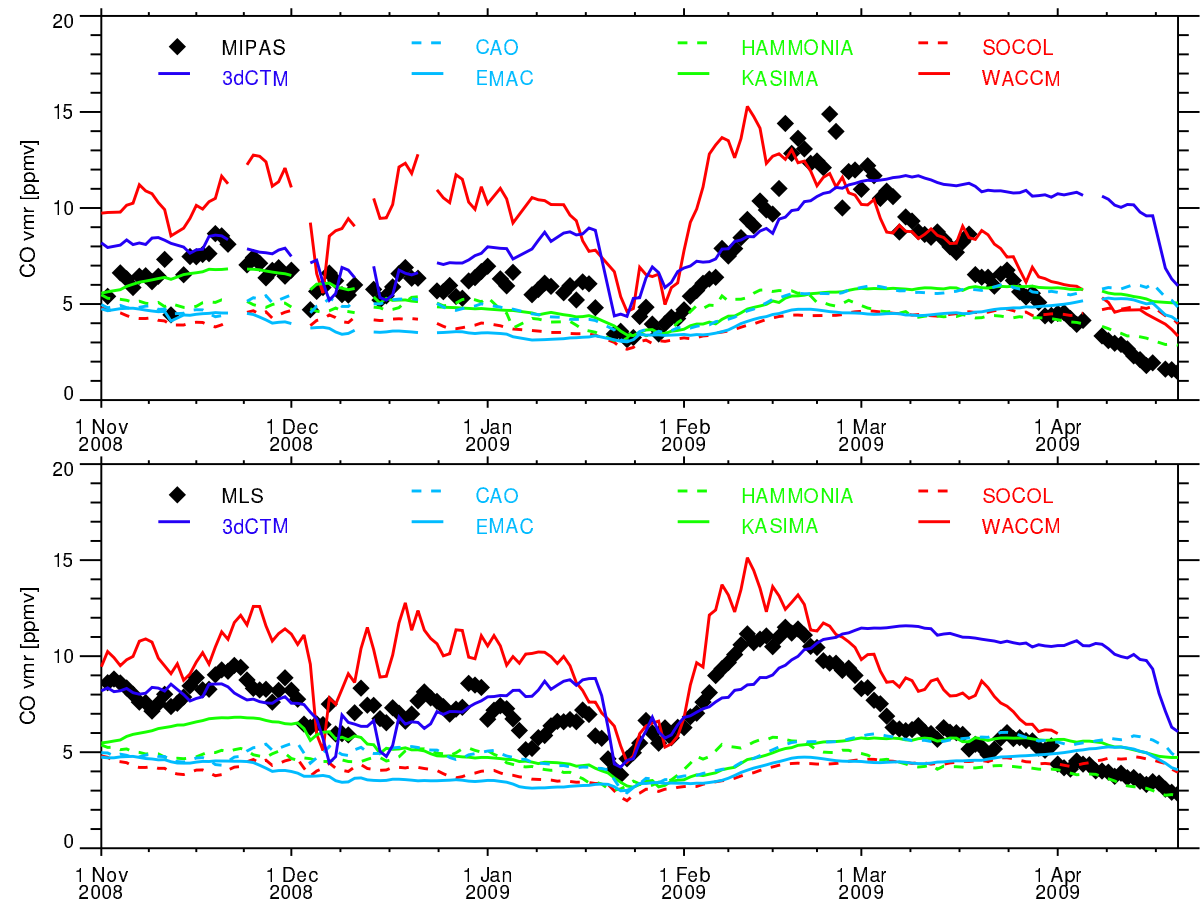

Figure 10. MIPAS-NOM (top) and MLS/Aura (bottom) temporal evolutions of CO VMR in comparison with the model results within $70-90^{\circ} \mathrm{N}$ at $0.02 \mathrm{hPa}$. 


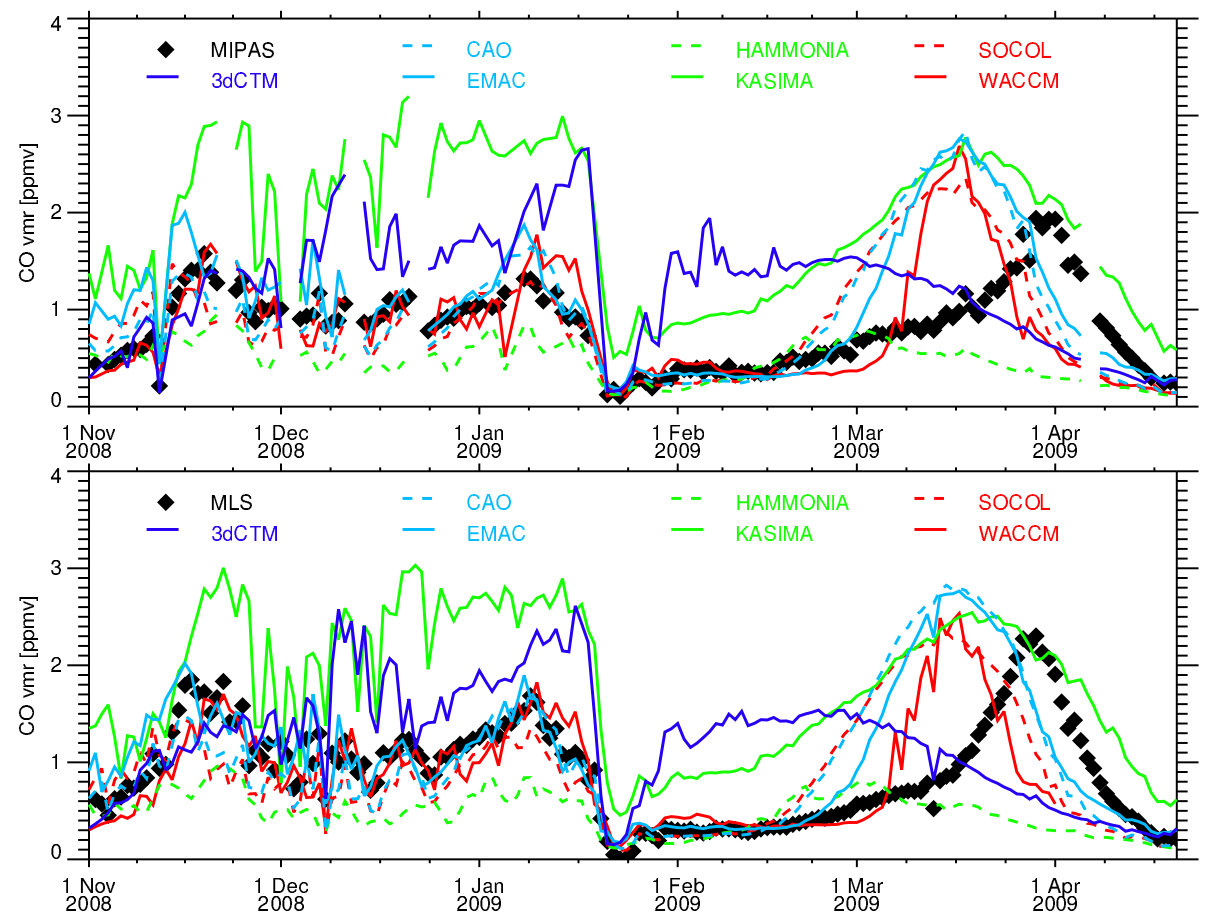

Figure 11. MIPAS-NOM (top) and MLS/Aura (bottom) temporal evolutions of CO VMR in comparison with the model results within $70-90^{\circ} \mathrm{N}$ at $0.5 \mathrm{hPa}$.

in slightly increased abundances during early winter. Further, minor differences in the late-winter abundances simulated by KASIMA and CAO on the one hand and EMAC and SOCOL on the other hand can be attributed to the use of different kinetic data in the chemistry schemes, primarily affecting $\mathrm{OH}$ involved in the $\mathrm{CO}$ loss reaction. The observed $\mathrm{CO}$ evolution at $0.02 \mathrm{hPa}$ is qualitatively well captured by WACCM, although the abundances during the preSSW phase of about 10 ppmv are overestimated by $\sim 40 \%$ compared to the observations and the ES-related peak occurs earlier than in the observations. HAMMONIA CO abundances are underestimated due to missing thermospheric $\mathrm{CO}$ production mechanisms (see previous section) and are very close to the $\mathrm{CO}$ amount simulated by the medium-top models $(\sim 5 \mathrm{ppmv})$. 3dCTM simulates early-winter $\mathrm{CO}$ abundances that are roughly in agreement with the observations. ESrelated CO enhancements in the post-SSW phase, however, are delayed and persist for a longer period than observed.

The observed $\mathrm{CO}$ evolution at $0.5 \mathrm{hPa}$ is well reproduced by most medium-top models and WACCM in the pre-SSW phase. KASIMA and 3dCTM overestimate the CO abundances by a factor of $\sim 2.5$ and $\sim 1.5$, respectively, while HAMMONIA simulates about $50 \%$ lower than observed $\mathrm{CO}$ abundances. The ES-related CO increases peak in most models too early (around mid-March) compared to the observed peak occurrence around 1 April, although the peak magnitude is reasonably well simulated (with exception of HAMMONIA). The CO peak in HAMMONIA occurs even
2 weeks earlier than in the other models. In 3dCTM, the CO tongue does not reach the $0.5 \mathrm{hPa}$ level (see Fig. 9), likely because of the too-late formation of the elevated stratopause discussed in the previous section. The high $\mathrm{CO}$ abundances of this model in February, immediately after the SSW, seem to be caused by horizontal mixing, after a short period of localized upwelling during the sudden warming.

The individual impacts of orographic and non-orographic GWD on the mesospheric CO evolution in the CMAM model has been evaluated by comparing with the same MLS observations during the 2008-2009 NH winter by McLandress et al. (2013). Our Fig. 11 can be qualitatively compared to their Fig. 8 (although the latter shows the $\mathrm{CO}$ evolution at a slightly higher pressure level). The $\mathrm{CO}$ evolution in the CMAM simulation, including all gravity wave sources, is very similar to that obtained by most of the models included in our study (note that the apparently smaller time lag of the ES-related peak in the McLandress et al., 2013 study is related to the higher pressure level of their comparison). However, there are similarities between their simulation without orographic GWD and the KASIMA simulation presented here, particularly regarding the $\mathrm{CO}$ overestimation in the pre-SSW phase and the relatively broad CO peak after the ES event. Note that KASIMA does not employ a specific parameterization for orographic GWD which may be justified as KASIMA is nudged up to $1 \mathrm{hPa}$ but seems not to be sufficient near the stratopause. This is also seen in the low bias of the stratopause temperature in the pre-SSW phase 

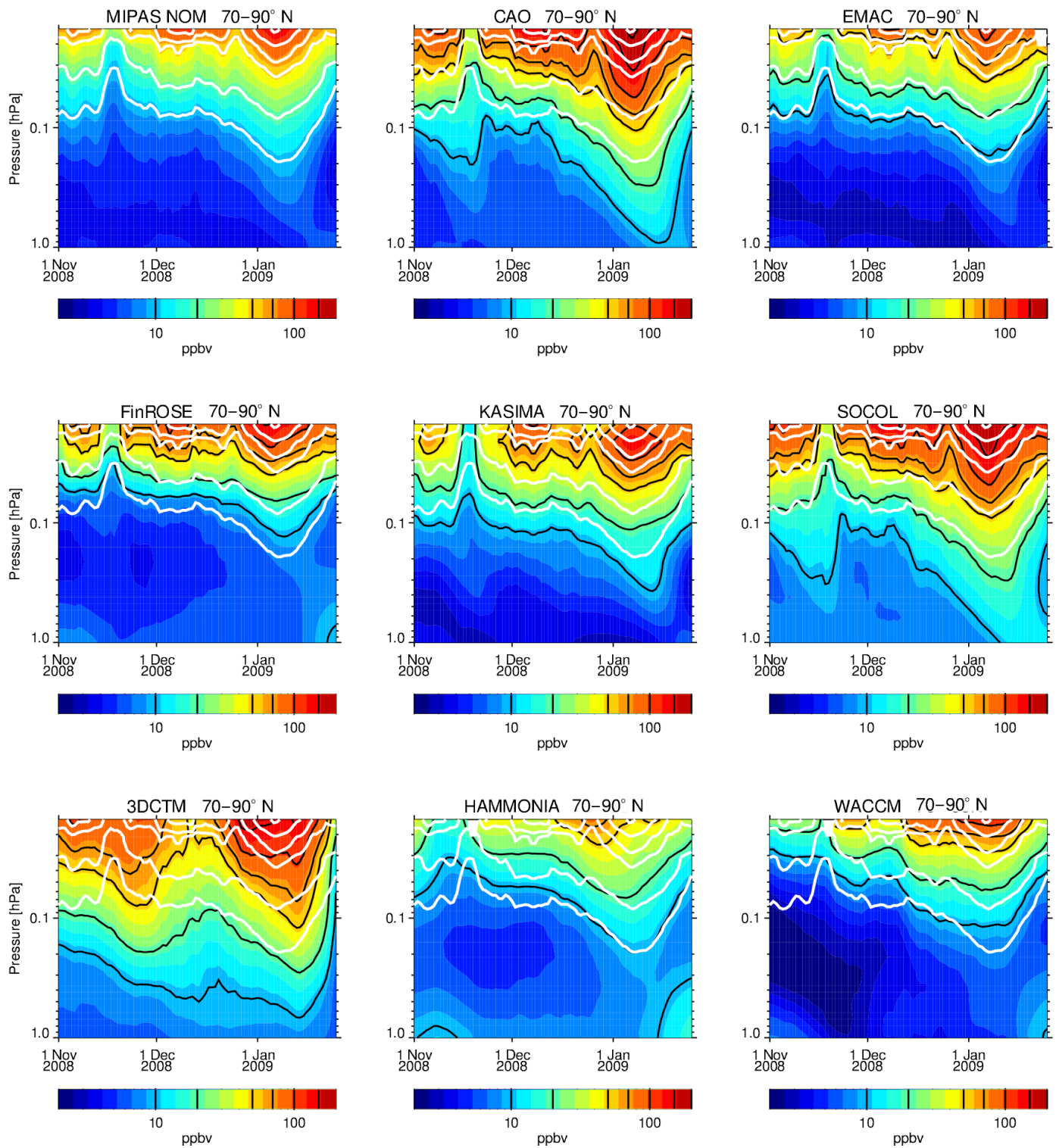

Figure 12. MIPAS-NOM and modelled temporal evolutions of $\mathrm{NO}_{x}$ in the pre-SSW phase of the 2008/09 NH winter at $1-0.02 \mathrm{hPa}$ within $70-90^{\circ} \mathrm{N}$. White lines indicate the observed VMR levels of 10, 20, 50, 70, 100, and $150 \mathrm{ppbv}$. White regions reflect missing or not meaningful data.

(see Fig. 18). Further, our 3dCTM results share some characteristics of the CMAM simulation without any GWD. In particular, both simulations exhibit a steady (though fluctuating) increase of CO until the SSW, a short recovery time after the warming, and the absence of an ES-related peak in March/April. This again highlights the importance of the proportion of the gravity wave spectrum not considered in the LIMA model - the subscale $(\leq 500 \mathrm{~km})$ waves for the mesospheric meridional wintertime circulation, in particular during the recovery phase of the elevated stratopause event as discussed in the previous section, but also for the "undisturbed" pre-event period.

\section{2 $\mathrm{NO}_{x}$ in the early (pre-SSW) phase}

In the following, the observed and modelled vertical structure of $\mathrm{NO}_{x}$ in the USM during mid-winter (pre-SSW phase) is analysed in more detail to evaluate how well the models reproduce the EPP indirect effect in this region for unperturbed conditions. Figure 12 compares the $\mathrm{NO}_{x}$ evolution of all models at $1-0.02 \mathrm{hPa}$ with the MIPAS data. All models capture the observed early-winter $\mathrm{NO}_{x}$ descent characterized by a quasi-continuous increase of $\mathrm{NO}_{x}$ until the SSW-related disruption in mid-January. The magnitude of the observed $\mathrm{NO}_{x}$ enhancements is well reproduced by EMAC, FinROSE, KASIMA, HAMMONIA, and WACCM. Descending $\mathrm{NO}_{x}$ 


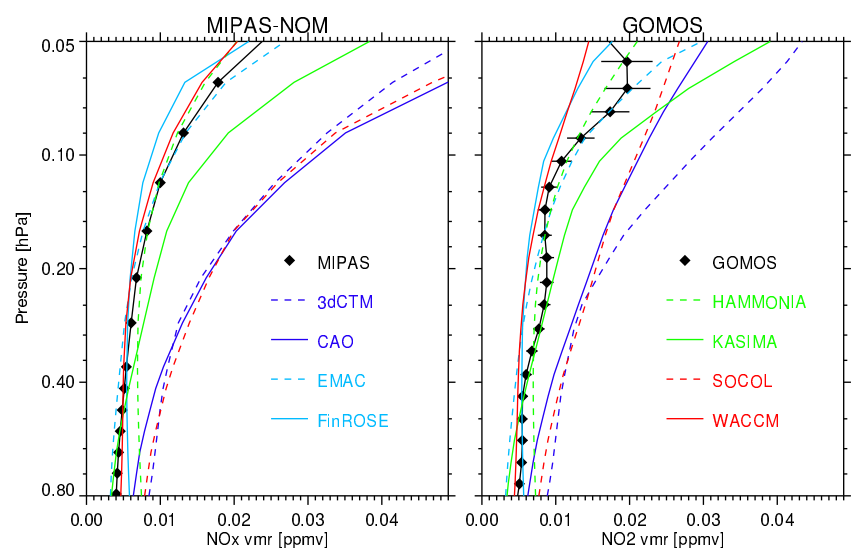

Figure 13. Left: MIPAS-NOM and modelled mean $\mathrm{NO}_{x}$ profile for the period 15 December 2008-12 January 2009 within $70-90^{\circ} \mathrm{N}$. Right: GOMOS and modelled mean night-time $\mathrm{NO}_{2}$ for the same period within $75-85^{\circ} \mathrm{N}$. The error bars indicate random retrieval errors of the averaged observational data.

can be distinguished from the background in these simulations and in the observations down to pressure levels of 0.3$0.5 \mathrm{hPa}$. Further descent below this level cannot be traced because $\mathrm{NO}_{x}$ is converted to other reservoir nitrogen species (principally $\mathrm{HNO}_{3}$ ) below approximately $45 \mathrm{~km}$. Descent of EPP-generated total reactive nitrogen has been observed down to altitudes as low as $30 \mathrm{~km}$ during the pre-SSW phase of Arctic winter 2009 (Funke et al., 2014a).

As discussed in Sect. 6, 3dCTM overestimates the observed $\mathrm{NO}_{x}$ increasingly towards lower altitudes and shows a double peak structure (with a $\mathrm{NO}_{x}$ depletion around midDecember) that is not seen in the MIPAS $\mathrm{NO}_{x}$ data, though a similar feature is also observed in 3dCTM CO, and at least indicated in MIPAS CO, at the same time. Also SOCOL and CAO overestimate substantially the descending $\mathrm{NO}_{x}$ amounts. Since the $\mathrm{CO}$ descent is well described by the latter two models, the $\mathrm{NO}_{x}$ overestimation is likely related to the prescription of $\mathrm{NO}_{x}$ at the upper model lid. The $\mathrm{NO}_{x}$ abundances at the upper model level $(0.01 \mathrm{hPa})$ are in agreement with the values specified by the UBC. However, in contrast to the observations and other models, which show a rapid decrease towards lower altitudes, the abundances remain nearly constant in the entire vertical range above $0.03 \mathrm{hPa}$. This behaviour is caused by a model boundary artefact introducing unrealistically fast vertical propagation of the $\mathrm{NO}_{x}$ caused either by too-high vertical velocities at the model lid or low vertical model resolution. Indeed, the descending $\mathrm{NO}_{x}$ amounts are substantially reduced in a test simulation with $\mathrm{NO}_{x}$ prescribed at the second layer from the top (not shown), making the SOCOL results similar to those of EMAC.

A more quantitative view of the modelled mid-winter $\mathrm{NO}_{x}$ profiles in comparison with observations of the MIPAS and GOMOS instruments (the latter measuring night-time $\mathrm{NO}_{2}$ ) is provided in Fig. 13. Other instruments measuring $\mathrm{NO}_{x}$ species could not be included in this comparison: SMR because they measured only $\mathrm{NO}$ but most of $\mathrm{NO}_{x}$ is in the form of $\mathrm{NO}_{2}$ below $0.1 \mathrm{hPa}$ in dark conditions, SCIAMACHY because it is not sensitive to NO below $\sim 65 \mathrm{~km}$, and ACEFTS because it did not sample latitudes polewards of $70^{\circ} \mathrm{N}$ in mid-winter. Both MIPAS and GOMOS consistently show VMRs of about $20 \mathrm{ppbv}$ at $0.05 \mathrm{hPa}$, decreasing to the background values of $5 \mathrm{ppbv}$ at $0.8 \mathrm{hPa}$. The observed profile is reproduced within $20 \%$ by EMAC, FinROSE, HAMMONIA, and WACCM. The KASIMA results are about $50 \%$ higher than the observations. 3dCTM, CAO, and SOCOL overestimate the observations by a factor of 2-3.

Overall, most atmospheric models are capable of providing a realistic and consistent picture of $\mathrm{NO}_{x}$ descent in dynamically and geomagnetically unperturbed $\mathrm{NH}$ early winters as in 2008/2009. This is the case for high-top models explicitly considering odd nitrogen production by EPP in the MLT region, as well as for medium-top models employing a $\mathrm{NO}_{x}$ UBC. However, some individual models show significant biases in the simulated early-winter $\mathrm{NO}_{x}$ descent which could be traced back to deficiencies in either the dynamical or chemical schemes.

\section{3 $\mathrm{NO}_{x}$ in the perturbed late (post-SSW) phase}

Limitations of high-top models to reproduce quantitatively the observed $\mathrm{NO}_{x}$ descent from the upper mesosphere during the perturbed part of the 2008/09 NH winter (post-SSW phase) have already been discussed in Sect. 6. An important question is whether medium-top models, prescribing realistic $\mathrm{NO}_{x}$ distributions at the model's upper lid, could provide a better description of ES-induced odd nitrogen transport by bypassing the problem of underestimated descent in the region above $80 \mathrm{~km}$, as encountered in the high-top models. Figures 14 and 15 show the temporal evolutions of modelled $\mathrm{NO}_{x}$ during the ES event in comparison with MIPAS-NOM and ACE-FTS observations, respectively. Despite the sampling-related differences, both instruments provide a very consistent picture of model biases. In particular, the time shift (earlier occurrence) of the modelled $\mathrm{NO}_{x}$ tongue (except 3dCTM), also identified in the CO comparisons, is clearly visible in the comparisons with both instruments.

Again, SOCOL and CAO overestimate significantly the observed $\mathrm{NO}_{x}$ (about a factor of 5) in the descending tongue (for the reasons already identified in the mid-winter comparisons). This overestimation is even more pronounced than in the pre-SSW phase. In the case of HAMMONIA, related to the fast downward propagation of the ES (see Sect. 6), the $\mathrm{NO}_{x}$ peak occurs earlier and the tongue descends faster, merging with the background already in mid-February. In $3 \mathrm{dCTM}$, the $\mathrm{NO}_{x}$ tongue reaches the lower mesosphere $(0.02 \mathrm{hPa})$ later than in the other models and in observations due to the too-slow descent rates throughout the mesosphere. Thus, the development of the $\mathrm{NO}_{x}$ tongue in the lower meso- 

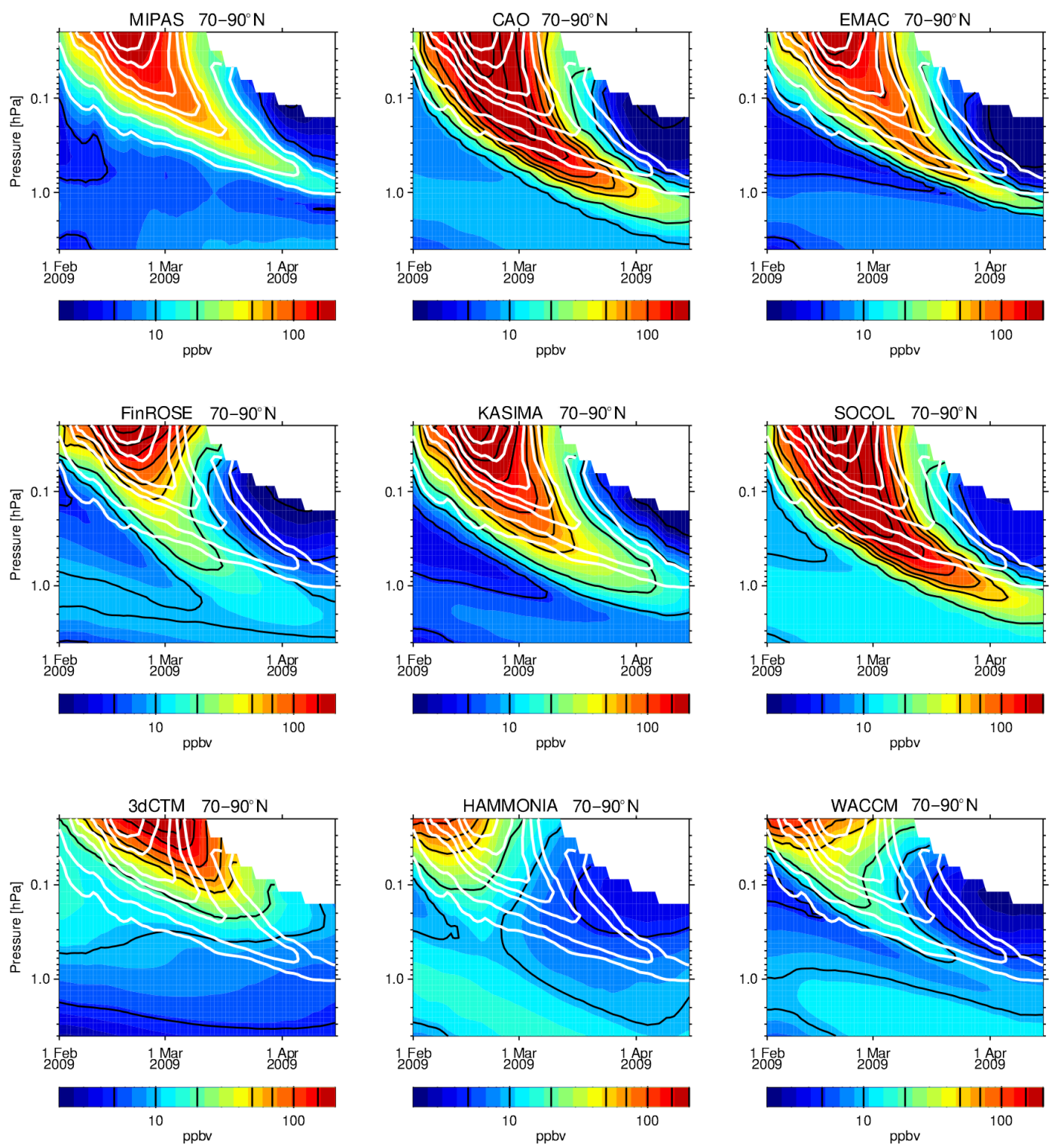

Figure 14. MIPAS-NOM and modelled temporal evolutions of $\mathrm{NO}_{x}$ during the ES event at $1-0.02 \mathrm{hPa}$ within $70-90^{\circ} \mathrm{N}$. White lines indicate the observed VMR levels of 10, 20, 50, 70, 100, 150, and 200 ppbv.

sphere is delayed, and it does not reach to stratospheric altitudes.

The $\mathrm{NO}_{x}$ tongue observed by MIPAS reaches the $1 \mathrm{hPa}$ level by the end of April. The reversal of the residual circulation in spring disabled further downward propagation of the tongue. ACE-FTS observed polar latitudes until 25 March, when the tongue reached the $0.3 \mathrm{hPa}$ level in agreement with MIPAS observations at the same time. Compared to the observations, the $\mathrm{NO}_{x}$ tongue in the model simulations (except HAMMONIA and $3 \mathrm{dCTM}$ ) penetrates deeper, reaching the 2-3 $\mathrm{hPa}$ pressure levels at the end of April.

Figure 16 shows more quantitatively the observed and modelled occurrence time and magnitude of the $\mathrm{NO}_{x}$ peak as a function of pressure level. The similar peak timing sim- ulated by all models (except 3dCTM and HAMMONIA), about 2 weeks earlier than the observed peak below the $0.2 \mathrm{hPa}$ level, is surprising. In the WACCM simulation, this time shift with respect to the observations is present over the whole vertical range. Interestingly, the peak occurrence time in the medium-top models, all prescribing the observed $\mathrm{NO}_{x}$ evolution at their upper lid, converges with the descent to the same occurrence time as simulated by WACCM at lower altitudes, i.e. earlier than in the observations. It is worth noting that a HAMMONIA simulation (not shown) with reduced non-orographic gravity wave amplitude (Meraner et al., 2016) exhibits both a $\mathrm{NO}_{x}$ peak occurrence time and magnitude in very good agreement with the observations down to pressure levels around $0.3 \mathrm{hPa}$. Below, however, the 

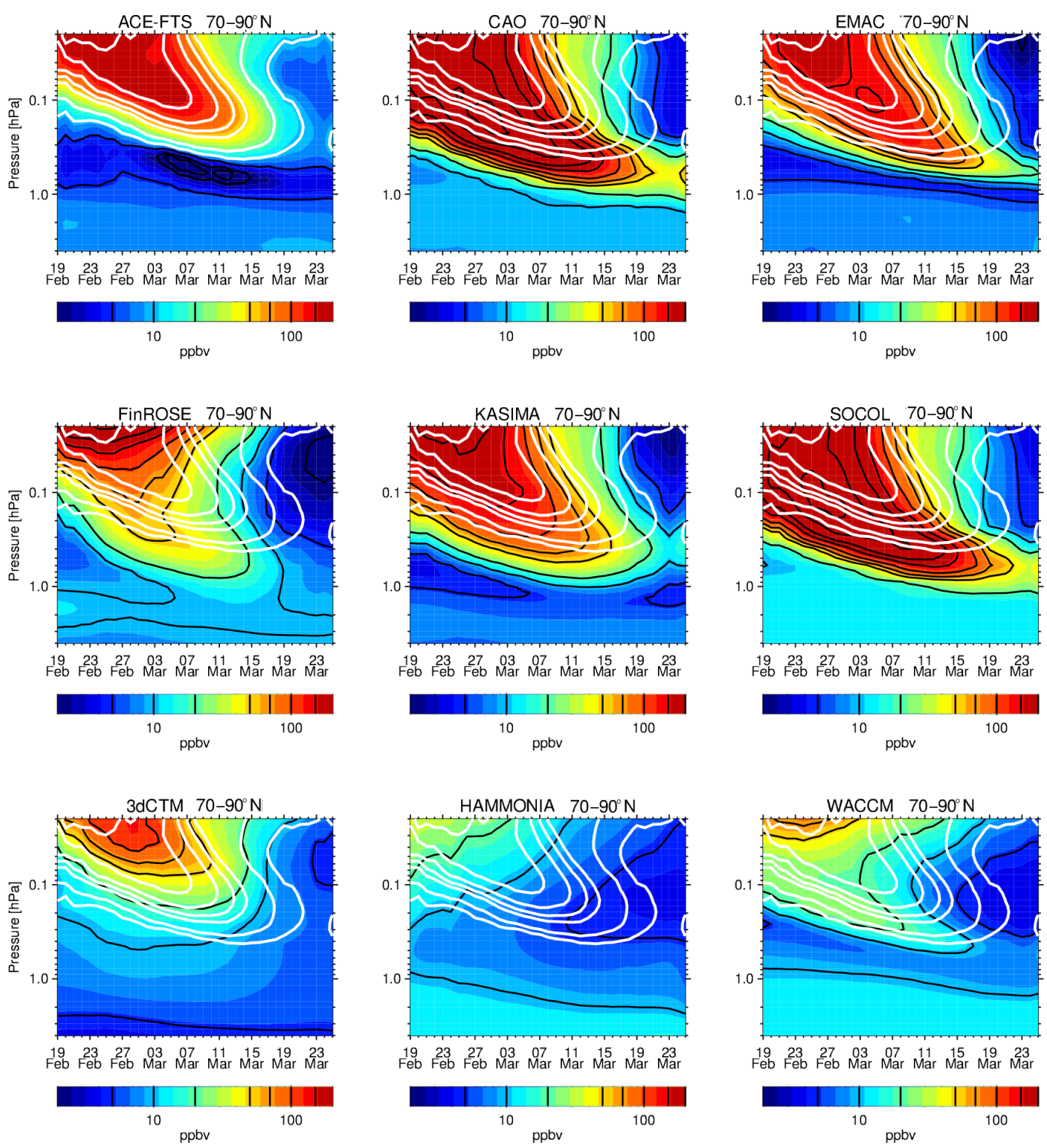

Figure 15. Same as Fig. 14, but for ACE-FTS.

peak occurrence time in this particular HAMMONIA simulation converges again to that of most of the other simulations.

Despite the consistency of the models with respect to the timing of the $\mathrm{NO}_{x}$ descent in the lower mesosphere, indicating similar dynamical representations, the spread of the magnitude of the modelled $\mathrm{NO}_{x}$ peaks (right panel of Fig. 16) is very large (within $0.2-3$ times the observed magnitude), even when excluding the $\mathrm{CAO}$ and SOCOL results. This is particularly surprising in the case of the medium-top models, all of them prescribing the same $\mathrm{NO}_{x}$ obtained from observations, and will be discussed in more detail at the end of this section.

Figure 17 shows the temporal evolution of the MIPAS observations and modelled $\mathrm{NO}_{x}$ at $0.5 \mathrm{hPa}$ together with the temperature evolution slightly above, at $0.2 \mathrm{hPa}$. There is a clear link between the earlier occurrence of the modelled
$\mathrm{NO}_{x}$ peaks and the time shift of the modelled temperature increases after the SSW, occurring systematically about 2 weeks earlier than in the observations (with the exceptions of HAMMONIA and 3dCTM). In order to check whether the temperature bias of the simulations with respect to MIPAS is consistent with the other measurements, we show in Fig. 18 the vertical structure of the temperature differences between the medium-top models and MIPAS-NOM, MLS, ACE-FTS, and SABER observations, similarly as done for the high-top models in Sect. 6. All medium-top models show a warm bias of $15-25 \mathrm{~K}$ around $0.2 \mathrm{hPa}$ in February and early March, and a cold bias of 5-10 K around $1 \mathrm{hPa}$ during the same period (though slightly less pronounced in KASIMA). Similar biases have been detected in the WACCM simulations (see Fig. 8). 

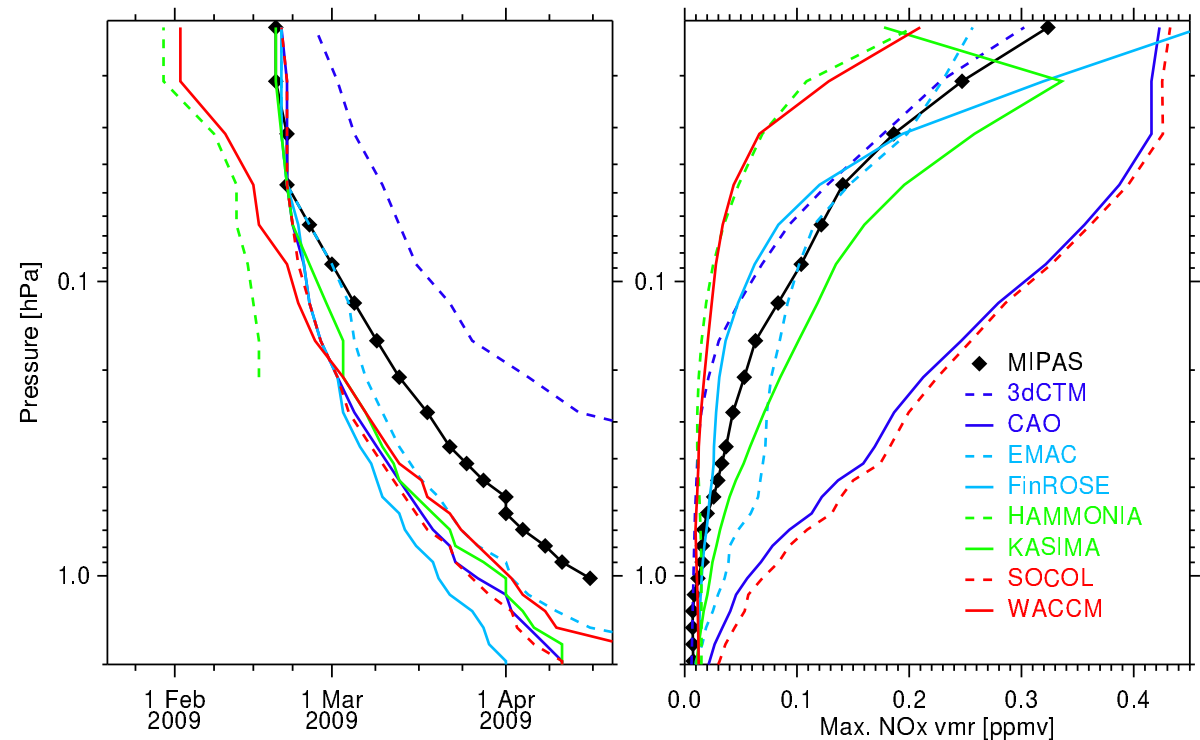

Figure 16. Left: MIPAS-NOM and modelled time evolution of the occurrence of the $\mathrm{NO}_{x}$ peak as function of pressure after the ES event. Right: observed and modelled $\mathrm{NO}_{x}$ peak values, averaged over $70-90^{\circ} \mathrm{N}$.

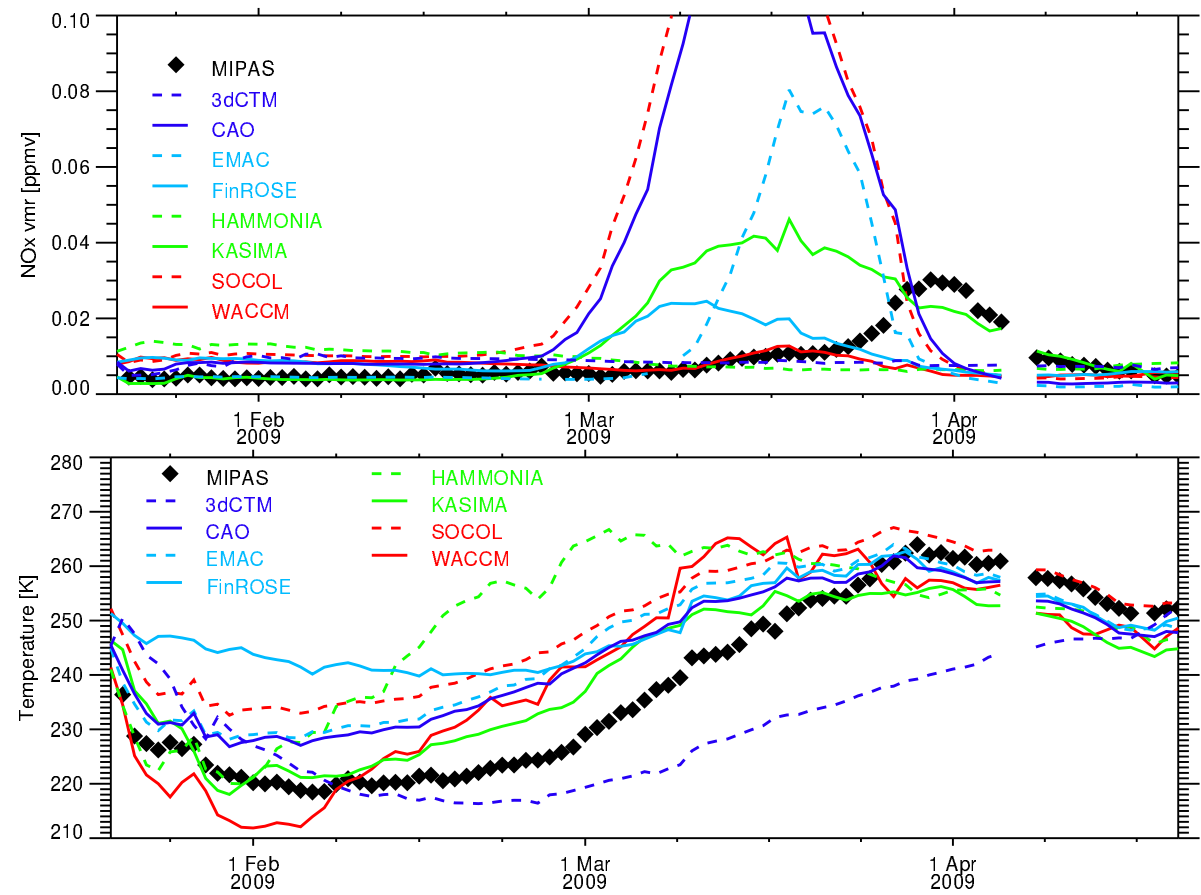

Figure 17. MIPAS-NOM and modelled temporal evolutions of $\mathrm{NO}_{x}$ at $0.5 \mathrm{hPa}$ (top) and of temperature at $0.2 \mathrm{hPa}$ (bottom) within $70-90^{\circ} \mathrm{N}$ during the ES event.

The systematic, dipole-type temperature bias of the hightop model WACCM and all medium-top models, with similar amplitudes and time evolutions, explains the consistently too-early occurrence of the $\mathrm{NO}_{x}$ descent encountered in these models. It also hints at a common origin. One plausible reason for the temperature bias could be the meteorological data nudged in most models below $1 \mathrm{hPa}$. Around this pressure level, a cold bias of these models is observed, including FinROSE, which relies entirely on ECMWF operational analysis data, and EMAC, which applies the nudging to ERA-Interim reanalysis data up to the altitude of $0.2 \mathrm{hPa}$. This indicates that the cold bias is present already in the ECMWF operational analysis and ERA-Interim data. This bias might then likely influence the model dynamics extend- 

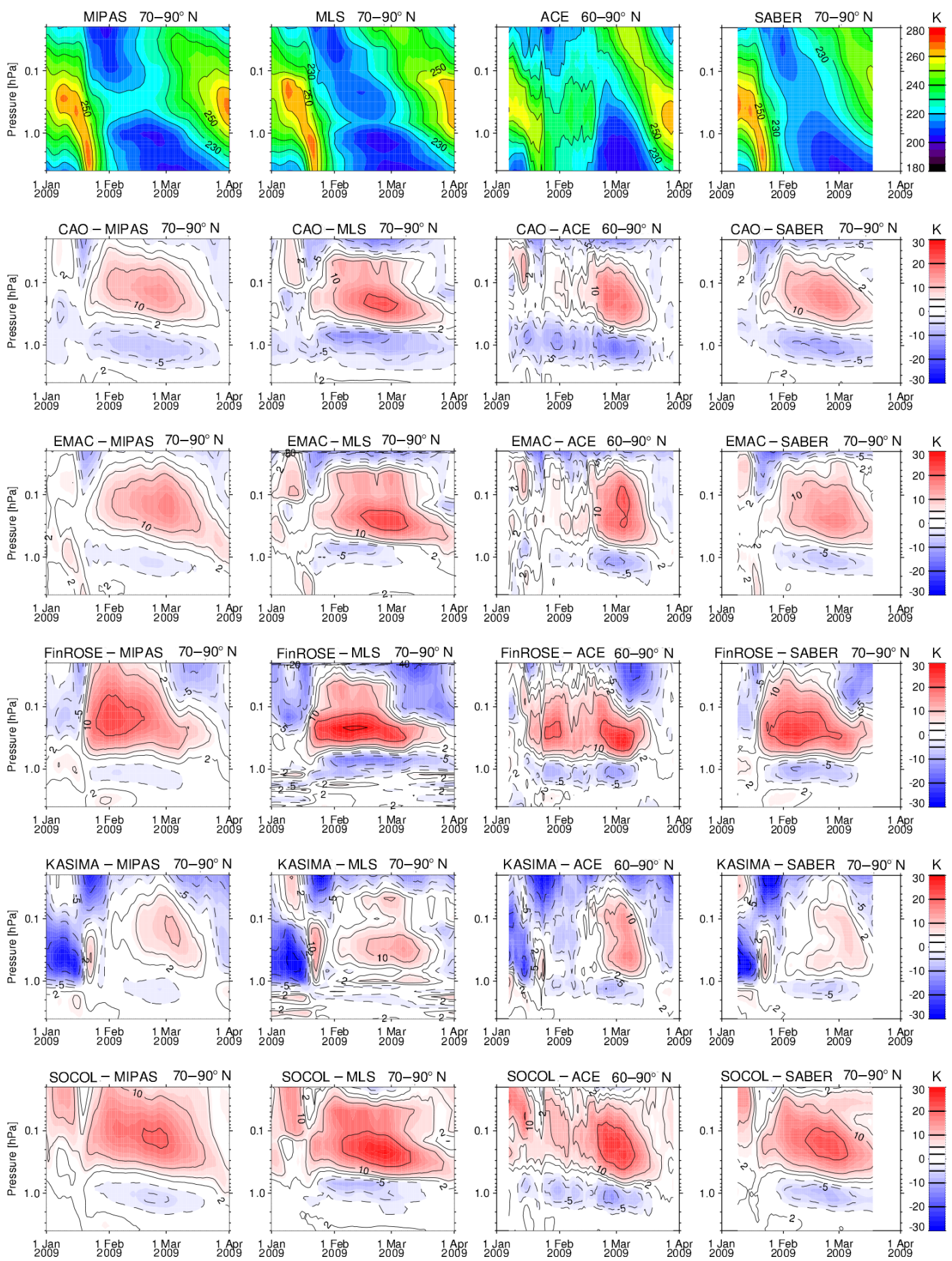

Figure 18. Top: temporal evolution of daily averaged polar cap temperatures at 4-0.02 hPa observed by MIPAS-NOM, MLS/Aura, ACEFTS, and SABER (from left to right). Bottom: corresponding differences between temperatures simulated with the "medium-top" models (CAO, EMAC, FinROSE, KASIMA, and SOCOL) and the observations.

ing above the nudged region. The cold bias around $1 \mathrm{hPa}$ in February is also seen in the WACCM simulation (see Fig. 7), suggesting that it is also present in the MERRA reanalysis. This is confirmed by comparison of MERRA and MLS temperatures (not shown). Only in the HAMMONIA simulation, which shows a pronounced warm bias in the entire $2-0.1 \mathrm{hPa}$ region, the local influence of the nudged meteorology at the edge of the nudging region seems to be outweighed by the internal model dynamics. It is beyond the scope of this paper to investigate in detail the possible mechanisms for the 

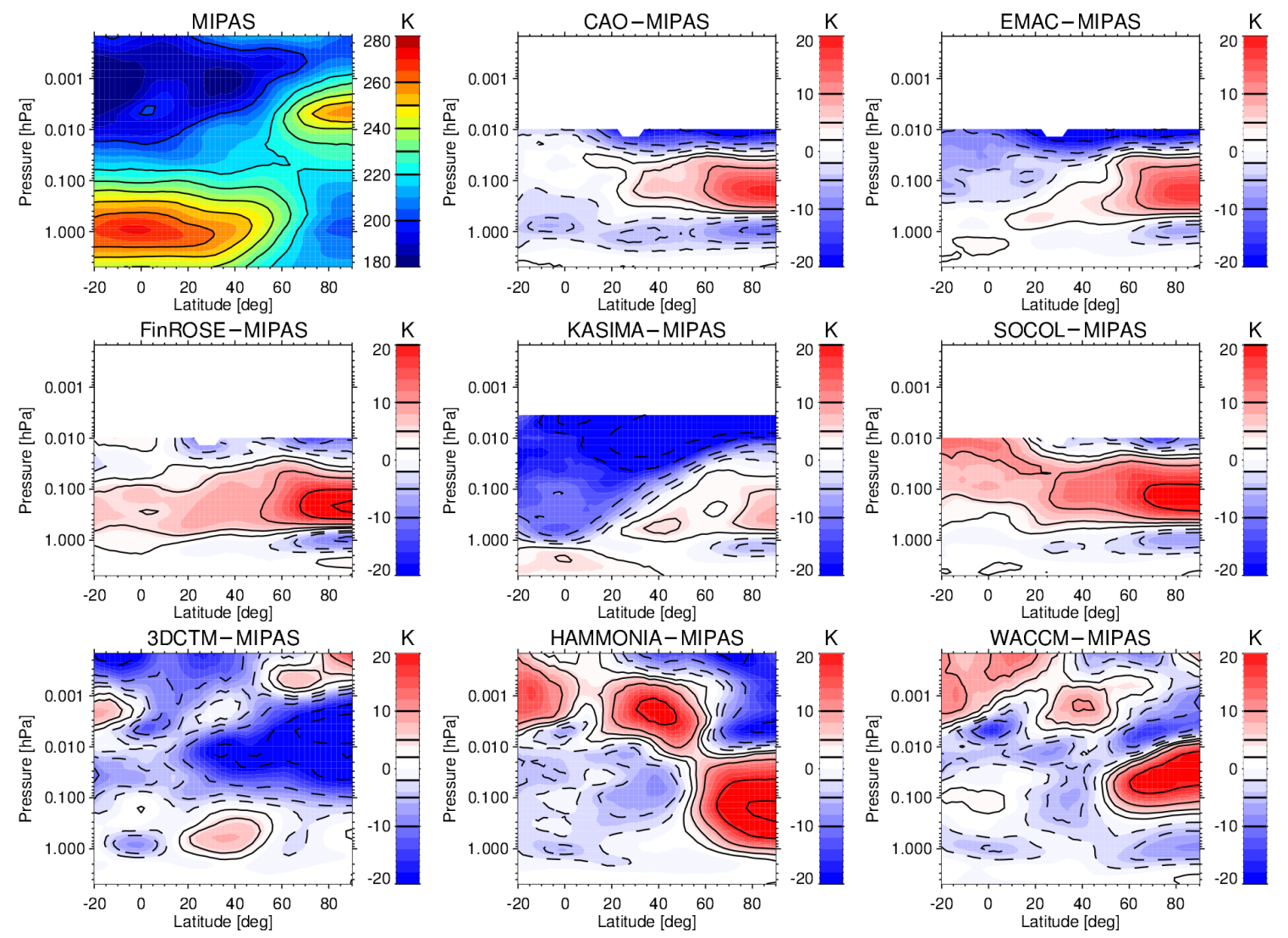

Figure 19. MIPAS-UA and modelled NH zonal mean temperature distribution on 15 February 2009.

vertical propagation of dynamical biases, introduced by the nudging, resulting in a descent of mesospheric $\mathrm{NO}_{x}$ that is too early. However, since the cold bias encountered at $1 \mathrm{hPa}$ is restricted to latitudes northward of $60^{\circ}$ (see Fig. 19) and hence implies a strengthening of the meridional temperature gradient, it is likely to accelerate zonal winds at this level and above, which in turn would lead to changed filtering conditions for the propagation of gravity waves. Another important question which needs to be addressed in upcoming studies is the causes of the cold bias in the employed reanalysis datasets that have been found here.

The spread of the magnitude of the ES-related $\mathrm{NO}_{x}$ tongue encountered below $0.1 \mathrm{hPa}$ in the medium-top models, despite the prescription of a common odd nitrogen upper boundary above, deserves some further discussion. The consistency of simulated temperature evolutions indicates that vertical transport is represented in these models in a similar way. It is therefore unlikely that differences in the descent velocities are the main cause for the spread. Differences in meridional transport and mixing above the vortex edge and subsequent enhanced photochemical loss could also contribute to the differences but would not explain overestimation. A most plausible explanation is the detailed treatment of the UBC. Prescribing at an altitude with too fast vertical transport, as indicated here at $0.2 \mathrm{hPa}$, will unavoidably cause a too-strong flux of $\mathrm{NO}_{x}$ into the domain below. Therefore, models that use a UBC definition extending to lower pressure levels likely overestimate the $\mathrm{NO}_{x}$ flux. This is, for example, the case of EMAC, which prescribes $\mathrm{NO}_{x}$ in the entire vertical domain above $0.1 \mathrm{hPa}$ : the peak magnitude of the tongue is, as expected, close to the observations in the UBC domain. However, it becomes increasingly larger than the observed magnitude during the descent down to $0.7 \mathrm{hPa}$, where it is overestimated by a factor of 3 . This highlights the importance of a realistic dynamical representation in the UBC domain in models prescribing $\mathrm{NO}_{x}$ concentrations.

\section{Conclusions}

We have presented the results of the HEPPA-II intercomparison project, conducted in the framework of SPARC/WCRP's SOLARIS-HEPPA activity, which aims at evaluating the simulations of the $\mathrm{NH}$ polar winter 2008/2009 from eight atmospheric models by comparison with observations of temperature and concentrations of $\mathrm{NO}_{x}$ and $\mathrm{CO}$ from seven satellite instruments. The large number of participating models allowed for a comprehensive assessment of the ability of state-of-the-art chemistry climate models to reproduce the observed EPP indirect effect in a dynamically perturbed $\mathrm{NH}$ 
winter under conditions of very low geomagnetic activity. The use of multi-instrument data for model evaluation allowed for not only the assessment of the significance of identified model biases but also the estimation of the uncertainty range of our current knowledge on tracer and temperature distributions in Arctic winters. It has been shown that the appropriate consideration of the instrument-specific sampling patterns is key to a meaningful multi-instrument analysis, particularly during perturbed dynamical conditions. The high degree of consistency between the comparisons of the models to individual observations has proven the reliability of the currently available satellite record during polar winter conditions.

Most models provide a good representation of the mesospheric tracer descent in general, and the EPP indirect effect in particular, during the unperturbed (pre-SSW) period of the $\mathrm{NH}$ winter 2008/2009. Observed $\mathrm{NO}_{x}$ descent into the lower mesosphere and stratosphere is generally reproduced within $20 \%$. Larger discrepancies of a few model simulations, resulting in overestimated $\mathrm{NO}_{x}$ enhancements, could be traced back either to an unrealistic representation of the polar winter dynamics or to an inadequate prescription of the $\mathrm{NO}_{x}$ partitioning at the uppermost model layer leading to boundary artefacts.

In March-April, after the ES event, however, modelled mesospheric and stratospheric $\mathrm{NO}_{x}$ distributions deviate significantly from the observations. The too-fast and early downward propagation of the $\mathrm{NO}_{x}$ tongue, encountered in most simulations, coincides with a warm bias in the lower mesosphere $(0.2-0.05 \mathrm{hPa})$ likely caused by an overestimation of descent velocities. In contrast, upper-mesospheric temperatures at $0.05-0.001 \mathrm{hPa}$ are in general underestimated by the high-top models after the onset of the ES event, being indicative of a too-slow descent and hence too small $\mathrm{NO}_{x}$ fluxes. As a consequence, the magnitude of the simulated $\mathrm{NO}_{x}$ tongue is generally underestimated by these models. Descending $\mathrm{NO}_{x}$ amounts simulated by the medium-top models with prescribed $\mathrm{NO}_{x}$ are on average closer to the observations but show a large spread of up to several hundred percent. This is primarily attributed to the different vertical model regimes where the $\mathrm{NO}_{x}$ upper boundary condition is applied.

In general, the intercomparison demonstrates the ability of state-of-the-art atmospheric models to reproduce the observed EPP indirect effect in dynamically and geomagnetically quiescent early $\mathrm{NH}$ winter conditions as present in November 2008-January 2009. It should be noted, however, that the extrapolation of this result to high geomagnetic activity conditions should be done with caution since mid-energy electron impact in the mesosphere, which was of minor importance during this particular winter, could lead to additional complications. Further, to obtain good agreement between simulated and observed mesospheric tracer descent it is necessary to constrain stratospheric dynamics in the models by (re-)analysed meteorology.
The differences encountered between observed and simulated $\mathrm{NO}_{x}, \mathrm{CO}$, and temperature distributions during the perturbed phase of the 2009 NH winter (i.e. February-April), however, emphasise the need for model improvements in the dynamical representation of ES events in order to allow for a better description of the EPP indirect effect under these particular conditions. Our results reinforce the findings from previous studies that the adequate parameterization of unresolved GWD, particularly of its non-orographic component, is crucial for achieving such improvements. They also demonstrate that the dynamical boundary condition at $1 \mathrm{hPa}$, employed in our models, is not sufficient to fully determine the mesospheric circulation yet is crucial for the tracer transport into the stratosphere. Even when the winds are constrained in the stratosphere by observations, the calculated GWD in the mesosphere by different parameterizations can differ strongly. As discussed by McLandress and Scinocca (2005), such differences are related more to the characteristics of the launch spectra rather than to the treatment of the dissipation mechanisms in the parameterizations used. Indeed, Meraner et al. (2016) have shown that by modifying the launch characteristics of the gravity waves it is possible to tune the simulated $\mathrm{NO}_{x}$ descent towards the observations. Depending on the model, heating rates are calculated from coupled fields of radiative active gases or climatologies are used, adding further to differences and uncertainties. In addition, despite the similar definition of the nudging regime $(<1 \mathrm{hPa})$ in all model simulations, the vertical extent of the transition region between fully constrained and free-running mode varies among the models, which could introduce additional model spread. Finally, Smith et al. (2017) have shown that model dynamical fields are prone to errors due to the nudging approach itself, even when data and forcing terms are known exactly and there are no model biases. Interestingly, these intrinsic errors tend to grow with the complexity of the GWD representation employed in the model.

Many of the model-specific issues identified in the course of this project are currently being solved (e.g. Meraner et al., 2016). Lessons learned are hoped to also be of use for future model developments, particularly with respect to the consideration of EPP effects in upcoming coordinated model intercomparison projects. However, the bias encountered in the meteorological reanalysis data in the post-SSW upper stratosphere and lower mesosphere potentially triggered the common tendency of the models to produce a descent in the lower mesosphere that is too early. These results imply the need to improve data assimilation systems for producing reanalysis data, especially with respect to the representation of the polar winter USM. This is particularly important because the use of specified dynamics in atmospheric models is a necessary step to allow for meaningful comparisons to observations on seasonal and shorter timescales. 
Data availability. All the model and observational data supporting the analysis and conclusions have been archived and are available upon request from the corresponding author.

Competing interests. The authors declare that they have no conflict of interest.

Acknowledgements. This work has been conducted in the frame of the WCRP/SPARC SOLARIS-HEPPA activity. The IAA team was supported by the Spanish MCINN under grant ESP2014-54362-P and EC FEDER funds. The MPI-MET team was supported by the Max Planck Gesellschaft (MPG), and computational resources were made available by Deutsches Klimarechenzentrum (DKRZ) through support from Bundesministerium für Bildung und Forschung (BMBF). The FMI team was supported by the Academy of Finland through the projects 276926 (SECTIC: Sun-Earth Connection Through Ion Chemistry), 258165, and 265005 (CLASP: Climate and Solar Particle Forcing). CAO team was supported by the Russian Science Foundation under grant 15-17-10024. SOCOL team was funded by Swiss National Science Foundation (SNSF) grants 200021-149182 (SILA), 200020-163206 (SIMA), and CRSII2-147659 (FUPSOL-II). S. Bender, M. Sinnhuber, and H. Nieder (all KIT) gratefully acknowledge funding by the Helmholtz Association of German Research Centres (HGF), grant VH-NG-624. NCAR is sponsored by the National Science Foundation (NSF). Computing resources for WACCM simulations were provided by the Climate Simulation Laboratory at NCAR's Computational and Information Systems Laboratory, sponsored by the NSF and other agencies. Work at the Jet Propulsion Laboratory, California Institute of Technology, was carried out under a contract with the National Aeronautics and Space Administration. The Atmospheric Chemistry Experiment (ACE), also known as SciSat, is a Canadian-led mission mainly supported by the Canadian Space Agency. Odin is a Swedish-led satellite project funded jointly by Sweden (SNSB), Canada (CSA), Finland (TEKES), and France (CNES) and is part of European Space Agency's (ESA) third-party mission program. We thank two anonymous reviewers for helpful suggestions that led to improvements in the quality of the present work.

Edited by: F.-J. Lübken

Reviewed by: two anonymous referees

\section{References}

Abe, T., Kurihara, J., Iwagami, N., Nozawa, S., Ogawa, Y., Fujii, R., Hayakawa, H., and Oyama, K.-i.: Dynamics and Energetics of the Lower Thermosphere in Aurora (DELTA) - Japanese sounding rocket campaign, Earth Planets Space, 58, 1165-1171, doi:10.1186/BF03352006, 2006.

Andersson, M. E., Verronen, P. T., Marsh, D. R., Päivärinta, S.-M., and Plane, J. M. C.: WACCM-D - Improved modeling of nitric acid and active chlorine during energetic particle precipitation, J. Geophys. Res., 121, 10328-10341, doi:10.1002/2015JD024173, 2016.
Baumgaertner, A. J. G., Seppälä, A., Jöckel, P., and Clilverd, M. A.: Geomagnetic activity related $\mathrm{NO}_{\mathrm{x}}$ enhancements and polar surface air temperature variability in a chemistry climate model: modulation of the NAM index, Atmos. Chem. Phys., 11, 45214531, doi:10.5194/acp-11-4521-2011, 2011.

Bender, S., Sinnhuber, M., Burrows, J. P., Langowski, M., Funke, B., and López-Puertas, M.: Retrieval of nitric oxide in the mesosphere and lower thermosphere from SCIAMACHY limb spectra, Atmos. Meas. Tech., 6, 2521-2531, doi:10.5194/amt-62521-2013, 2013.

Bender, S., Sinnhuber, M., von Clarmann, T., Stiller, G., Funke, B., López-Puertas, M., Urban, J., Pérot, K., Walker, K. A., and Burrows, J. P.: Comparison of nitric oxide measurements in the mesosphere and lower thermosphere from ACE-FTS, MIPAS, SCIAMACHY, and SMR, Atmos. Meas. Tech., 8, 4171-4195, doi:10.5194/amt-8-4171-2015, 2015.

Bender, S., Sinnhuber, M., Langowski, M., and Burrows, J. P.: Retrieval of nitric oxide in the mesosphere from SCIAMACHY nominal limb spectra, Atmos. Meas. Tech., 10, 209220, doi:10.5194/amt-10-209-2017, 2017.

Berger, U.: Modeling of middle atmosphere dynamics with LIMA, J. Atmos. Sol.-Terr. Phy., 70, 1170-1200, doi:10.1016/j.jastp.2008.02.004, 2008.

Bernath, P. F., McElroy, C. T., Abrams, M. C., Boone, C. D., Butler, M., Camy-Peyret, C.and Carleer, M., Clerbaux, C., Coheur, P.-F., Colin, R., DeCola, P., DeMazière, M., Drummond, J. R., Dufour, D., Evans, W. F. J., Fast, H., Fussen, D., Gilbert, K., Jennings, D. E., Llewellyn, E. J., Lowe, R. P., Mahieu, E., McConnell, J. C., McHugh, M., McLeod, S. D., Michaud, R., Midwinter, C., Nassar, R., Nichitiu, F., Nowlan, C., Rinsland, C. P., Rochon, Y. J., Rowlands, N., Semeniuk, K., Simon, P., Skelton, R., Sloan, J. J., Soucy, M.-A., Strong, K., Tremblay, P., Turnbull, D., Walker, K. A., Walkty, I., Wardle, D. A., Wehrle, V., Zander, R., and Zou, J.: Atmospheric Chemistry Experiment (ACE): Mission overview, Geophys. Res. Lett., 32, L15S01, doi:doi:10.1029/2005GL022386, 2005.

Bertaux, J. L., Kyrölä, E., Fussen, D., Hauchecorne, A., Dalaudier, F., Sofieva, V., Tamminen, J., Vanhellemont, F., Fanton d'Andon, O., Barrot, G., Mangin, A., Blanot, L., Lebrun, J. C., Pérot, K., Fehr, T., Saavedra, L., Leppelmeier, G. W., and Fraisse, R.: Global ozone monitoring by occultation of stars: an overview of GOMOS measurements on ENVISAT, Atmos. Chem. Phys., 10, 12091-12148, doi:10.5194/acp-10-12091-2010, 2010.

Boone, C. D., Nassar, R., Walker, K. A., Rochon, Y., McLeod, S. D., Rinsland, C. P., and Bernath, P. F.: Retrievals for the atmospheric chemistry experiment Fourier-transform spectrometer, Appl. Opt., 44, 7218-7231, 2005.

Boone, C. D., Walker, K. A., and Bernath, P. F.: Version 3 Retrievals for the Atmospheric Chemistry Experiment Fourier Transform Spectrometer (ACE-FTS), in: The Atmospheric Chemistry Experiment ACE at 10: A Solar Occultation Anthology, edited by: Bernath, P. F., 103-127, A. Deepak Publishing, Hampton, Virginia, USA, 2013.

Bovensmann, H., Burrows, J. P., Buchwitz, M., Frerick, J., Noël, S., Rozanov, V. V., Chance, K. V., and Goede, A. P. H.: SCIAMACHY: Mission Objectives and Measurement Modes, J. Atmos. Sci., 56, 127-150, doi:10.1175/15200469(1999)056<0127:SMOAMM>2.0.CO;2, 1999. 
Burrows, J. P., Hölzle, E., Goede, A. P. H., Visser, H., and Fricke, W.: SCIAMACHY - scanning imaging absorption spectrometer for atmospheric chartography, Acta Astronaut., 35, 445-451, doi:10.1016/0094-5765(94)00278-T, 1995.

Chance, K. and Kurucz, R.: An improved high-resolution solar reference spectrum for earth's atmosphere measurements in the ultraviolet, visible, and near infrared, J. Quant. Spectrosc. Ra., 111, 1289-1295, doi:10.1016/j.jqsrt.2010.01.036, 2010.

Chandran, A., Collins, R. L., Garcia, R. R., and Marsh, D. R.: A case study of an elevated stratopause generated in the Whole Atmosphere Community Climate Model, Geophys. Res. Lett., 38, 108804, doi:10.1029/2010GL046566, 2011.

Chang, J., Brost, R., Isaksen, I., Madronich, S., Middleton, P., Stockwell, W., and Walcek, C.: A three-dimensional Eulerian acid deposition model: Physical concepts and formulation, J. Geophys. Res., 92, 14681-14700, doi:10.1029/JD092iD12p14681, 1987.

Charron, M. and Manzini, E.: Gravity Waves from Fronts: Parameterization and Middle Atmosphere Response in a General Circulation Model, J. Atmos. Sci., 59, 923-941, doi:10.1175/15200469(2002)059<0923:GWFFPA>2.0.CO;2, 2002.

Chipperfield, M.: Multiannual simulations with a three-dimensional chemical transport model, J. Geophys. Res., 104, 1781-1805, 1999.

Damski, J., Thölix, L., Backman, L., Kaurola, J., Taalas, P., Austin, J., Butchart, N., and Kulmala, M.: A chemistry-transport model simulation of middle atmospheric ozone from 1980 to 2019 using coupled chemistry GCM winds and temperatures, Atmos. Chem. Phys., 7, 2165-2181, doi:10.5194/acp-7-2165-2007, 2007.

Dee, D. P., Uppala, S. M., Simmons, A. J., Berrisford, P., Poli, P., Kobayashi, S., Andrae, U., Balmaseda, M. A., Balsamo, G., Bauer, P., Bechtold, P., Beljaars, A. C. M., van de Berg, L., Bidlot, J., Bormann, N., Delsol, C., Dragani, R., Fuentes, M., Geer, A. J., Haimberger, L., Healy, S. B., Hersbach, H., Hólm, E. V., Isaksen, L., Kållberg, P., Köhler, M., Matricardi, M., McNally, A. P., Monge-Sanz, B. M., Morcrette, J.-J., Park, B.-K., Peubey, C., de Rosnay, P., Tavolato, C., Thépaut, J.-N., and Vitart, F.: The ERA-Interim reanalysis: configuration and performance of the data assimilation system, Q. J. Roy. Meteor. Soc., 137, 553-597, doi:10.1002/qj.828, 2011.

Egorova, T., Rozanov, E., Ozolin, Y., Shapiro, A., Calisto, M., Peter, T., and Schmutz, W.: The atmospheric effects of October 2003 solar proton event simulated with the chemistryclimate model $\{$ SOCOL $\}$ using complete and parameterized ion chemistry, J. Atmos. Sol.-Terr. Phy., 73, 356-365, doi:10.1016/j.jastp.2010.01.009, 2011.

Egorova, T. A., Rozanov, E. V., Zubov, V. A., and Karol, I. L.: Model for investigating ozone trends (MEZON), Atmos. Ocean. Phys., 39, 277-292, 2003.

Eyring, V., Lamarque, J.-F., Hess, P., Arfeuille, F., Bowman, K., Chipperfield, M. P., Duncan, B., Fiore, A., Gettelman, A., Giorgetta, M. A., Granier, C., Hegglin, M., Kinnison, D. E., Kunze, M., Langematz, U., Luo, B., Martin, R., Matthes, K., Newman, P. A., Peter, T., Robock, A., Ryerson, T., Saiz-Lopez, A., Salawitch, R., Schultz, M., Shepherd, T. G., Shindell, D., Staehelin, J., Tegtmeier, S., Thomason, L., Tilmes, S., Vernier, J.-P., Waugh, D. W., and Young, P. J.: Overview of IGAC/SPARC Chemistry-Climate Model Initiative (CCMI) Community Simulations in Support of
Upcoming Ozone and Climate Assessments, SPARC newsletter, Zurich, Switzerland, 40, 48-66, 2013.

Eyring, V., Bony, S., Meehl, G. A., Senior, C. A., Stevens, B., Stouffer, R. J., and Taylor, K. E.: Overview of the Coupled Model Intercomparison Project Phase 6 (CMIP6) experimental design and organization, Geosci. Model Dev., 9, 1937-1958, doi:10.5194/gmd-9-1937-2016, 2016.

Filipiak, M. J., Harwood, R. S., Jiang, J. H., Li, Q., Livesey, N. J., Manney, G. L., Read, W. G., Schwartz, M. J., Waters, J. W., and Wu, D. L.: Carbon monoxide measured by the EOS Microwave Limb Sounder on Aura: First results, Geophys. Res. Lett., 32, L14825, doi:10.1029/2005GL022765, 2005.

Fischer, H., Birk, M., Blom, C., Carli, B., Carlotti, M., von Clarmann, T., Delbouille, L., Dudhia, A., Ehhalt, D., Endemann, M., Flaud, J. M., Gessner, R., Kleinert, A., Koopman, R., Langen, J., López-Puertas, M., Mosner, P., Nett, H., Oelhaf, H., Perron, G., Remedios, J., Ridolfi, M., Stiller, G., and Zander, R.: MIPAS: an instrument for atmospheric and climate research, Atmos. Chem. Phys., 8, 2151-2188, doi:10.5194/acp-8-2151-2008, 2008.

Froidevaux, L., Livesey, N. J., Read, W. G., Jiang, Y. B., Jimenez, C., Filipiak, M. J., Schwartz, M. J., Santee, M. L., Pumphrey, H. C., Jiang, J. H., Wu, D. L., Manney, G. L., Drouin, B. J., Waters, J. W., Fetzer, E. J., Bernath, P. F., Boone, C. D., Walker, K. A., Jucks, K. W., Toon, G. C., Margitan, J. J., Sen, B., Webster, C. R., Christensen, L. E., Elkins, J. W., Atlas, E., Lueb, R. A., and Hendershot, R.: Early Validation Analyses of Atmospheric Profiles From EOS MLS on the Aura Satellite, IEEE T. Geosci. Remote Sens., 44, 1106-1121, doi:10.1109/TGRS.2006.864366, 2006.

Funke, B., García-Comas, M., López-Puertas, M., Glatthor, N., Stiller, G. P., von Clarmann, T., Semeniuk, K., and McConnell, J. C.: Enhancement of $\mathrm{N}_{2} \mathrm{O}$ during the October-November 2003 solar proton events, Atmos. Chem. Phys., 8, 3805-3815, doi:10.5194/acp-8-3805-2008, 2008.

Funke, B., López-Puertas, M., García-Comas, M., Stiller, G. P., von Clarmann, T., Höpfner, M., Glatthor, N., Grabowski, U., Kellmann, S., and Linden, A.: Carbon monoxide distributions from the upper troposphere to the mesosphere inferred from $4.7 \mu \mathrm{m}$ non-local thermal equilibrium emissions measured by MIPAS on Envisat, Atmos. Chem. Phys., 9, 2387-2411, doi:10.5194/acp-92387-2009, 2009.

Funke, B., Baumgaertner, A., Calisto, M., Egorova, T., Jackman, C. H., Kieser, J., Krivolutsky, A., López-Puertas, M., Marsh, D. R., Reddmann, T., Rozanov, E., Salmi, S.-M., Sinnhuber, M., Stiller, G. P., Verronen, P. T., Versick, S., von Clarmann, T., Vyushkova, T. Y., Wieters, N., and Wissing, J. M.: Composition changes after the "Halloween" solar proton event: the High Energy Particle Precipitation in the Atmosphere (HEPPA) model versus MIPAS data intercomparison study, Atmos. Chem. Phys., 11, 90899139, doi:10.5194/acp-11-9089-2011, 2011.

Funke, B., López-Puertas, M., Stiller, G. P., and von Clarmann, T.: Mesospheric and stratospheric $\mathrm{NO}_{y}$ produced by energetic particle precipitation during 2002-2012, J. Geophys. Res., 119, 4429-4446, doi:10.1002/2013JD021404, 2014a.

Funke, B., Puertas, M. L., Holt, L., Randall, C. E., Stiller, G. P., and von Clarmann, T.: Hemispheric distributions and interannual variability of $\mathrm{NO}_{y}$ produced by energetic particle precipitation in 2002-2012, J. Geophys. Res., 119, 13565-13582, doi:10.1002/2014JD022423, 2014b. 
Garcia, R. R., López-Puertas, M., Funke, B., Marsh, D. R., Kinnison, D. E., Smith, A. K., and González-Galindo, F.: On the distribution of $\mathrm{CO}_{2}$ and $\mathrm{CO}$ in the mesosphere and lower thermosphere, J. Geophys. Res., 119, 5700-5718, doi:10.1002/2013JD021208, 2014.

García-Comas, M., López-Puertas, M., Marshall, B. T., Wintersteiner, P. P., Funke, B., Bermejo-Pantaleón, D., Mertens, C. J., Remsberg, E. E., Gordley, L. L., Mlynczak, M. G., and Russell III, J. M.: Errors in Sounding of the Atmosphere using Broadband Emission Radiometry (SABER) kinetic temperature caused by non-local-thermodynamic-equilibrium model parameters, J. Geophys. Res., 113, D24106, doi:10.1029/2008JD010105, 2008.

García-Comas, M., Funke, B., Gardini, A., López-Puertas, M., Jurado-Navarro, A., von Clarmann, T., Stiller, G., Kiefer, M., Boone, C. D., Leblanc, T., Marshall, B. T., Schwartz, M. J., and Sheese, P. E.: MIPAS temperature from the stratosphere to the lower thermosphere: Comparison of vM21 with ACE-FTS, MLS, OSIRIS, SABER, SOFIE and lidar measurements, Atmos. Meas. Tech., 7, 3633-3651, doi:10.5194/amt-7-3633-2014, 2014

Hauchecorne, A., Bertaux, J. L., Dalaudier, F., Russell, J. M., Mlynczak, M. G., Kyrölä, E., and Fussen, D.: Large increase of $\mathrm{NO}_{2}$ in the north polar mesosphere in January-February 2004: Evidence of a dynamical origin from GOMOS/ENVISAT and SABER/TIMED data, Geophys. Res. Lett., 34, L03810, doi:10.1029/2006GL027628, 2007.

Hines, C. O.: Doppler-spread parameterization of gravity-wave momentum deposition in the middle atmosphere. Part 1: Basic formulation, J. Atmos. Sol.-Terr. Phy., 59, 371-386, doi:10.1016/S1364-6826(96)00079-X, 1997.

Holton, J. and Zhu, X.: A further study of gravity wave induced drag and diffusion in the mesosphere, J. Atmos. Sci., 41, 2653-2662, 1984.

Holton, J. R.: The Role of Gravity Wave Induced Drag and Diffusion in the Momentum Budget of the Mesosphere, J. Atmos. Sci., 39, 791-799, doi:10.1175/15200469(1982)039<0791:TROGWI>2.0.CO;2, 1982.

Hurrell, J. W., Holland, M., Gent, P. R., Ghan, S., Kay, J. E., Kushner, P. J., Lamarque, J.-F., Large, W., Lawrence, D., Lindsay, K., Lipscomb, W. H., Long, M. C., Mahowald, N., Marsh, D. R., Neale, R. B., Rasch, P., Vavrus, S., Vertenstein, M., Bader, D., Collins, W., Hack, J., Kiehl, J., and Marshall, S.: The Community Earth System Model: A Framework for Collaborative Research, B. Am. Meteorol. Soc., 130715075145003, doi:10.1175/BAMSD-12-00121.1, 2013

Jackman, C. H., DeLand, M. T., Labow, G. J., Fleming, E. L., Weisenstein, D. K., Ko, M. K. W., Sinnhuber, M., and Russell, J. M.: Neutral atmospheric influences of the solar proton events in October-November 2003, J. Geophys. Res., 110, A09S27, doi:10.1029/2004JA010888, 2005a.

Jackman, C. H., DeLand, M. T., Labow, G. J., Fleming, E. L., Weisenstein, D. K., Ko, M. K. W., Sinnhuber, M., and Russell, J. M.: Neutral atmospheric influences of the solar proton events in October-November 2003, J. Geophys. Res., 110, A09S27, doi:10.1029/2004JA010888, 2005b.

Jeuken, A. B. M., Siegmund, P. C., Heijboer, L. C., Feichter, J., and Bengtsson, L.: On the potential of assimilating meteorological analyses in a global climate model for the pur- pose of model validation, J. Geophys. Res., 101, 16939-16950, doi:10.1029/96JD01218, 1996.

Jöckel, P., Kerkweg, A., Pozzer, A., Sander, R., Tost, H., Riede, H., Baumgaertner, A., Gromov, S., and Kern, B.: Development cycle 2 of the Modular Earth Submodel System (MESSy2), Geosci. Model Dev., 3, 717-752, doi:10.5194/gmd-3-717-2010, 2010.

Kieser, J.: The Influence of Precipitating Solar and Magnetospheric Energetic Charged Particles on the Entire Atmosphere Simulations with Hammonia, Max-Planck-Inst. für Meteorologie, 2011.

Kinnison, D. E., Brasseur, G. P., Walters, S., Garcia, R. R., Marsh, D. R., Sassi, F., Harvey, V. L., Randall, C. E., Emmons, L., Lamarque, J. F., Hess, P., Orlando, J. J., Tie, X. X., Randel, W., Pan, L. L., Gettelman, A., Granier, C., Diehl, T., Niemeier, U., and Simmons, A. J.: Sensitivity of chemical tracers to meteorological parameters in the MOZART-3 chemical transport model, J. Geophys. Res., 112, D20302, doi:10.1029/2006JD007879, 2007.

Kouker, W., Offermann, D., Küll, V., Reddmann, T., Ruhnke, R., and Franzen, A.: Streamers observed by the CRISTA experiment and simulated in the KASIMA model, J. Geophys. Res., 104, 16405-16418, 1999.

Kylling, A., Albold, A., and Seckmeyer, G.: Transmittance of a cloud is wavelength - dependent in the UV-range: Physical interpretation, Geophys. Res. Lett., 24, 397-400, doi:10.1029/97GL00111, 1997.

Kyrölä, E., Tamminen, J., Sofieva, V., Bertaux, J. L., Hauchecorne, A., Dalaudier, F., Fussen, D., Vanhellemont, F., Fanton d'Andon, O., Barrot, G., Guirlet, M., Mangin, A., Blanot, L., Fehr, T., Saavedra de Miguel, L., and Fraisse, R.: Retrieval of atmospheric parameters from GOMOS data, Atmos. Chem. Phys., 10, 1188111903, doi:10.5194/acp-10-11881-2010, 2010.

Lean, J., Rottman, G., Harder, J., and Kopp, G.: SORCE contributions to new understanding of global change and solar variability, Sol. Phys., 230, 27-53, doi:10.1007/s11207-005-1527-2, 2005.

Lin, S. J. and Rood, R. B.: Multidimensional flux-form semiLagrangian transport schemes, Mon. Weather Rev., 124, 20462070, 1996.

Livesey, N. J.: Earth Observing System (EOS) Aura Microwave Limb Sounder (MLS) Version 4.2x Level 2 data quality and description document, Jpl d-33509, Jet Propulsion Laboratory, California Institute of Technology, Pasadena, CA, 2016.

Lott, F. and Miller, M. J.: A new subgrid-scale orographic drag parametrization: Its formulation and testing, Q. J. Roy. Meteor. Soc., 123, 101-127, doi:10.1002/qj.49712353704, 1997.

Maliniemi, V., Asikainen, T., and Mursula, K.: Spatial distribution of Northern Hemisphere winter temperatures during different phases of the solar cycle, J. Geophys. Res., 119, 9752-9764, doi:10.1002/2013JD021343, 2014.

Manney, G. L., Harwood, R. S., MacKenzie, I. A., Minschwaner, K., Allen, D. R., Santee, M. L., Walker, K. A., Hegglin, M. I., Lambert, A., Pumphrey, H. C., Bernath, P. F., Boone, C. D., Schwartz, M. J., Livesey, N. J., Daffer, W. H., and Fuller, R. A.: Satellite observations and modeling of transport in the upper troposphere through the lower mesosphere during the 2006 major stratospheric sudden warming, Atmos. Chem. Phys., 9, 47754795, doi:10.5194/acp-9-4775-2009, 2009.

Marsh, D. R., Garcia, R. R., Kinnison, D. E., Boville, B. A., Sassi, F., Solomon, S. C., and Matthes, K.: Modeling the whole atmosphere response to solar cycle changes in radia- 
tive and geomagnetic forcing, J. Geophys. Res., 112, D23306, doi:10.1029/2006JD008306, 2007.

Marsh, D. R., Mills, M. J., Kinnison, D. E., Lamarque, J.-F., Calvo, N., and Polvani, L. M.: Climate Change from 1850 to 2005 Simulated in CESM1(WACCM), J. Climate, 26, 7372-7391, doi:10.1175/JCLI-D-12-00558.1, 2013.

Matthes, K., Funke, B., Anderson, M. E., Barnard, L., Beer, J., Charbonneau, P., Clilverd, M. A., Dudok de Wit, T., Haberreiter, M., Hendry, A., Jackman, C. H., Kretschmar, M., Kruschke, T., Kunze, M., Langematz, U., Marsh, D. R., Maycock, A., Misios, S., Rodger, C. J., Scaife, A. A., Seppälä, A., Shangguan, M., Sinnhuber, M., Tourpali, K., Usoskin, I., van de Kamp, M., Verronen, P. T., and Versick, S.: Solar Forcing for CMIP6 (v3.1), Geosci. Model Dev. Discuss., doi:10.5194/gmd-2016-91, in review, 2016.

McLandress, C. and Scinocca, J. F.: The GCM Response to Current Parameterizations of Nonorographic Gravity Wave Drag, J. Atmos. Sci., 62, 2394-2413, doi:10.1175/JAS3483.1, 2005.

McLandress, C., Scinocca, F., Shepherd, T. G., Reader, M. C., and Manney, G. L.: Dynamical Control of the Mesosphere by Orographic and Nonorographic Gravity Wave Drag during the Extended Northern Winters of 2006 and 2009, J. Atmos. Sci., 70, 2152-2169, doi:10.1175/JAS-D-12-0297.1, 2013.

Meraner, K. and Schmidt, H.: Transport of nitrogen oxides through the winter mesopause in HAMMONIA, J. Geophys. Res., 121, 2015JD024136, doi:10.1002/2015JD024136, 2016.

Meraner, K., Schmidt, H., Manzini, E., Funke, B., and Gardini, A.: Sensitivity of Simulated Meospheric Transport of Nitrogen Oxides to Parameterized Gravity Waves, J. Geophys. Res., 121, 12045-12061, doi:10.1002/2016JD025012, 2016.

Merino, F., Murtagh, D. P., Ridal, M., Eriksson, P., Baron, P., Ricaud, P., and de la Noë, J.: Studies for the Odin sub-millimetre radiometer: III. Performance simulations, Can. J. Phys., 80, 357373, doi:10.1139/p01-154, 2002.

Murtagh, D., Frisk, U., Merino, F., Ridal, M., Jonsson, A., Stegman, J., Witt, G., Eriksson, P., Jiménez, C., Megie, G., de la Noë, J., Ricaud, P., Baron, P., Pardo, J. R., Hauchcorne, A., Llewellyn, E. J., Degenstein, D. A., Gattinger, R. L., Lloyd, N. D., Evans, W. F., McDade, I. C., Haley, C. S., Sioris, C., von Savigny, C., Solheim, B. H., McConnell, J. C., Strong, K., Richardson, E. H., Leppelmeier, G. W., Kyrölä, E., Auvinen, H., and Oikarinen, L.: An overview of the Odin atmospheric mission, Can. J. Phys., 80, 309-319, doi:10.1139/p01-157, 2002.

Nieder, H., Winkler, H., Marsh, D., and Sinnhuber, M.: $\mathrm{NO}_{x}$ production due to energetic particle precipitation in the MLT region: Results from ion chemistry model studies, J. Geophys. Res., 119, 2137-2148, doi:10.1002/2013JA019044, 2014.

Päivärinta, S.-M., Verronen, P. T., Funke, B., Gardini, A., Seppälä, A., and Andersson, M. E.: Transport versus energetic particle precipitation: Northern polar stratospheric $\mathrm{NO}_{x}$ and ozone in January-March 2012, J. Geophys. Res., 121, 6085-6100, doi:10.1002/2015JD024217, 2016.

Pedatella, N. M., Fuller-Rowell, T., Wang, H., Jin, H., Miyoshi, Y., Fujiwara, H., Shinagawa, H., Liu, H.-L., Sassi, F., Schmidt, H., Matthias, V., and Goncharenko, L.: The neutral dynamics during the 2009 sudden stratosphere warming simulated by different whole atmosphere models, J. Geophys. Res., 119, 1306-1324, doi:10.1002/2013JA019421, 2014.
Pedatella, N. M., Fang, T.-W., Jin, H., Sassi, F., Schmidt, H., Chau, J. L., Siddiqui, T. A., and Goncharenko, L.: Multimodel comparison of the ionosphere variability during the 2009 sudden stratosphere warming, J. Geophys. Res., 121, 7204-7225, doi:10.1002/2016JA022859, 2016.

Pérot, K., Urban, J., and Murtagh, D. P.: Unusually strong nitric oxide descent in the Arctic middle atmosphere in early 2013 as observed by Odin/SMR, Atmos. Chem. Phys., 14, 8009-8015, doi:10.5194/acp-14-8009-2014, 2014.

Porter, H. S., Jackman, C. H., and Green, A. E. S.: Efficiencies for production of atomic nitrogen and oxygen by relativistic proton impact in air, J. Chem. Phys., 65, 154-167, doi:10.1063/1.432812, 1976.

Pöschl, U., von Kuhlmann, R., Poisson, N., and Crutzen, P. J.: Development and intercomparison of condensed isoprene oxidation mechanisms for global atmospheric modeling, J. Atmos. Chem., 37, 29-52, doi:10.1023/A:1006391009798, 2000.

Price, C. and Rind, D.: A simple lightning parameterization for calculating global lightning distributions, J. Geophys. Res., 97, 9919-9933, doi:10.1029/92JD00719, 1992.

Pumphrey, H. C., Filipiak, M. J., Livesey, N. J., Schwartz, M. J., Boone, C., Walker, K. A., Bernath, P., Ricaud, P., Barret, B., Clerbaux, C., Jarnot, R. F., Manney, G. L., and Waters, J. W.: Validation of middle-atmosphere carbon monoxide retrievals from the Microwave Limb Sounder on Aura, J. Geophys. Res., 112, d24S38, doi:10.1029/2007JD008723, 2007.

Randall, C. E., Harvey, V. L., Singleton, C. S., Bailey, S. M., Bernath, P. F., Codrescu, M., Nakajima, H., and Russell III, J. M.: Energetic particle precipitation effects on the Southern Hemisphere stratosphere in 1992-2005, J. Geophys. Res., 112, D08308, doi:10.1029/2006JD007696, 2007.

Randall, C. E., Harvey, V. L., Siskind, D. E., France, J., Bernath, P. F., Boone, C. D., and Walker, K. A.: $\mathrm{NO}_{x}$ descent in the Arctic middle atmosphere in early 2009, Geophys. Res. Lett., 36, L18811, doi:10.1029/2009GL039706, 2009.

Randall, C. E., Harvey, V. L., Holt, L. A., Marsh, D. R., Kinnison, D., Funke, B., and Bernath, P. F.: Simulation of energetic particle precipitation effects during the 2003-2004 Arctic winter, J. Geophys. Res., 120, 5035-5048, doi:10.1002/2015JA021196, 2015.

Reddmann, T., Ruhnke, R., Versick, S., and Kouker, W.: Modeling disturbed stratospheric chemistry during solar-induced $\mathrm{NO}_{x}$ enhancements observed with MIPAS/ENVISAT, J. Geophys. Res., 115, D00I11, doi:10.1029/2009JD012569, 2010.

Remsberg, E. E., Marshall, B. T., García-Comas, M., Krueger, D., Lingenfelser, G. S., Martin-Torres, F. J., Mlynczak, M. G., Russell, III, J. M., Smith, A. K., Zhao, Y., Brown, C., Gordley, L. L., López-Gonzalez, M. J., López-Puertas, M., She, C.-Y., Taylor, M. J., and Thompson, R. E.: Assessment of the quality of the Version 1.07 temperature-versus-pressure profiles of the middle atmosphere from TIMED/SABER, J. Geophys. Res., 113, D17101, doi:10.1029/2008JD010013, 2008.

Rienecker, M. M., Suarez, M. J., Gelaro, R., Todling, R., Bacmeister, J., Liu, E., Bosilovich, M. G., Schubert, S. D., Takacs, L., Kim, G.-K., Bloom, S., Chen, J., Collins, D., Conaty, A., da Silva, A., Gu, W., Joiner, J., Koster, R. D., Lucchesi, R., Molod, A., Owens, T., Pawson, S., Pegion, P., Redder, C. R., Reichle, R., Robertson, F. R., Ruddick, A. G., Sienkiewicz, M., and Woollen, J.: MERRA: NASA's Modern-Era Retrospective Anal- 
ysis for Research and Applications, J. Climate, 24, 3624-3648, doi:10.1175/jcli-d-11-00015.1, 2011.

Roeckner, E., Brokopf, R., Esch, M., Giorgetta, M., Hagemann, S., Kornblueh, L., Manzini, E., Schlese, U., and Schulzweida, U.: Sensitivity of Simulated Climate to Horizontal and Vertical Resolution in the ECHAM5 Atmosphere Model, J. Climate, 19, 3771-3791, doi:10.1175/JCLI3824.1, 2006.

Rozanov, E., Calisto, M., Egorova, T., Peter, T., and Schmutz, W.: Influence of the Precipitating Energetic Particles on Atmospheric Chemistry and Climate, Surv. Geophys., 33, 483-501, doi:10.1007/s10712-012-9192-0, 2012.

Russell III, J. M., Mlynczak, M. G., Gordley, L. L., Tansock, J., and Esplin, R.: An overview of the SABER experiment and preliminary calibration results, in: Proc. SPIE, 277-288, 1999.

Salmi, S.-M., Verronen, P. T., Thölix, L., Kyrölä, E., Backman, L., Karpechko, A. Yu., and Seppälä, A.: Mesosphere-to-stratosphere descent of odd nitrogen in February-March 2009 after sudden stratospheric warming, Atmos. Chem. Phys., 11, 4645-4655, doi:10.5194/acp-11-4645-2011, 2011.

Sander, R., Baumgaertner, A., Gromov, S., Harder, H., Jöckel, P., Kerkweg, A., Kubistin, D., Regelin, E., Riede, H., Sandu, A., Taraborrelli, D., Tost, H., and Xie, Z.-Q.: The atmospheric chemistry box model CAABA/MECCA-3.0, Geosci. Model Dev., 4, 373-380, doi:10.5194/gmd-4-373-2011, 2011.

Sander, R., Jöckel, P., Kirner, O., Kunert, A. T., Landgraf, J., and Pozzer, A.: The photolysis module JVAL-14, compatible with the MESSy standard, and the JVal PreProcessor (JVPP), Geosci. Model Dev., 7, 2653-2662, doi:10.5194/gmd-7-26532014, 2014.

Sander, S. P., Finlayson-Pitts, B. J., Friedl, R. R., Golden, D. M., Huie, R. E., Kolb, C. E., Kurylo, M. J., Molina, M. J., Moortgat, G. K., Orkin, V. L., and Ravishankara, A. R.: Chemical kinetics and Photochemical Data for the Use in Atmospheric Studies. Evaluation Number 14, JPL publication 02-25, Jet Propulsion Laboratory, California Institute of Technology, Pasadena, CA, 2003

Sander, S. P., Friedl, R. R., Golden, D. M., Kurylo, M. J., Moortgat, G. K., Keller-Rudek, H., Wine, P. H., Ravishankara, A. R., Kolb, C. E., Molina, M. J., Finlayson-Pitts, B. J., Huie, R. E., and Orkin, V. L.: Chemical kinetics and photochemical data for Use in Atmospheric Studies, Evaluation Number 15, JPL Publication 06-2, Jet Propulsion Laboratory, California Institute of Technology, Pasadena, USA, 2006.

Sander, S. P., Abbatt, J., Barker, J. R., Burkholder, J. B., Friedl, R. R., Golden, D. M., Huie, R. E., Kolb, C. E., Kurylo, M. J., Moortgat, G. K., Orkin, V. L., and Wine, P. H.: Chemical kinetics and photochemical data for use in atmospheric studies, Evaluation No. 17, JPL publication 10-6, Jet Propulsion Laboratory, California Institute of Technology, Pasadena, CA, 2011.

Schmidt, H., Brasseur, G., Charron, M., Manzini, E., Giorgetta, M., Diehl, T., Formichev, V., Kinnison, D., Marsh, D., and Walters, S.: The HAMMONIA chemistry climate model: sensitivity of the mesopause region to the 11-year solar cycle and $\mathrm{CO}_{2}$ doubling, J. Climate, 19, 3903-3931, 2006.

Schwartz, M. J., Lambert, A., Manney, G. L., Read, W. G., Livesey, N. J., Froidevaux, L., Ao, C. O., Bernath, P. F., Boone, C. D., Cofield, R. E., Daffer, W. H., Drouin, B. J., Fetzer, E. J., Fuller, R. A., Jarnot, R. F., Jiang, J. H., Jiang, Y. B., Knosp, B. W., Krüger, K., Li, J.-L. F., Mlynczak, M. G., Pawson, S., Russell,
J. M., Santee, M. L., Snyder, W. V., Stek, P. C., Thurstans, R. P., Tompkins, A. M., Wagner, P. A., Walker, K. A., Waters, J. W., and $\mathrm{Wu}, \mathrm{D}$. L.: Validation of the Aura Microwave Limb Sounder temperature and geopotential height measurements, J. Geophys. Res., 113, d15S11, doi:10.1029/2007JD008783, 2008.

Seppälä, A. and Clilverd, M. A.: Energetic Particle Forcing of the Northern Hemisphere winter stratosphere: Comparison to solar irradiance forcing, Frontiers in Physics, 2, 25 pp., doi:10.3389/fphy.2014.00025, 2014.

Seppälä, A., Clilverd, M. A., and Rodger, C. J.: $\mathrm{NO}_{x}$ enhancements in the middle atmosphere during 2003-2004 polar winter: Relative significance of solar proton events and the aurora as a source, J. Geophys. Res., 112, D23303, doi:10.1029/2006JD008326, 2007.

Seppälä, A., Randall, C. E., Clilverd, M. A., Rozanov, E., and Rodger, C. J.: Geomagnetic activity and polar surface air temperature variability, J. Geophys. Res., 114, A10312, doi:10.1029/2008JA014029, 2009.

Sheese, P. E., Strong, K., Gattinger, R. L., Llewellyn, E. J., Urban, J., Boone, C. D., and Smith, A. K.: Odin observations of Antarctic nighttime NO densities in the mesosphere-lower thermosphere and observations of a lower NO layer, J. Geophys. Res., 118, 7414-7425, doi:10.1002/jgrd.50563, 2013.

Sheese, P. E., Walker, K. A., Boone, C. D., Bernath, P. F., Froidevaux, L., Funke, B., Raspollini, P., and von Clarmann, T.: ACEFTS ozone, water vapour, nitrous oxide, nitric acid, and carbon monoxide profile comparisons with MIPAS and MLS, J. Quant. Spectrosc. Ra., 186, 63-80, doi:10.1016/j.jqsrt.2016.06.026, 2016a.

Sheese, P. E., Walker, K. A., Boone, C. D., McLinden, C. A., Bernath, P. F., Bourassa, A. E., Burrows, J. P., Degenstein, D. A., Funke, B., Fussen, D., Manney, G. L., McElroy, C. T., Murtagh, D., Randall, C. E., Raspollini, P., Rozanov, A., Russell III, J. M., Suzuki, M., Shiotani, M., Urban, J., von Clarmann, T., and Zawodny, J. M.: Validation of ACE-FTS version $3.5 \mathrm{NO}_{y}$ species profiles using correlative satellite measurements, Atmos. Meas. Tech., 9, 5781-5810, doi:10.5194/amt-9-5781-2016, 2016 b.

Sinnhuber, B.-M., Weber, M., Amankwah, A., and Burrows, J. P.: Total ozone during the unusual Antarctic winter of 2002, Geophys. Res. Lett., 30, 1580, 2003.

Sinnhuber, M., Nieder, H., and Wieters, N.: Energetic particle precipitation and the chemistry of the mesosphere/lower thermosphere, Surv. Geophys., 33, 1281, doi:10.1007/s10712-0129201-3, 2012.

Siskind, D. E., Eckermann, S. D., Coy, L., McCormack, J. P., and Randall, C. E.: On recent inter-annual variability of the Arctic winter mesosphere: Implications for tracer descent, Geophys. Res. Lett., 34, L09806, doi:10.1029/2007GL029293, 2007.

Siskind, D. E., Eckermann, S. D., McCormack, J. P., Coy, L., Hoppel, K. W., and Baker, N. L.: Case studies of the mesospheric response to recent minor, major, and extended stratospheric warmings, J. Geophys. Res., 115, d00N03, doi:10.1029/2010JD014114, 2010.

Siskind, D. E., Sassi, F., Randall, C. E., Harvey, V. L., Hervig, M. E., and Bailey, S. M.: Is a high-altitude meteorological analysis necessary to simulate thermosphere-stratosphere coupling?, Geophys. Res. Lett., 42, 8225-8230, doi:10.1002/2015GL065838, 2015. 
Smith, A., Pedatella, N., Marsh, D., and Matsuo, T.: On the dynamical control of the mesosphere-lower thermosphere by the lower and middle atmosphere, J. Atmos. Sci., 74, 933-947, doi:10.1175/JAS-D-16-0226.1, 2017.

Solomon, S. C. and Qian, L.: Solar extreme-ultraviolet irradiance for general circulation models, J. Geophys. Res., 110, A10306, doi:10.1029/2005JA011160, 2005.

Stenke, A., Schraner, M., Rozanov, E., Egorova, T., Luo, B., and Peter, T.: The SOCOL version 3.0 chemistry-climate model: description, evaluation, and implications from an advanced transport algorithm, Geosci. Model Dev., 6, 1407-1427, doi:10.5194/gmd-6-1407-2013, 2013.

Sukhodolov, T., Rozanov, E., Shapiro, A. I., Anet, J., Cagnazzo, C., Peter, T., and Schmutz, W.: Evaluation of the ECHAM family radiation codes performance in the representation of the solar signal, Geosci. Model Dev., 7, 2859-2866, doi:10.5194/gmd-72859-2014, 2014.

Tamminen, J., Kyrölä, E., Sofieva, V. F., Laine, M., Bertaux, J.-L., Hauchecorne, A., Dalaudier, F., Fussen, D., Vanhellemont, F., Fanton-d'Andon, O., Barrot, G., Mangin, A., Guirlet, M., Blanot, L., Fehr, T., Saavedra de Miguel, L., and Fraisse, R.: GOMOS data characterisation and error estimation, Atmos. Chem. Phys., 10, 9505-9519, doi:10.5194/acp-10-9505-2010, 2010.

Toohey, M., Hegglin, M. I., Tegtmeier, S., Anderson, J., Añel, J. A., Bourassa, A., Brohede, S., Degenstein, D., Froidevaux, L., Fuller, R., Funke, B., Gille, J., Jones, A., Kasai, Y., Krüger, K., Kyrölä, E., Neu, J. L., Rozanov, A., Smith, L., Urban, J., von Clarmann, T., Walker, K. A., and Wang, R.: Characterizing sampling biases in the trace gas climatologies of the SPARC Data Initiative, J. Geophys. Res., 118, 11847-11862, doi:10.1002/jgrd.50874, 2013.

Verronen, P. T., Ceccherini, S., Cortesi, U., Kyrölä, E., and Tamminen, J.: Statistical comparison of night-time $\mathrm{NO}_{2}$ observations in 2003-2006 from GOMOS and MIPAS instruments, Adv. Space Res., 43, 1918-1925, 2009.

Verronen, P. T., Andersson, M. E., Marsh, D. R., Kovács, T., and Plane, J. M. C.: WACCM-D - Whole Atmosphere Community Climate Model with D-region ion chemistry, J. Adv. Model. Earth Syst., 8, 954-975, doi:10.1002/2015MS000592, 2016. von Clarmann, T., Höpfner, M., Kellmann, S., Linden, A., Chauhan, S., Funke, B., Grabowski, U., Glatthor, N., Kiefer, M., Schieferdecker, T., Stiller, G. P., and Versick, S.: Retrieval of temperature, $\mathrm{H}_{2} \mathrm{O}, \mathrm{O}_{3}, \mathrm{HNO}_{3}, \mathrm{CH}_{4}, \mathrm{~N}_{2} \mathrm{O}, \mathrm{ClONO}_{2}$ and $\mathrm{ClO}$ from MIPAS reduced resolution nominal mode limb emission measurements, Atmos. Meas. Tech., 2, 159-175, doi:10.5194/amt-2-159-2009, 2009.

von Clarmann, T., Funke, B., López-Puertas, M., Kellmann, S., Linden, A., Stiller, G. P., Jackman, C. H., and Harvey, V. L.: The Solar Proton Events in 2012 as Observed by MIPAS, Geophys. Res. Lett., 40, 1-5, doi:10.1002/grl.50119, 2013.

Waters, J., Froidevaux, L., Harwood, R., Jarnot, R., Pickett, H., Read, W., Siegel, P., Cofield, R., Filipiak, M., Flower, D., Holden, J., Lau, G., Livesey, N., Manney, G., Pumphrey, H., Santee, M., Wu, D., Cuddy, D., Lay, R., Loo, M., Perun, V., Schwartz, M., Stek, P., Thurstans, R., Boyles, M., Chandra, K., Chavez, M., Chen, G., Chudasama, B., Dodge, R., Fuller, R., Girard, M., Jiang, J., Jiang, Y., Knosp, B., LaBelle, R., Lam, J., Lee, K., Miller, D., Oswald, J., Patel, N., Pukala, D., Quintero, O., Scaff, D., Van Snyder, W., Tope, M., Wagner, P., and Walch, M.: The Earth Observing System Microwave Limb Sounder (EOS MLS) on the Aura satellite, IEEE T. Geosci. Remote Sens., 44, 1075-1092, doi:10.1109/TGRS.2006.873771, 2006.

Wissing, J. M. and Kallenrode, M.-B.: Atmospheric Ionization Module Osnabrück (AIMOS): A 3-D model to determine atmospheric ionization by energetic charged particles from different populations, J. Geophys. Res., 114, A06104, doi:10.1029/2008JA013884, 2009.

WMO: SPARC Report on the Evaluation of Chemistry-Climate Models, SPARC Report No. 5, WCRP-132, WMO/TD-No. 1526, 2010.

Yamashita, C., England, S. L., Immel, T. J., and Chang, L. C.: Gravity wave variations during elevated stratopause events using SABER observations, J. Geophys. Res., 118, 5287-5303, doi:10.1002/jgrd.50474, 2013. 